\title{
Land Use Pressure and Climate Impacts on Fire Regimes and Forest Regeneration in the Upper Tuul River Watershed, Mongolia
}

Thomas M. Saladyga

West Virginia University

Follow this and additional works at: https://researchrepository.wvu.edu/etd

\section{Recommended Citation}

Saladyga, Thomas M., "Land Use Pressure and Climate Impacts on Fire Regimes and Forest Regeneration in the Upper Tuul River Watershed, Mongolia" (2011). Graduate Theses, Dissertations, and Problem Reports. 3420.

https://researchrepository.wvu.edu/etd/3420

This Dissertation is protected by copyright and/or related rights. It has been brought to you by the The Research Repository @ WVU with permission from the rights-holder(s). You are free to use this Dissertation in any way that is permitted by the copyright and related rights legislation that applies to your use. For other uses you must obtain permission from the rights-holder(s) directly, unless additional rights are indicated by a Creative Commons license in the record and/ or on the work itself. This Dissertation has been accepted for inclusion in WVU Graduate Theses, Dissertations, and Problem Reports collection by an authorized administrator of The Research Repository @ WVU.

For more information, please contact researchrepository@mail.wvu.edu. 


\title{
Land Use Pressure and Climate Impacts on Fire Regimes and Forest Regeneration in the Upper Tuul River Watershed, Mongolia
}

Thomas M. Saladyga

\begin{abstract}
Dissertation submitted to the
Eberly College of Arts and Sciences

at West Virginia University

in partial fulfillment of the requirements

for the degree of

Doctor of Philosophy

In

Geography

Amy Hessl, Ph.D., Chair

Neil Pederson, Ph.D.

Peter Brown, Ph.D.

Timothy Warner, Ph.D.

Brenden McNeil, Ph.D.

Jamison Conley, Ph.D.
\end{abstract}

Department of Geology and Geography

Morgantown, West Virginia

2011

Keywords: wildfire, climate, land use, Mongolia, dendrochronology

Copyright 2011 Thomas M. Saladyga 


\section{ABSTRACT \\ Land Use Pressure and Climate Impacts on Fire Regimes and Forest Regeneration in the Upper Tuul River Watershed, Mongolia}

\section{Thomas M. Saladyga}

This dissertation is composed of three chapters addressing the broad issues of land use, climate variability, and wildfire in central Mongolia. The first chapter describes a GIS model developed to map human impacts in the Upper Tuul River watershed. Forest establishment data were used to validate the application of the model with results indicating a high level of correspondence with a field assessment of human disturbance. Chapter two is a tree-ring based reconstruction of Palmer Drought Severity Index (PDSI) for the central Khan Khentii Mountains from 1675-2000. Changes in moisture availability were more frequent during the $20^{\text {th }}$ century than any other period of the reconstruction, suggesting a growing need for increased adaptability of the livestock industry and natural resource managers. In the final chapter, we used tree rings to reconstruct wildfire frequency and extent in the Upper Tuul River watershed during the period 1875-2009. Results indicate a recent decrease in wildfire frequency and extent; trends which might be observed in other arid regions where prolonged drought and human land use inhibit fuel accumulation. Chapter one was formatted for and submitted to The Geographical Journal on July 2, 2011, while the remaining two chapters are pending submission to peer-reviewed journals. 


\section{Acknowledgements}

I would like to thank my advisor, Amy Hessl, for offering me the opportunity to conduct research in Mongolia and for her thoughtful comments throughout the production of this document. I also want to thank Bataarbileg Nachin, Byambagerel Suran, and Uyanga Aryia for their invaluable guidance and input whilst engaged in fieldwork in Mongolia. Additional thanks go to Neil Pederson and Peter Brown and my other committee members Tim Warner, Brenden McNeil, and Jamison Conley for their comments and suggestions throughout this process.

I am especially grateful for the friendship and random acts of support from my former and current lab mates Stockton Maxwell, Josh Wixom, Cari Leland, and Pete Clark. I only hope they learned as much from me as I did from them. Also integral to the completion of my research were the folks at the Tree-Ring Laboratory at Lamont-Doherty Earth Observatory. Their fifteen years of dendrochronology work in Mongolia and east inner Asia have provided a base for current and future research endeavors in the region. Finally, the National Science Foundation and Explorer's Club Washington Group were instrumental in providing the financial support that made my research possible. 


\section{Table of Contents}

$\begin{array}{lll}\text { Abstract } & \text { ii }\end{array}$

$\begin{array}{ll}\text { Acknowledgments } & \text { iii }\end{array}$

Table of Contents $\quad$ iv

List of Tables $\quad$ V

List of Figures $\quad$ vi

Overview

Chapter 1: Using GIS to Map Human Impacts in the Upper Tuul River Watershed, Mongolia

Chapter 2: Tree-Ring Based Drought Reconstruction for the Central Khan Khentii Mountains, Mongolia (1675-2000)

Chapter 3: Tree-Ring Reconstruction of Wildfire in the Upper Tuul River Watershed, Mongolia (1875-2009)

$\begin{array}{ll}\text { Summary } & 100\end{array}$

$\begin{array}{ll}\text { Curriculum Vitae } & 102\end{array}$ 


\section{List of Tables}

\section{Chapter One}

Table 1. Sample locations in the UTRW including latitude, longitude, elevation, slope, aspect, and human impact indices (HI and ROSA).

Table 2. Contingency table of HI (GIS-based) and ROSA (field-based) human impact classifications.

Table 3. Sample locations with number of samples (N), HI and ROSA classes (Low, Medium, High), median establishment date, the total percentage of remnant samples, the percentage of stumps, snag, and logs that were sampled, total seedling/sapling counts, and tree density (trees/hectare).

Table 4. Tree establishment distributions for HI and ROSA. Sites classified by quartile ranges; Low (index $<$ Q1), Medium $(\mathrm{Q} 1 \leq$ index $\leq$ Q3), and High (index $>$ Q3)

Table 5. Sample composition and tree density for HI and ROSA. Sites classified by quartile ranges; Low (index $<$ Q1), Medium $(\mathrm{Q} 1 \leq$ index $\leq$ Q3), and High (index $>$ Q3).

\section{Chapter Two}

Table 1. Chronologies used and their statistics for the April-August PDSI reconstruction.

Table 2. Calibration-verification statistics for the April-August PDSI reconstruction. RE $=$ reduction of error. $\mathrm{CE}=$ coefficient of efficiency.

Table 3. Multi-annual to decadal-scale drought events.

Table 4. Multi-annual to decadal-scale pluvial events.

Table 5. Drought and pluvial regimes as determined by regime shift detection (5year cut-off length, $\alpha=0.05$ ) including time period, duration (years), mean, minimum, and maximum PDSI value and variance for each regime and drought to pluvial ratio $(\mathrm{D}: \mathrm{P})$.

Table 6. Drought and pluvial regimes as determined by regime shift detection (10year cut-off length, $\alpha=0.05$ ) including time period, duration (years), mean, minimum, and maximum PDSI value and variance for each regime and drought to pluvial ratio $(\mathrm{D}: \mathrm{P})$.

Table 7. Drought and pluvial regimes as determined by regime shift detection (20year cut-off length, $\alpha=0.05$ ) including time period, duration (years), mean, minimum, and maximum PDSI value and variance for each regime and drought to pluvial ratio (D : P). 


\section{Chapter Three}

Table 1. Sample locations in the UTRW including latitude, longitude, elevation, number of samples, total number of dated scars and injuries, first and last ring dates, ROSA scores, and ROSA classification bins.

Table 2. Fire events based on a two scar per site filter. Impact class indicates which site(s) recorded fire ( $\mathrm{L}=\mathrm{Low}, \mathrm{M}=$ Medium, $\mathrm{H}=\mathrm{High}$ ). Watershed events with greater than $20 \%$ sites recording fire are highlighted. Mean fire interval $=3.04$ years.

Table 3. Fire regimes as determined by regime shift detection including time period, number of years, number of fire events, the percentage of years with fire, mean fire interval (MFI), and mean fire extent (MFE; \% sites burned per event).

\section{List of Figures}

\section{Chapter One}

Figure 1. Winter camp in the foothills of the Khan Khentii Mountains north of Ulaanbaatar.

Figure 2. Livestock population of Mongolia 1918-2008 (in thousands). *Recreated from Humphrey and Sneath 1999. ^Mongolian National Statistics Office 2011 (no data for 1999, 2000, and 2009).

Figure 3. Human population of Mongolia 1960-2009. Source: United Nations 2011

Figure 4. Map of the Tuul River basin in central Mongolia. Sample locations are located in the forest-steppe ecological zone to the north and east of the capital city of Ulaanbaatar.

Figure 5. GIS-based human impact index (HI) for the UTRW; 5 grid km resolution. Index values range from 1 to 10 . Variables used in analysis included 1) distance to nearest road 2) road type 3) distance to nearest urban center 4) relative human population of nearest urban center and 5) elevation difference between nearest urban center and grid point.

Figure 6. UT21 - Low Impact Class. Note: minimal evidence of grazing and logging; coarse woody debris is present.

Figure 7. UT32 - Medium Impact Class. Note: some evidence of grazing and salvage logging.

Figure 8. UT02 - High Impact Class. Note: substantial evidence of grazing and salvage logging. 
Figure 9. Regression analysis for GIS-based human impact index (HI) and Rapid on-site assessment (ROSA). The outlier UT20 is circled. $\mathrm{r}^{2}=0.23, \mathrm{p}=0.035 ; \mathrm{ROSA}\left(\log _{10}\right)=0.675$ $+0.535 \mathrm{HI}\left(\log _{10}\right)$.

Figure 10. GIS-based index (HI) and field-based index (ROSA) classified by human impact (quartiles). Low (index $<$ Q1), Medium $(\mathrm{Q} 1 \leq$ index $\leq$ Q3), and High (index $>$ Q3).

Figure 11. Tree establishment distributions by human impact class for HI and ROSA; Low (index $<$ Q1), Medium $(\mathrm{Q} 1 \leq$ index $\leq$ Q3), and High (index $>$ Q3). DBH $\geq 7.5 \mathrm{~cm}$.

\section{Chapter Two}

Figure 1. Map of north-central Mongolia showing the location of regional PDSI grid points (diamonds) and the locations of the 15 tree-ring sites (triangles, Pederson et al. 2001; squares, expanded network) used for the reconstruction. The reconstructed PDSI grid point situated over the Khan Khentii Mountains is indicated by the boxed diamond.

Figure 2. Actual (solid line) and reconstructed (dotted line) mean April-August PDSI. Instrumental data are from Dai et al. 2004 (grid point $48.75 \mathrm{~N}, 108.75 \mathrm{E}$ ). Vertical line indicates where the data are split for calibration and verification. $\mathrm{R}=$ 0.78 for the entire period (1945-1993). Instrumental streamflow data for the Kherlen River at Undurkhaan (shaded area) is provided for comparison (19592008). Note the extreme drought from 1978-1983 and the abrupt shift to prolonged drought conditions in 1996.

Figure 3. Mean April-August PDSI reconstruction based on tree rings (1675-2000) with the actual April-August PDSI values from 2001-2005 (Dai et al. 2004). The black line shows the data smoothed by a 21-year loess curve. Below are the number of chronologies included in the model through time, calibration $r$ square for nested full period reconstruction, and the statistics of correlation ( $r$ ), reduction of error (RE), and coefficient of efficiency (CE) for calibration and verification of the split periods (19451969 and 1970-1993).

Figure 4. Box plots of April-August reconstructed PDSI regimes (10-year cut-off length, $\alpha=0.05$ ). Drought conditions continue into the $21^{\text {st }}$ century based on instrumental data (Dai et al. 2004).

Figure 5. Magnitude values for multi-annual and decadal-scale drought and pluvial events (1675-2000, reconstructed April-August PDSI; 2001-2005, instrumental data). High magnitude and short duration (i.e. long, narrow bars) = greater intensity. Also shown are April-August drought and pluvial regimes (sold line; 10-year cut-off, $\alpha=$ $0.05)$. 


\section{Chapter Three}

Figure 1. The number of fires and area burned in Mongolia during the period 1963-1997 (redrawn from Goldammer 2002).

Figure 2. Livestock population of Mongolia 1918-2008 (in thousands).

*Recreated from Humphrey and Sneath 1999. ^Mongolian National Statistics Office 2011 (no data for 1999, 2000, and 2009).

Figure 3. Map of the Tuul River basin in central Mongolia. Sample locations are located in the forest-steppe ecological zone to the north and northeast of the capital city of Ulaanbaatar.

Figure 4. Sample locations in the UTRW classified by human impact (Rapid on-site assessment; ROSA)

Figure 5. Box plots of four fire regimes as determined by regime shift detection. 18751913: low frequency, variable extent. 1915-1964: increased frequency, less variable extent, with one watershed fire. 1965-1997: greatest frequency, highly variable extent. 1998-2009: low frequency and extent, low variability. The 1914 fire event is shown for comparison.

Figure 6. Above: Reconstructed April-August PDSI with fire events using a 2-scar per site filter (closed triangles are $\geq 20 \%$ sites recording; refer to table 2). Below: Percentage of sites recording fire (dotted line) with an 11-year loess curve (solid black line). Sample size is indicated by the solid gray line. The vertical lines divide the period of analysis into four fire regimes based on regime shift detection. The extent of the 1914 fire event was anomalous and, therefore, considered a unique regime period. There is a documented fire event in 2009 at UT19, but no corresponding PDSI data exists.

Figure 7. Above: Reconstructed April-August PDSI with fire events using a 2-scar per site filter (closed triangles are $\geq 20 \%$ sites recording; refer to table 2). Below: Percentage of sites recording fire (dotted line) with an 11-year loess curve (solid black line); (a) low (b) medium and (c) high human impact class. Sample size is indicated by the solid gray line. The vertical lines divide the period of analysis into four fire regimes based on regime shift detection. The extent of the 1914 fire event was anomalous and, therefore, considered a unique regime period. There is a documented fire event in 2009 at UT19, but no corresponding PDSI data exists.

Figure 8. Superposed epoch analysis (SEA) of average April-August PDSI departures for (a) site-level fire events (b) watershed events with $\geq 20 \%$ sites recording fire and (c) events during fire regime 1 (1875-1913). A star indicates a departure exceeding the 95\% confidence interval. No significant departures were found for fire regimes 2 and 3 and there were too few events during fire regime 4 for SEA. 


\section{Overview}

This dissertation is divided into three chapters that address the interacting variables of land use, climate and wildfire in the Upper Tuul River watershed (UTRW) in central Mongolia. To keep this section focused and devoid of unnecessary language, I have not recreated scenes of academic enlightenment that have occurred over the course of four years. The reader should simply know that this dissertation developed primarily from experiences and observations while conducting fieldwork in Mongolia. My universal objective was to investigate the intersection of human and ecological systems, specifically forests, in the context of climate variability.

My goal for the first chapter was to develop a basic GIS model for mapping human impacts on forests in regions where economic development is outpacing the implementation of management and conservation strategies. Specifically, the objectives of my research were to: 1) assess the GIS model in predicting human impacts in the UTRW; 2) evaluate the effectiveness of the model in assessing human impacts on forests; and 3) make recommendations for further applications of the model and future research needs. I used forest establishment data to validate the application of the model to the study area with results indicating a high level of correspondence between the model and a field assessment of human disturbance. This type of model can be used to assist in policy development and implementation, particularly in regions with limited or newly developing natural resource management strategies.

The main objective of chapter two was to create a local spring-summer Palmer Drought Severity Index (PDSI) reconstruction that places moisture availability into a regional and historical context. Additionally, my intention was to indentify major drought and pluvial events as well as significant shifts in moisture regimes throughout the time series. I used a nested reconstruction that extends from 1675 to 2000 and explains $60 \%$ of the variance in instrumental 
PDSI (1945-1993). The results can be used to further understand local variation in drought conditions and to inform sustainable resource management initiatives in this mountainous region. This study also highlights the need for meteorological stations in mountainous regions in order to decrease uncertainties in predicting and understanding localized climate change.

The purpose of the third chapter was to assess human and climatic influences on fire frequency and extent during the period 1875-2009 in the UTRW. I was interested in addressing the following questions: 1) To what degree does human land use influence fire activity? 2) Is moisture availability related to fire activity? and 3) Has wildfire frequency and extent in the study area increased coincident with rising temperatures? I used tree rings to reconstruct wildfire frequency and extent during the period 1875-2009 during which I identified four distinct wildfire regimes using regime shift detection methods. The most recent regime (1998-2009) is characterized by the lowest frequency and extent of wildfire, which is contrary to expected trends in wildfire activity. Areas with the greatest present-day human impact have recorded less fire than other areas throughout the entire period of analysis, suggesting fire exclusion via grazing and fuelwood collection. As temperatures rise, similar trends of decreased wildfire frequency and extent might be observed in other arid regions where prolonged drought and human land use inhibit fuel accumulation. Rapid economic development and land use intensification might be compounding the effects of prolonged drought on wildfire and forest regeneration in the UTRW. In reading this dissertation, the reader might consider the realistic application of these results to policy development and on-the-ground implementation. 


\title{
Chapter 1: Using GIS to Map Human Impacts in the Upper Tuul River Watershed, Mongolia
}

\author{
Thomas M. Saladyga ${ }^{1}$, Amy E. Hessl ${ }^{2}$ and Baatarbileg Nachin ${ }^{3}$ \\ ${ }^{1}$ Corresponding Author \\ West Virginia University \\ Department of Geology and Geography \\ P.O. Box 6300 \\ Morgantown, WV 26506-6300 \\ Email: tom.saladyga@gmail.com \\ ${ }^{2}$ West Virginia University \\ Department of Geology and Geography \\ P.O. Box 6300 \\ Morgantown, WV 26506-6300 \\ Email: Amy.Hessl@mail.wvu.edu \\ ${ }^{3}$ National University of Mongolia \\ Ulaanbaatar, Mongolia \\ Email: bataarbileg@num.edu.mn
}

This chapter was formatted for and submitted to The Geographical Journal on July 2, 2011. 


\section{Abstract}

Human systems are on par with other natural systems in driving global environmental change. This influence is evident in the transformation of most terrestrial ecosystems during the last 300 years to anthropogenic biomes. Understanding and predicting the spatial distribution of human impacts is essential to developing sustainable resource management plans especially in rapidly developing countries undergoing rapid environmental change. Our objective was to develop a GIS model of human impacts for the Upper Tuul River watershed (UTRW) in central Mongolia. In representing the most extreme range of urban to rural development in Mongolia, the UTRW is an ideal case study for mapping human impacts. Here we present the results of the GIS-based model in predicting the spatial distribution of human impacts. We used forest establishment data to validate the application of the model to the study area. Results indicate a high level of correspondence between the model and a field assessment of human disturbance. Errors in the model are concentrated in the urban fringe where land use patterns are most unpredictable. Forests within high impact areas have seen little regeneration since the mid- $20^{\text {th }}$ century. Other studies have shown evidence of forest decline in this region due to prolonged drought and other ecological forcings, but forests under greater pressure from human activities will inevitably be affected sooner and to a greater degree. Management and conservation initiatives should focus on these forests as they provide valuable ecosystems services to the sprawling capital city of Ulaanbaatar.

Key Words: Mongolia, forest disturbance, GIS, human impacts, dendrochronology, conservation 


\section{Introduction}

Human activities are a pervasive force in driving Earth system processes (Crutzen 2002; Steffen et al. 2011). In a world transformed by humans, mapping the distribution of human impacts on terrestrial ecosystems will be crucial for conservation planning and resource management. McCloskey and Spalding (1989) provided the first global-scale assessment of undisturbed (i.e. wilderness) areas, and determined that less than one third of the Earth's surface remained as wilderness. In the last twenty years others have examined global-scale human impacts in terms of biodiversity and natural habitat (Hannah et al. 1995), forested ecosystems (Bryant et al. 1997), the global human footprint (Sanderson et al. 2002), and domestication of the landscape for human benefit (Kareiva et al. 2007). More recently, Ellis and others (2010) determined that in the last 300 years the terrestrial biosphere transitioned from being mostly wild to being mostly anthropogenic. This shift has varied across regions and biomes as some have remained wilderness while most were altered for human use. These global-scale assessments of human impacts have applications to the study of global environmental change, but issues of resolution and appropriateness arise when considering regional ecological, social, and economic systems.

The differences in regional politics and socioeconomic conditions that influence land management practices cannot fully be understood in a global-scale assessment. This is important as the impacts from landscape modifications are not necessarily wholesale (i.e. complete or irreversible destruction), especially as more sustainable methods of agriculture and development are being implemented in certain regions (e.g. shade tree coffee plantations, energy efficient buildings). When assessing or predicting anthropogenic disturbance of local and regional ecosystems, it is more suitable to work at a finer scale and consider conservation needs in the context of the associated social and economic environment (e.g. Woolmer et al. 2008) rather 
than using large-scale generalizations. Additionally, the intensity and rate of human disturbance to Earth systems is not uniform across the globe. Regions undergoing rapid increases in human population and economic growth might be the most vulnerable to natural resource degradation (Barbier 1997; Shandra et al. 2003). This vulnerability is especially high in arid and semiarid lands where the abundance and quality of natural resources such as water, forests, and grasslands are sensitive to abrupt changes in climate and land use.

In Mongolia, a traditionally pastoralist nation located in Central Asia at the intersection of the Gobi Desert, the semi-arid steppe and the boreal forests of Siberia, rapid industrialization began with the transition to a Soviet-backed, centrally-planned economy during the 1920s. Herding collectives that tended state-owned livestock were established following the founding of the People's Republic of Mongolia in 1924. These collectives were segregated by species and each step in the processing of livestock became specialized (Fernandez-Gimenez 1999). The collectives also resulted in a reduction in herder mobility and a campaign was initiated to construct permanent winter camps (Figure 1) to protect animals from harsh weather conditions (Fernandez-Gimenez 1996). Livestock populations remained stable during the collective era until 1990 when Mongolia began an abrupt transition to a free market economy and livestock numbers (particularly goats) increased dramatically (Figure 2). The privatization of livestock and other previously state-owned industries led to an increase in poverty, loss of formal regulations, increases in out-of-season grazing and further diminished the spatial distribution of livestock (Johnson et al. 2006). Although the land itself remains under government ownership, the increased differentiation in wealth among herders has negatively influenced access to campsites and pasture for the poor (Fernández-Giménez 2001). These changes in land use and social conditions have recently intensified as the human population is becoming increasingly 
urbanized (Figure 3) and dependent on limited resources such as water in this semiarid environment. Mapping human impacts in Mongolia will be crucial to sustainable resource management as these conditions evolve.

Understanding the spatial distribution of human impacts on natural resources not only provides a baseline status, but can aid in future land management and conservation strategies. The Tuul River basin, located in central Mongolia, provides an excellent opportunity to investigate methods for mapping human impacts as it contains the sprawling capital city of Ulaanbaatar as well as more remote areas of the Khan Khentii Mountains (Figure 4). In this study, we used forest establishment data to test the application of a GIS-based human impact model for the Upper Tuul River watershed (UTRW). Others have studied the impacts of human activity (e.g. grazing, fire suppression) on forest regeneration in western North America (Rummel 1951; Michalk 1982; Belsky and Blumenthal 1997; Keeley et al. 2003), Patagonia (Armesto et al. 1992; Veblen et al. 1992), Europe (Bradshaw and Hannon 1992; Rozas 2003) and Mongolia (Sankey et al. 2006), but none have attempted to predict human impacts on forest establishment at the watershed scale.

Recently, the European Commission's Joint Research Centre in Ispra, Italy and the World Bank (2009) published a model that was developed to map the world's most remote places. In this model, terrain and access to road, rail, and river networks were considered, including factors that may slow travel such as elevation, steepness of terrain, and border crossings. Another study published by the Wildlife Conservation Society (WCS) and the Center for International Earth Science Information Network (CIESIN) at Columbia University (2005) set out to map the human footprint at the global and continental scales. We attempted to downscale these approaches to the watershed scale and assess their predictive power. Our goal was to create a foundation for 
mapping human impacts on natural resources in regions where economic development is outpacing the implementation of management and conservation strategies. Specifically, the objectives of our study were to: 1) assess the GIS model in predicting human impacts in the UTRW; 2) evaluate the effectiveness of the model in assessing human impacts on forests; and 3) make recommendations for further applications of the model and future research needs.

\section{Methods}

\section{Study area}

The entire Tuul River basin makes up only 3.2\% of the total land area of Mongolia, but contains more than half of the country's population (Figure 4). The UTRW includes the upper reaches of the Tuul River and its tributaries, located in central Mongolia spanning approximately $46.5^{\circ}$ to $49^{\circ} \mathrm{N}$ latitude and $103^{\circ}$ to $108^{\circ} \mathrm{E}$ longitude. Land and resources of the Upper Tuul River watershed currently contribute income and marketed products worth around Tug 28 billion ( 22 million USD) per year in tourism, herding, and forest-based sectors (Emerton et al. 2009). Therefore, in representing the most extreme range of urban to rural development in Mongolia, the UTRW is an ideal case study for exploring human impacts on forests.

Forested area in the UTRW totals $3,876 \mathrm{~km}^{2}$ with $55 \%$ dominated by Larix sibirica, $42 \%$ by Pinus spp., and the remaining 3\% by Betula spp., Abies sibirica, and Picea obovata (Ministry of Nature and Environment 2009). Elevation in the UTRW ranges from $1187 \mathrm{~m}$ in the Tuul River valley just southwest of Ulaanbaatar to 2795 m at Asralt Khairkhan Mt. in the Khan Khentii Mountains. Three conservation areas exist within the Khentii region including the Strictly Protected Area of Khan Khentii $\left(12.3 \mathrm{~km}^{2}\right)$, the Gorkhi-Terelj National Park (2.9 km²), 
and the Onon-Balj $\left(4.2 \mathrm{~km}^{2}\right)$. These conservation areas have relatively low human use; however, this protection status does not prevent use of resources by local residents.

\section{GIS-based human impact index (HI)}

We described the watershed based on relative human impacts (i.e. potential access). Ulaanbaatar was permanently settled in 1778 , but did not experience industrial growth until the early $20^{\text {th }}$ century. Therefore, it is assumed that potential access to forest and rangeland resources has remained stable during the most recent 150 years even as use intensity increased during the $20^{\text {th }}$ century. In an effort to downscale from the global Last of the Wild Project (WCS and CIESIN 2005), the parameters for our watershed-scale study included (1) distance to nearest road, (2) road type (i.e. paved or unimproved), (3) distance to nearest urban center, (4) relative population of nearest urban center, and (5) elevation difference between grid point and nearest urban center. Sources for these variables were a digitized roads layer and urban center point data (Ministry of Nature and Environment 2009) and a digital elevation model (DEM; 3-sec grid; World Wildlife Foundation/USGS HydroSHEDS 2009). We ran analysis on a 2, 5, and $10 \mathrm{~km}$ grid to interpolate a continuous surface of potential human impacts for the UTRW. Results based on the 2 and 5 $\mathrm{km}$ grid were qualitatively similar, while the $10 \mathrm{~km}$ grid produced an index that was too generalized for the purposes of this study. Therefore, the $5 \mathrm{~km}$ resolution was deemed the most appropriate in terms of accuracy and processing time. Methods for developing the HI index are detailed in the appendix. Twenty sample sites were located randomly to span the range of the HI index. All locations were located in forests comprised of Larix sibirica solely or dominated by Larix sibirica. 


\section{Rapid on-site assessment (ROSA)}

Sites were located using a random sample design that captured variability in HI values. A qualitative rapid (15 minutes per site) on-site assessment (ROSA) was used to assess present-day human impacts at each site. We looked for evidence of grazing, logging, trash, and campfire remains and scored each variable (0 - 3) based on presence and area (ocular estimations; see Appendix). The index was calculated by summing qualitative assessment scores for each disturbance variable. Grazing indicators included the presence of dung, hoof prints, livestock remains and trails. Indicators of logging disturbance included the presence of stumps, slash, machinery tracks, and other altered microtopography. These variables were chosen because of their nearly ubiquitous presence on the landscape and their direct or indirect influence on ecosystem processes such as forest regeneration and productivity.

\section{Forest history}

We developed forest age structures based on tree recruitment dates from cross-dated cores and cross-section samples from each of the 20 sites. To determine tree recruitment dates, we used five $n$-tree distance plots (e.g., Jonsonn et al. 1992) to sample the nearest four trees to each plot center $(n=20$ trees). Four plots were arranged in a square with $100 \mathrm{~m}$ spacing while the fifth plot was located at the center of the square. Samples included living trees $\geq 7.5 \mathrm{~cm}$ in diameter at breast height (1.4 m; DBH) and remnant trees (stumps, snags, and logs) that were not too decayed to be sampled. Distance from each plot center was measured, the condition (i.e. live, stump, snag, or log) and species was recorded for all trees. Fire-scarred samples collected for the purposes of another study were included in establishment data if the pith was present in the sample. These samples were not included in any calculations of tree density. Two increment 
cores were removed from approximately $10 \mathrm{~cm}$ in height above ground level on living trees while cross sections were cut from stumps, logs, and snags from a similar height. At each site, two $1 \mathrm{~m}$ radius regeneration plots were located $10 \mathrm{~m}$ from the center point of two of the $5 n$ distance plots $(\mathrm{n}=4)$. All stems $<7.5 \mathrm{~cm}$ DBH were counted and placed into height classes $(<$ $0.5 \mathrm{~m}, 0.5-1.0 \mathrm{~m},>1.0 \mathrm{~m})$.

\section{Laboratory}

All tree-ring samples were surfaced with progressively finer grit sandpaper until cells were clearly visible under magnification according to established tree-ring procedures (e.g., Stokes and Smiley 1968). Samples were crossdated using already established chronologies via Mongolian American Tree-ring Project (MATRIP) and NOAA's International Tree Ring Databank (ITRDB) to provide absolute dates for all tree rings. Establishment dates for each tree were derived from crossdated increment cores (two from each tree) collected as close to the base of each tree as possible $(<10 \mathrm{~cm})$. If the pith was not present in the sample, estimations were made according to the curvature of the innermost visible rings (Arno and Sneck 1977). Establishment dates were collapsed into 10 year bins to account for possible error in age estimation.

\section{Analysis}

Linear regression was used to assess the relationship between HI and ROSA and to test whether a basic GIS model is useful for predicting on-the-ground human disturbance. Prior to regression analysis it was necessary to log transform values for HI and ROSA due to the non-normal distribution of each index. 
Sites were classified into human impact classes based on lower and upper quartile values of the log transformed indices. Binning the continuous variables is appropriate because the relative position of an individual value, for each respective index, is more meaningful than the value itself. For both indices, sites with index values less than Q1 were classified as low impact sites, index values between Q1 and Q3 as medium impact sites, and index values greater than Q3 as high impact sites. This classification method ensured the grouping of sites with typical human impacts (Medium) and sites outside the typical range (Low and High). Other methods such as quantiles, natural breaks, or equal intervals were not appropriate due to the non-normal distribution of each index.

A comparative analysis was used to compare site classification results for HI and ROSA (e.g. Fuller et al. 1998). Descriptive statistics were calculated for each impact class including; median establishment dates, median tree density, the percentage of live and remnant samples, and the percentage of stumps, snags, and logs sampled. Tree establishment distributions for each impact class were graphed and the shape of each distribution was assessed (i.e. skewness and kurtosis). To understand general temporal patterns of establishment, the percentage of trees established prior to 1900, between 1900 and 1949, and since 1950 was calculated for each index and impact class. These dates were chosen to represent the increase in land use intensity during the $20^{\text {th }}$ century due to human population growth and changes in land management. The nonparametric Kruskal-Wallis test was used to assess within group (i.e. within index) variation in the temporal distribution of establishment dates, \% remnant sampled, \% stumps sampled, and tree density. The nonparametric Mann-Whitney test was used to test for a difference in the temporal distribution of establishment dates, $\%$ remnants sampled, \% stumps sampled, and tree density between indices for corresponding impact classes. These nonparametric tests were 
chosen over their parametric counterparts (i.e. ANOVA and t-test) due to the non-normal distribution of all data.

\section{Results}

\section{Human impact indices}

The GIS-based human impact index (HI) resulted in a range of values from 1.60 to 6.34 for the field sites; the higher values indicate greater potential for human impacts (Table 1, Figure 5). ROSA index values range from 2 - 16, the higher values indicating more human disturbance (Table 1). No correlation exists between $\mathrm{HI}$ and slope or $\mathrm{HI}$ and elevation $(\mathrm{p}=0.250$ and $\mathrm{p}=$ 0.344, respectively). Sites classified as Low impact were generally lacking evidence of grazing and salvage logging (Figure 6). The Medium impact class was characterized by more evidence and grazing and logging (Figure 7), while sites in the High impact class had substantial evidence of human disturbance (Figure 8).

Linear regression testing the relationship between $\mathrm{HI}$ and ROSA indicate a weak, but statistically significant positive relationship (Figure $9 ; r^{2}=0.23, p=0.035$ ). If, however, site $\mathrm{UT2} 2(\mathrm{HI}=1.60, \mathrm{ROSA}=14)$ is removed from the analysis, the $\mathrm{r}^{2}$ value increases to $0.37(\mathrm{p}=$ 0.006). A comparative analysis of impact classes between $\mathrm{HI}$ and ROSA resulted in $80 \%$ agreement (Table 2). Human impacts were slightly overestimated by HI at two sites (UT29 and UT33), slightly underestimated at one site (UT31), and drastically underestimated at another site (UT20). Sites UT29 and UT33 were most likely overestimated due their proximity to the main road between Ulaanbaatar and points east (Figure 10). The underestimation of human impacts (HI) at sites UT31 and UT20 was due to high ROSA scores for grazing (i.e. dung and hoof 
prints) and logging (i.e. stumps) even though these sites are located in a relatively remote drainage, but with the unexpected presence of winter encampments nearby (Figure 1).

\section{Forest characteristics}

Tree establishment dates, sample composition, and tree density were assessed for each of the 20 sites in the UTRW (Table 3). Differences in sample size between sites are due to the presence of tree cores that were incomplete or damaged. Also, the existence of trees (live or remnant) with preserved fire scars varied between sites (13 - 26 trees). Median tree establishment varied by more than 100 years and remnant trees made up a large proportion of samples $(0 \%$ - 86\%) taken across the study area. Tree density also varied between sites (235 trees/ha to 1424 trees/ha), suggesting different disturbance histories. Seedlings and samplings were recorded at five of the twenty sites (ranging from 1 - 20 seedlings/saplings).

\section{Human impacts on forests}

Descriptive statistics were generated for each index and related human impact classes. Median establishment dates range from the early 1920s in the High impact class to the 1940s for the Low and Medium impact classes (Table 4). There is significant within index variation in the temporal distribution of establishment dates for each index (HI, p = 0.003; ROSA, $\mathrm{p}<0.001)$ suggesting that the timing of tree establishment is associated with human impacts regardless of the index used. There is no significant difference in establishment dates between respective impact classes indicating that both indices resulted in similarly grouped human impact classes. All distributions are negatively skewed (Figure 11; Table 4), meaning that the majority of trees established more recently than mean establishment dates. Skewness values are similar for the Low and Medium 
impact classes, but are markedly different for the High impact class. Kurtosis varies between impact classes with the Medium impact class being the most "peaked". Kurtosis values were similar for the Low impact class and the Medium impact class, but again the distribution was different for the High impact class.

We divided the period of analysis into three groups to assess temporal patterns of establishment as related to increases in human population and reduced pastoral mobility during the $20^{\text {th }}$ century. Tree establishment prior to 1900 was greatest in the Low and High impact classes (Table 4). Tree establishment during the period 1900-1949 was markedly greatest in the High impact class (55\% HI and 74\% ROSA). Only a small proportion of trees were established after 1950 (22\% HI and 8\% ROSA) in the High impact class.

Tree density varied between impact classes for each index (Table 5). There is significant within index differences in tree density for ROSA $(p=0.014)$, but not for HI $(p=0.252)$. Tree density was shown to increase with human impact based on the field-based index, while there was an insignificant difference in tree density between indices for each impact class.

Sample composition (live/remnant) was calculated for both indices (Table 5). The percentage of remnant samples increases with human impact, but this pattern is most pronounced for ROSA where the percentage more than triples from the Low to High impact class. There is not significant within index variation in the percentage of remnant samples. A comparison of the median percentage of remnant samples between each index resulted in no significant difference for each impact class.

The percentage of stump, snag, and log samples was calculated by impact class for each index (Table 5). The percentage of samples taken from stumps is least in the Low impact class and greatest in the High impact class. There was significant within index variation of the 
percentage of stumps sampled for ROSA $(p=0.034)$, but not for HI $(p=0.120)$. A comparison of the median percentage of stump samples between each index resulted in no significant difference for each impact classes. Results indicate an inverse pattern of the percentage of snags sampled for each index. The percentage of logs sampled was generally low, making up only $1 \%$ of the remnant samples.

\section{Discussion}

\section{Predicting human impacts}

Human land use activities influence forest ecosystems in other developing regions (Chazdon 2003; Baker et al. 2005; Thapa and Chapman 2010). However, this study is the first to evaluate forest regeneration along a classified human impact gradient at the watershed scale. We have demonstrated that a basic GIS model can be used to predict on-the-ground human disturbance in the UTRW $\left(\mathrm{r}^{2}=0.37, \mathrm{p}=0.006\right.$, excluding one obvious outlier). Classifying sites into three human impact classes strengthened this prediction (80\% agreement). The temporal distribution of establishment dates was significantly different between human impact classes with establishment centered in the mid-1920s for the High impact class, which may be the result of a decrease in grazing pressure near urban areas during the Soviet era. An abrupt decrease in grazing pressure at these sites could have promoted larch establishment as the inverse effect has been observed in the Darhad Valley in northern Mongolia (Sankey et al. 2006). The recent (post-1950) decline in forest regeneration and high percentage of remnant samples in the High impact class might be due to the increase in grazing activity near urban areas and roads observed during the latter half of the $20^{\text {th }}$ century (Fernandez-Gimenez 1999), an urbanizing population, and the intensification of economic activity in the Ulaanbaatar metropolitan area. Since all 
twenty sample locations are situated within the same climatic region, it can be concluded that broad-scale variation in moisture availability was not the primary driver of observed regeneration patterns. Instead, the temporal differences in regeneration between human impact classes could only be the result of land use pressure or, alternatively, micro-site variation in soils, solar radiation, or individual site disturbance history (typically associated with land use), which were not addressed in this study.

Despite its general predictive strength, the GIS model has its limitations, as seen in the over- or underestimation of human disturbance at a few sample locations. These inaccuracies can be attributed to unpredicted land use as seen in one drainage north of Ulaanbaatar (UT20 and UT31) and the lack of human activity near certain stretches of road (UT29 and UT33; Figure 10). Grazing and logging activity was much greater than expected in the area of UT20 and UT31, which is most likely due to the presence of multiple winter camps in the area. The removal of sites, other than UT20, did not improve the predictive power of the model and, therefore, justified the treatment of UT20 as a true outlier. In comparison, less human impacts were observed in the neighboring drainage to the immediate west (UT19 and UT32) due to its confining topography and lack of pasture. Although located near the main east-west road, no motor vehicle tracks were present in the approach to sites UT29 and UT33 where human impacts were overestimated by the GIS model.

Human impacts near the Ulaanbaatar metropolitan area was more difficult to predict than in the upper reaches of the Tuul River valley due to unpredicted land use patterns. The spatial distribution of $\mathrm{HI}$ and ROSA index values are influenced by urban centers as well as geographic features (Figure 10). For HI, sites in the High impact class are located near Ulaanbaatar and just north of the main east-west road. For ROSA, however, all five sites in the High impact class are 
clustered around Ulaanbaatar. Medium impact sites are primarily located along the main branch of the Tuul and up one river valley north of Ulaanbaatar (Figure 10). With the exception of site UT20, Low impact sites are all located to the north and east of the main branch of the Tuul where access is limited to human activities.

Error in the model occurred on the urban fringe, the transition zone between the edge of urban sprawl and the more remote pastures and forests of the Khan Khentii Mountains, where human disturbance is highly variable. In these areas, our model was unable to predict variation in pastoral land use which is strongly influenced by variables such as mobility, access to water, livestock preferences, land tenure, and herder motivations (Sternberg 2008). The spatial distribution of forest resource use (e.g. salvage logging, antler collection) is also more uncertain in the urban fringe. Since privatization in the early 1990s, human impacts have been dependent not only on geography but also market pressure and individual financial decisions. A goal of predicting human impacts in other regions should be to focus on the use of social variables that would more accurately assess human impacts at the urban fringe.

\section{Forests as disturbed ecosystems}

Most of the world's forests are either intensively managed for timber production or under some form of conservation management as human dominance of forest ecosystems continues to increase (Noble and Dirzo 1997; Kareiva et al. 2007). The forest-steppe ecological zone in central Mongolia is not managed intensively for forest products, but it is under pressure from urban sprawl, non-commercial forest products (i.e. fuelwood collection and small-scale salvage logging), and the pastoral market economy. These human pressures on forests are compounded by climate variability and other ecological disturbances. 
The global phenomenon of forest dieback has been attributed to increased drought incidence and an overall decrease in moisture availability (Allen 2009; van Mantgem et al. 2009), insect defoliation (e.g. Hogg et al. 2002), and urban air pollution (e.g. Kubikova 1991). In Mongolia, it is predicted that increasing aridity in the western Khan Khentii Mountains will result in a further decline in larch-dominated forests during the $21^{\text {st }}$ century (Dulamsuren et al. 2010a). Outbreaks of native gypsy moths, however, have been shown to have little effect on the overall presence of Siberian larch in the Khan Khentii Mountains (Dulamsuren et al. 2010b). Regarding air pollution in Ulaanbaatar, chemicals and particulates from wood and coal burning stoves in the sprawling Ger (circular, felt-covered traditional home) districts, power plants, burning garbage, vehicle emissions, and road dust have dramatically increased in the last twenty years (Guttikunda 2008). This increase is likely too recent to draw conclusions about regional forest decline. However, it has been shown that to the immediate south of Ulaanbaatar, one forested slope facing a thermal power plant had higher concentrations of sulfur dioxide in larch needles than other nearby sites (Sase et al. 2005).

\section{Conclusions}

Human systems have become a defining planetary process on par with biological, atmospheric, hydrologic, and geologic systems (Ellis 2009). Understanding and assessing the impacts human systems have on other Earth system processes will require new and innovative methods in every region of the world as climatic, social, and economic conditions continually evolve. The methods described in this study can be used to establish a baseline spatial distribution of human impacts at various locations, especially at the local scale. Using only three GIS layers (roads, urban centers, DEM) and data on relative human population, we developed a useful assessment 
of human impacts on forests in the UTRW and demonstrated its utility for describing spatial patterns in forest regeneration. These types of GIS data, which are easily accessible, can be used by resource managers and regional planners to develop spatial models of current and potential human impacts. Using HI to assess variables such as grassland quality, fire regimes, or water pollution is valuable in Mongolia or other regions where pressures from rapid development and increasing climate variability are threatening the quality and quantity of natural resources. Similar to assessing forest establishment, developing models for assessing other natural resources will involve indentifying and quantifying disturbance variables such as livestock density and composition (for grasslands), ignition sources (for fire regimes), and point sources of pollution (for water quality). In Mongolia, understanding human impacts on ecological systems is crucial to ensuring the sustainability of natural resources on which the country depends.

The issues facing Mongolia in terms of natural resource degradation are similar to those being experienced by other rapidly developing nations (see Larsen et al. 2006). Understanding the spatial distribution of human impacts at the local scale will be vital for resource management planning as Mongolia and other nations continue to adjust to the pressures of a market economy and climatic variability in the $21^{\text {st }}$ century. Assessing and predicting human impacts on the landscape are transparent tools that can be used immediately to assist in policy development and implementation. This is especially true in regions with limited or newly developing natural resource management practices. Future research should concentrate on understanding land use dynamics in the urban fringe; for example, the foothills on the outskirts of Ulaanbaatar that are experiencing unplanned development and less predictable resource use. Conservation and management plans should target these forests which provide valuable ecosystem services, such as watershed protection, fuelwood and pasture to the growing population of Ulaanbaatar. 


\section{References}

Allen C D 2009 Climate-induced forest dieback an escalating global phenomenon? Unasylva 60 43-49

Armesto J J, Casassa I, and Dollenz O 1992 Age structure and dynamics of Patagonian Beech forests in Torres del Paine National Park, Chile Vegetation 98 13-22

Arno S F and Sneck K M 1977 A method for determining fire history in coniferous forests of the mountain west USDA Forest Service GTR INT-42 Intermountain Forest and Range Experiment Station, Ogden, UT

Baker P J, Bunyavejchewin S, Oliver C D, and Ashton P S 2005 Disturbance history and stand dynamics of a seasonal tropical forest in western Thailand Ecological Monographs 75 $317-343$

Barbier E B 1997 The economic determinants of land degradation in developing countries Philosophical Transactions of the Royal Society 352 891-899

Batima P, Natsagdorj L, Gombluudev P, and Erdenetsetseg P 2005 Observed climate change in Mongolia Assessments and Adaptations to Climate Change (AIACC) Working Paper No 12 (www.aiaccproject.org accessed October 2009)

Belsky A J and Blumenthal D M 1997 Effects of livestock grazing on stand dynamics and soils in upland forests of the interior West Conservation Biology 11 315-327

Bradshaw R and Hannon G 1992 Climate change, human influence and disturbance regime in the control of vegetation dynamics within Fiby Forest, Sweden Journal of Ecology 80 625632

Bryant D, Nielson D and Tangley $\mathbf{V}$ The last frontier forests Ecosystems and economies on the edge World Resources Institute, 1997

Chazdon R L 2003 Tropical forest recovery legacies of human impact and natural disturbances Perspectives in Plant Ecology, Evolution, and Systematics 6 51-71

Crutzen P J 2002 Geology of mankind Nature 41523

Dulamsuren C, Hauck M and Leuschner C 2010a Recent drought stress leads to growth reductions in Larix sibirica in the western Khentey, Mongolia Global Change Biology 16 3024-3035

Dulamsuren C, Hauck M, Leuschner H H and Leuschner C 2010b Gypsy moth-induced growth decline of Larix sibirica in a forest-steppe ecotone Dendrochronologia 28 207-213 
Ellis E C 2009 Earth science in the Anthropocene new epoch, new paradigm, new responsibilities Eos 90 473-474

Ellis E C, Goldewijk K K, Siebert S, Lightman D and Ramankutty N 2010 Anthropogenic transformation of the biomes, 1700-2000 Global Ecology and Biogeography 19 519-606

Emerton L, Erdenesaikhan N, De Veen B, Tsogoo D, Janchivdorj L, Suvd P, Enkhtsetseg B, Gandolgor G, Dorisuren C, Sainbayar D and Enkhbaatar A 2009 The Economic Value of the Upper Tuul Ecosystem Mongolia Discussion Papers, East Asia and Pacific Sustainable Development Department Washington, DC World Bank

European Commission, Joint Research Centre and the World Bank 2009 http://www.newscientist.com/article/mg20227041.500-wheres-the-remotest-place-onearth.html, accessed June 2009.

Fernández-Giménez M E 1996 Land use and land tenure in Mongolia: a brief history and current issues USDA Forest Service Proceedings RMRS-P-39

Fernández-Giménez M E 1999 Sustaining the steppes a geographical history of pastoral land use in Mongolia The Geographical Review 89 315-342

Fernández-Giménez M E 2001 The effects of livestock privatization on pastoral land use and land tenure in post-socialist Mongolia Nomadic Peoples 5 49-66

Guttikunda S 2008 Urban air pollution analysis in Ulaanbaatar, Mongolia SIM Working Paper No 2008-005 (available at SSRN http//ssrncom/abstract=1288328)

Hannah L, Carr J L and Lankerani A 1995 Human disturbance and natural habitat a biome level analysis of a global dataset Biodiversity and Conservation 4 128-155

Hogg E H, Brandt J P and Kochtubajda B 2005 Growth and dieback of aspen forests in northwestern Alberta, Canada in relation to climate and insects Canadian Journal of Forest Research 32 823-832

Humphrey C and Sneath D 1999 The End of Nomadism? Society, State, and the Environment in Inner Asia Duke University Press, 355 pp

Fuller R M, Groom G B, Mugisha S, Ipulet P, Pomeroy D, Katende A, Baily R, and OgutuOhwayo R 1998 The integration of field survey and remote sensing for biodiversity assessment a case study in the tropical forests and wetlands of Sango Bay, Uganda Biological Conservation 86 379-391

Johnson D A, Sheehy D P, Miller D and Daalkhaijav D 2006 Mongolian rangelands in transition Sécheresse 17 133-141 
Jonsson B, Holm S and Kallur H 1992 A forest inventory method based on density adapted circular plot size Scandinavian Journal of Forest Research 7 405-421

Kareiva P, Watts S, McDonald R, and Boucher T 2007 Domesticated nature shaping landscapes and ecosystems for human welfare Science 316 1866-1869

Keeley J E and Lubin D 2003 Fire and grazing impacts on plant diversity and alien plant invasions in the southern Sierra Nevada Ecological Applications 13 1355-1374

Kubikova J 1991 Forest dieback in Czechoslovakia Vegetatio 93 101-108

Larssen T et al. 2006 Acid rain in China Environmental Science \& Technology 40 418-425

McCloskey J M and Spalding H 1989 A Reconnaissance-Level Inventory of the Amount of Wilderness Remaining in the World Ambio 18 221-227

Michalk D L 1982 Navajo sheep the forgotten conqueror of the south-western United States Wool Technology and Sheep Breeding 30 174-181

Mongolian Ministry of Nature and Environment 2009 Paper topographic maps of northcentral Mongolia

Nobel I R and Dirzo R 1997 Forests as human-dominated ecosystems Science 277 522-525

Rummel R S 1951 Some effects of livestock grazing on Ponderosa pine forest and range in central Washington Ecology 32 594-607

Rozas V 2003 Regeneration patterns, dendroecology, and forest-use history in an old-growth beech-oak lowland forest in Northern Spain Forest Ecology and Management 182 175-194

Sankey T T, Montagne C, Graumlich L J, Lawrence R and Nielsen J 2006 Lower forestgrassland ecotones and 20th century livestock herbivory effects in northern Mongolia Forest Ecology and Management 233 36-44

Sanderson E W, Jaiteh M, Levy M A, Redford K H, Wannebo A V and Woolmer G 2002 The human footprint and the last of the wild BioScience 52 891-904

Sase H, Bulgan T, Batchuluun T, Shimizu H and Totsuka T 2005 Tree decline and its possible causes around Mt Bogdkhan in Mongolia Phyton 45 583-590

Shandra J M, London B, Williamson J B 2003 Environmental degradation, environmental sustainability, and overurbanization in the developing world a quantitative, cross-national analysis Sociological Perspectives 46 309-329

Steffen W, Grinevald J, Crutzen P J, and McNeill J 2011 The Anthropocene conceptual and historical perspectives Philosophical Transactions of the Royal Society 369 842-867 
Sternberg T 2008 Environmental challenges in Mongolia's dryland pastoral landscape Journal of Arid Environments 72 1294-1304

Stokes M A and Smiley T L 1968 An introduction to tree-ring dating University of Chicago Press, Chicago, $73 \mathrm{pp}$

Thapa S and Chapman D S 2010 Impacts of resource extraction on forest structure and diversity in Bardia National Park, Nepal Forest Ecology and Management 259 641-649

Wildlife Conservation Society and the Center for International Earth Science Information Network (CIESIN) at Columbia University 2005 Last of the Wild Project http//wwwciesincolumbiaedu/wild_areas/, accessed January 2011

Woolmer G, Trombulak SC, Ray J C, Doran P J, Anderson MG, Baldwin R F, Morgan A and Sanderson EW 2008 Rescaling the human footprint a tool for conservation planning at an ecoregional scale Landscape and Urban Planning $8942-53$

World Wildlife Foundation and the United State Geological Survey HydroSHEDS Project http//hydroshedscrusgsgov/, accessed September 2009

United Nations Population Division 2009 The 2008 Revision Population Database http//esaunorg/UNPP/, accessed February 2011

van Mantgem P J, Stephenson NL, Byrne J C, Daniels L D, Franklin J F, Fule P Z, Harmon M E, Larson A J, Smith J M, Taylor A H and Veblen T T 2009 Widespread increase of tree mortality rates in the western United States Science 323 521-524

Veblen T T, Kitzberger T, and Antonio L 1992 Disturbance and forest dynamics along a transect from Andean rainforest to Patagonian shrubland Journal of Vegetation Science 3 $507-520$

Zhang J and Lin Z 1992 Climate of China Wiley, 376 pp 


\section{Tables}

Table 1 Sample locations in the UTRW including latitude, longitude, elevation, slope, aspect, and human impact indices (HI and ROSA).

\begin{tabular}{cccccccc}
\hline Site ID & $\begin{array}{c}\text { Latitude } \\
\left({ }^{\mathbf{(}} \mathbf{)}\right)\end{array}$ & $\begin{array}{c}\text { Longitude } \\
\left({ }^{\mathbf{E}} \mathbf{)}\right)\end{array}$ & $\begin{array}{c}\text { Elevation } \\
(\mathbf{m})\end{array}$ & $\begin{array}{c}\text { Slope } \\
(\boldsymbol{\%})\end{array}$ & $\begin{array}{c}\text { Aspect } \\
\left({ }^{\mathbf{(}}\right)\end{array}$ & HI & ROSA \\
\hline UT02 & 47.84206 & 107.17078 & 1734 & 30 & 298 & 6.34 & 12 \\
UT04 & 48.08456 & 106.84557 & 1725 & 10 & 42 & 4.30 & 16 \\
UT09 & 48.12324 & 107.62940 & 1620 & 42 & 20 & 1.80 & 2 \\
UT17 & 48.14603 & 107.78245 & 1683 & 6 & 314 & 2.23 & 5 \\
UT19 & 48.13272 & 107.03880 & 1707 & 8 & 216 & 1.91 & 7 \\
UT20 & 48.10066 & 107.23615 & 1755 & 12 & 80 & 1.60 & 14 \\
UT21 & 48.15174 & 108.15524 & 1793 & 10 & 340 & 1.20 & 4 \\
UT23 & 48.19616 & 107.98087 & 1788 & 4 & 100 & 1.68 & 2 \\
UT29 & 47.80426 & 107.66104 & 1991 & 31 & 30 & 3.71 & 5 \\
UT30 & 48.10613 & 106.91950 & 1712 & 11 & 218 & 3.98 & 10 \\
UT31 & 48.01608 & 107.25186 & 1688 & 26 & 338 & 2.59 & 13 \\
UT32 & 48.08819 & 107.13362 & 1640 & 10 & 320 & 1.92 & 5 \\
UT33 & 47.85780 & 107.73329 & 1676 & 8 & 352 & 3.25 & 5 \\
UT34 & 47.94095 & 107.74693 & 1834 & 12 & 272 & 3.04 & 5 \\
UT35 & 48.01538 & 107.79398 & 1699 & 18 & 68 & 2.28 & 8 \\
UT36 & 48.07238 & 107.87352 & 1648 & 10 & 358 & 1.93 & 8 \\
UT37 & 48.12383 & 107.95766 & 1629 & 5 & 36 & 2.38 & 6 \\
UT38 & 48.06269 & 107.75574 & 1571 & 40 & 29 & 2.67 & 6 \\
UT39 & 48.19140 & 107.69537 & 1676 & 16 & 31 & 1.86 & 4 \\
UT40 & 48.03878 & 107.60961 & 1666 & 12 & 62 & 1.94 & 7 \\
\hline
\end{tabular}

$\mathrm{HI}=$ GIS-based human impact index

ROSA = Rapid on-site assessment (sum of grazing, logging, trash, and campfire scores) $\mathrm{r}^{2}=0.37, \mathrm{p}=0.006 ;$ ROSA $(\log 10)=0.843+0.444 \mathrm{HI}(\log 10) ;$ UT20 not included

Table 2 Contingency table of HI (GIS-based) and ROSA (field-based) human impact classifications.

\begin{tabular}{lccc|cc}
\hline Impact Class & Low $($ ROSA $)$ & Medium $($ ROSA $)$ & High $($ ROSA $)$ & Total & \% agreement \\
\hline Low $(H I)$ & $\mathbf{4}$ & 0 & 1 & 5 & 80 \\
Medium $(H I)$ & 0 & $\mathbf{9}$ & 1 & 10 & 90 \\
High $(H I)$ & 0 & 2 & $\mathbf{3}$ & 5 & 60 \\
& & & & & \\
\hline Total: & 4 & 11 & 5 & 20 & \\
\% agreement: & 100 & 82 & 60 & & \\
\hline
\end{tabular}

sum of diagonal $=16$; overall accuracy $=80 \%$ 
Table 3 Sample locations with number of samples (N), HI and ROSA classes (Low, Medium, High), median establishment date, the total percentage of remnant samples, the percentage of stumps, snag, and logs that were sampled, total seedling/sapling counts, and tree density (trees/hectare).

\begin{tabular}{|c|c|c|c|c|c|c|c|c|c|c|}
\hline $\begin{array}{l}\text { Site } \\
\text { ID }\end{array}$ & $\mathbf{N}$ & $\begin{array}{c}\text { HI } \\
{[\text { Bin] }}\end{array}$ & $\begin{array}{c}\text { ROSA } \\
\text { [Bin] }\end{array}$ & $\begin{array}{c}\text { Median } \\
\text { Estab. } \\
\text { Date }\end{array}$ & $\begin{array}{c}\% \\
\text { Remnant } \\
\text { Samples }\end{array}$ & $\begin{array}{c}\% \\
\text { Stumps }\end{array}$ & $\begin{array}{c}\% \\
\text { Snags }\end{array}$ & $\begin{array}{c}\% \\
\text { Logs }\end{array}$ & $\begin{array}{c}\text { Total } \\
\text { Seedling/ } \\
\text { Sapling }\end{array}$ & $\begin{array}{c}\text { Tree } \\
\text { Density } \\
\text { (trees } \\
\text { per ha) }\end{array}$ \\
\hline UT02 & 21 & High & High & 1925 & 86 & 67 & 19 & 0 & 0 & 657 \\
\hline UT04 & 21 & High & High & 1908 & 24 & 24 & 0 & 0 & 0 & 816 \\
\hline UT09 & 27 & Low & Low & 1861 & 11 & 0 & 11 & 0 & 0 & 287 \\
\hline UT17 & 25 & Medium & Medium & 1934 & 48 & 36 & 8 & 4 & 0 & 930 \\
\hline UT19 & 20 & Medium & Medium & 1962 & 40 & 0 & 35 & 5 & 0 & 1249 \\
\hline UT20 & 20 & Low & High & 1944 & 15 & 15 & 0 & 0 & 1 & 1424 \\
\hline UT21 & 21 & Low & Low & 1928 & 5 & 0 & 5 & 0 & 11 & 273 \\
\hline UT23 & 23 & Low & Low & 1943 & 17 & 0 & 17 & 0 & 14 & 308 \\
\hline UT29 & 23 & High & Medium & 1888 & 22 & 22 & 0 & 0 & 0 & 730 \\
\hline UT30 & 21 & High & High & 1921 & 19 & 14 & 5 & 0 & 1 & 1294 \\
\hline UT31 & 26 & Medium & High & 1920 & 57 & 42 & 15 & 0 & 0 & 1206 \\
\hline UT32 & 13 & Medium & Medium & 1928 & 27 & 27 & 0 & 0 & 0 & 1104 \\
\hline UT33 & 25 & High & Medium & 1985 & 0 & 0 & 0 & 0 & 20 & 380 \\
\hline UT34 & 20 & Medium & Medium & 1962 & 0 & 0 & 0 & 0 & 0 & 1075 \\
\hline UT35 & 22 & Medium & Medium & 1927 & 59 & 59 & 0 & 0 & 0 & 233 \\
\hline UT36 & 25 & Medium & Medium & 1950 & 0 & 0 & 0 & 0 & 0 & 1054 \\
\hline UT37 & 23 & Medium & Medium & 1943 & 38 & 17 & 17 & 4 & 0 & 380 \\
\hline UT38 & 22 & Medium & Medium & 1957 & 28 & 23 & 5 & 0 & 0 & 840 \\
\hline UT39 & 23 & Low & Low & 1945 & 15 & 0 & 13 & 0 & 0 & 235 \\
\hline UT40 & 25 & Medium & Medium & 1961 & 10 & 8 & 0 & 0 & 0 & 664 \\
\hline
\end{tabular}

$\mathrm{HI}$ [Bin] and ROSA [Bin] = sites classified by quartile ranges;

Low (index $<$ Q1), Medium $(\mathrm{Q} 1 \leq$ index $\leq$ Q3), and High (index $>$ Q3)

Note: samples are 94\% Larix sibirica, 5\% Pinus sylvestris, and 1\% Pinus sibirica 
Table 4 Tree establishment distributions for HI and ROSA. Sites classified by quartile ranges; Low (index $<$ Q1), Medium $(\mathrm{Q} 1 \leq$ index $\leq$ Q3), and High (index $>$ Q3).

\begin{tabular}{c|c|ccccc|ccc}
\hline \multirow{2}{*}{ Index } & $\begin{array}{c}\text { Impact } \\
\text { Class }\end{array}$ & $\begin{array}{c}\mathbf{N} \\
\text { (sites) }\end{array}$ & $\begin{array}{c}\mathbf{N} \\
\text { (trees) }\end{array}$ & $\begin{array}{c}\text { Median } \\
\text { Estab. } \\
\text { Date }\end{array}$ & Skewness & Kurtosis & $\begin{array}{c}\text { \% } \\
\text { Pre- } \\
\mathbf{1 9 0 0}\end{array}$ & $\begin{array}{c}\text { 1900- } \\
\mathbf{1 9 5 0}\end{array}$ & $\begin{array}{c}\text { \% } \\
\text { Post- } \\
\mathbf{1 9 5 0}\end{array}$ \\
\hline \multirow{3}{*}{ HI } & Low & 5 & 114 & $1942^{*}$ & -1.37 & 0.97 & 21 & 44 & 35 \\
& Medium & 10 & 221 & $1945^{*}$ & -3.70 & 19.21 & 13 & 45 & 42 \\
& High & 5 & 111 & $1925^{*}$ & -3.89 & 24.04 & 23 & 55 & 22 \\
\hline \multirow{3}{*}{ ROSA } & Low & 4 & 94 & $1941^{*}$ & -1.15 & 0.22 & 25 & 36 & 39 \\
& Medium & 11 & 243 & $1948^{*}$ & -3.98 & 21.56 & 14 & 40 & 46 \\
& High & 5 & 109 & $1922^{*}$ & -0.10 & 1.44 & 18 & 74 & 8 \\
\hline
\end{tabular}

*p $<0.05$ (Kruskal-Wallis test)

Table 5 Sample composition and tree density for HI and ROSA. Sites classified by quartile ranges; Low (index $<$ Q1), Medium $(\mathrm{Q} 1 \leq$ index $\leq$ Q3), and High (index $>$ Q3).

\begin{tabular}{c|c|ccc|ccc|c}
\hline \multirow{2}{*}{ Index } & $\begin{array}{c}\text { Impact } \\
\text { Class }\end{array}$ & $\begin{array}{c}\mathbf{N} \\
\text { (sites) }\end{array}$ & $\begin{array}{c}\mathbf{N} \\
\text { (trees) }\end{array}$ & $\begin{array}{c}\% \\
\text { Remnant }\end{array}$ & $\begin{array}{c}\text { \% } \\
\text { Stumps* }\end{array}$ & $\begin{array}{c}\% \\
\text { Snags }\end{array}$ & $\begin{array}{c}\% \\
\text { Logs }\end{array}$ & $\begin{array}{c}\text { Median Tree } \\
\text { Density^ }\end{array}$ \\
\hline \multirow{3}{*}{ HI } & Low & 5 & 114 & 12 & 2 & 10 & 0 & 0.03 \\
& Medium & 10 & 221 & 31 & 22 & 8 & 1 & 0.10 \\
& High & 5 & 111 & 29 & 24 & 5 & 0 & 0.07 \\
\hline \multirow{3}{*}{ ROSA } & Low & 4 & 94 & 12 & 12 & 0 & 0 & $0.03 *$ \\
& Medium & 11 & 243 & 24 & 17 & 6 & 1 & $0.08^{*}$ \\
& High & 5 & 109 & 41 & 33 & 8 & 0 & $0.12^{*}$ \\
\hline
\end{tabular}

$\wedge$ Trees/sq meter (does not include samples collected outside of $n$-distance plots)

$* \mathrm{p}<0.05$ (Kruskal-Wallis test) 


\section{Figure Captions}

Figure 1. Winter camp in the foothills of the Khan Khentii Mountains north of Ulaanbaatar.

Figure 2. Livestock population of Mongolia 1918-2008 (in thousands). *Recreated from Humphrey and Sneath 1999. ^Mongolian National Statistics Office 2011 (no data for 1999, 2000, and 2009).

Figure 3. Human population of Mongolia 1960-2009. Source: United Nations 2011

Figure 4. Map of the Tuul River basin in central Mongolia. Sample locations are located in the forest-steppe ecological zone to the north and east of the capital city of Ulaanbaatar.

Figure 5. GIS-based human impact index (HI) for the UTRW; 5 grid km resolution. Index values range from 1 to 10 . Variables used in analysis included 1) distance to nearest road 2) road type 3) distance to nearest urban center 4) relative human population of nearest urban center and 5) elevation difference between nearest urban center and grid point.

Figure 6. UT21 - Low Impact Class. Note: minimal evidence of grazing and logging; coarse woody debris is present.

Figure 7. UT32 - Medium Impact Class. Note: some evidence of grazing and salvage logging.

Figure 8. UT02 - High Impact Class. Note: substantial evidence of grazing and salvage logging.

Figure 9. Regression analysis for GIS-based human impact index (HI) and Rapid on-site assessment (ROSA). The outlier UT20 is circled. $\mathrm{r}^{2}=0.23, \mathrm{p}=0.035$; ROSA $\left(\log _{10}\right)=0.675+0.535 \mathrm{HI}\left(\log _{10}\right)$.

Figure 10. GIS-based index (HI) and field-based index (ROSA) classified by human impact (quartiles). Low (index $<$ Q1), Medium $(\mathrm{Q} 1 \leq$ index $\leq$ Q3), and High (index $>$ Q3).

Figure 11. Tree establishment distributions by human impact class for HI and ROSA; Low (index < Q1), Medium $(\mathrm{Q} 1 \leq$ index $\leq$ Q3), and High (index $>$ Q3). DBH $\geq 7.5 \mathrm{~cm}$. 


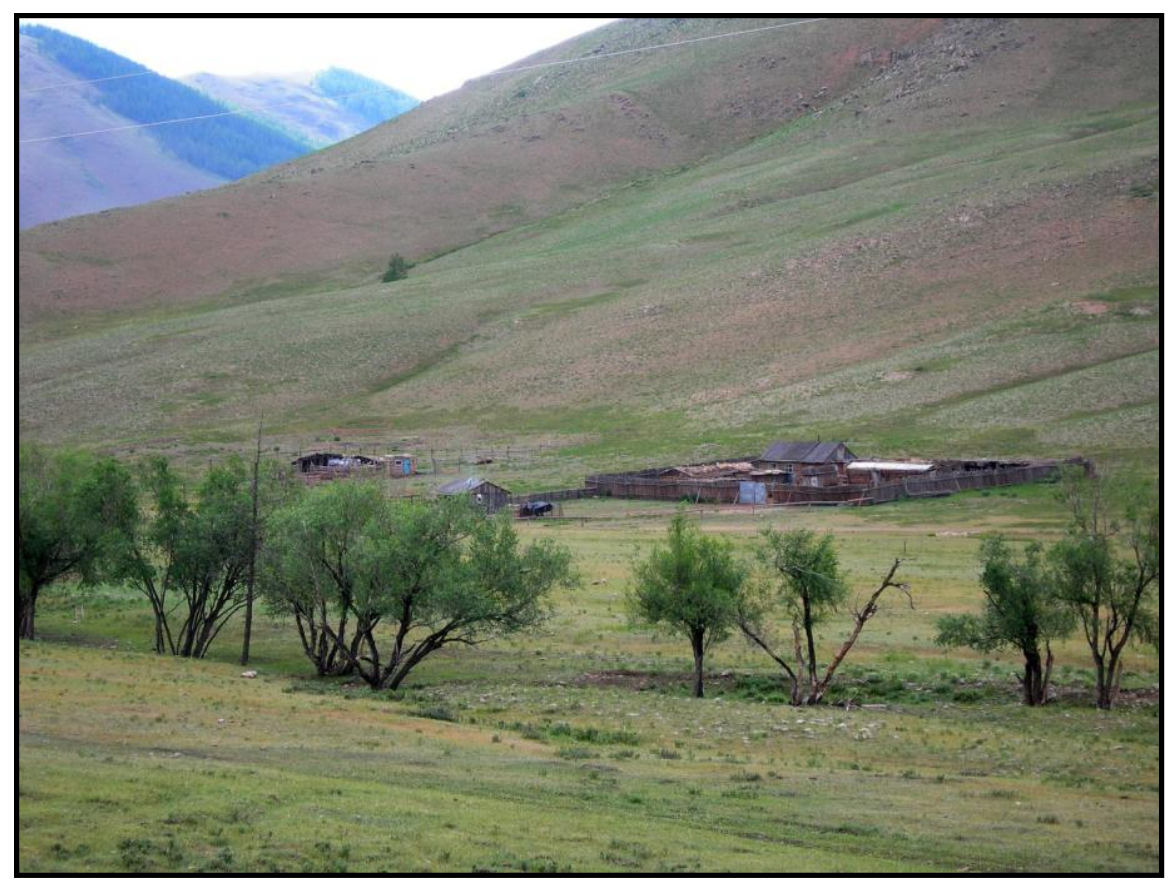

Figure 1

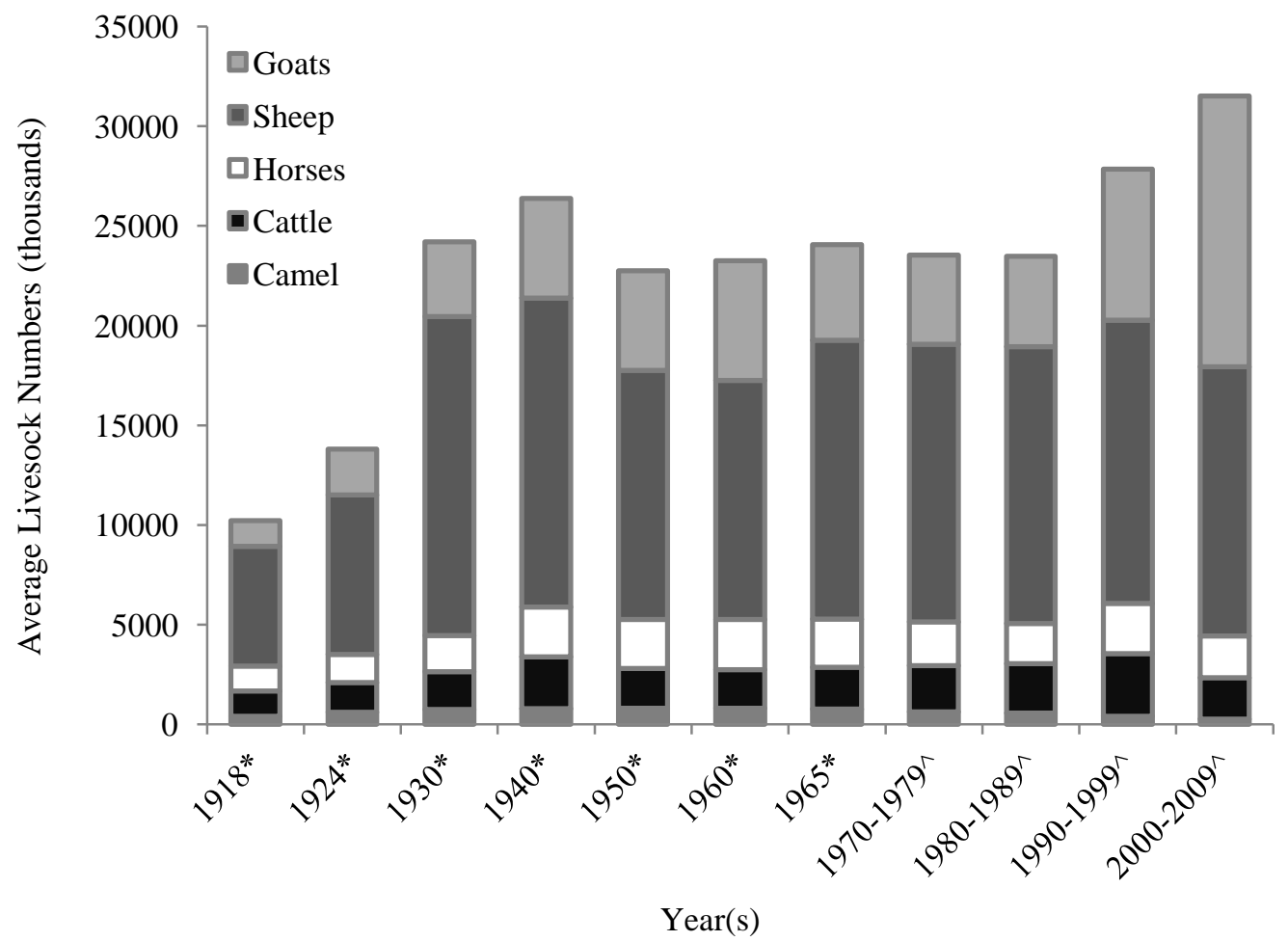

Figure 2 


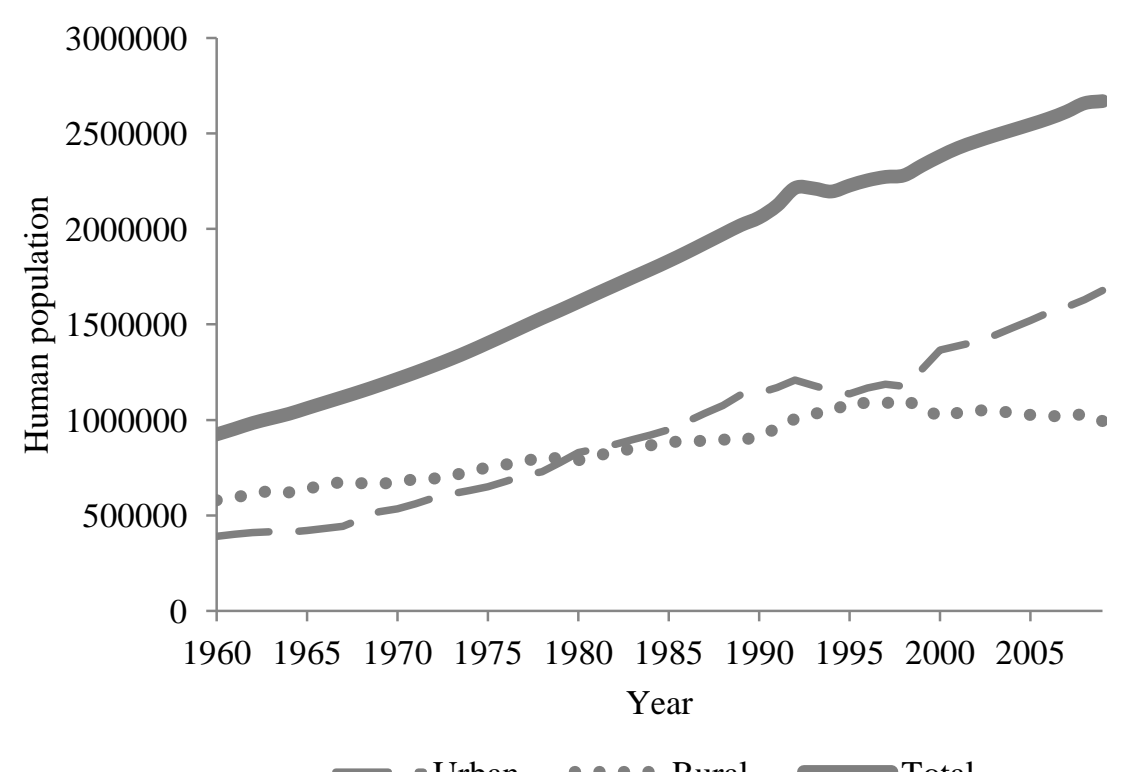

Figure 3

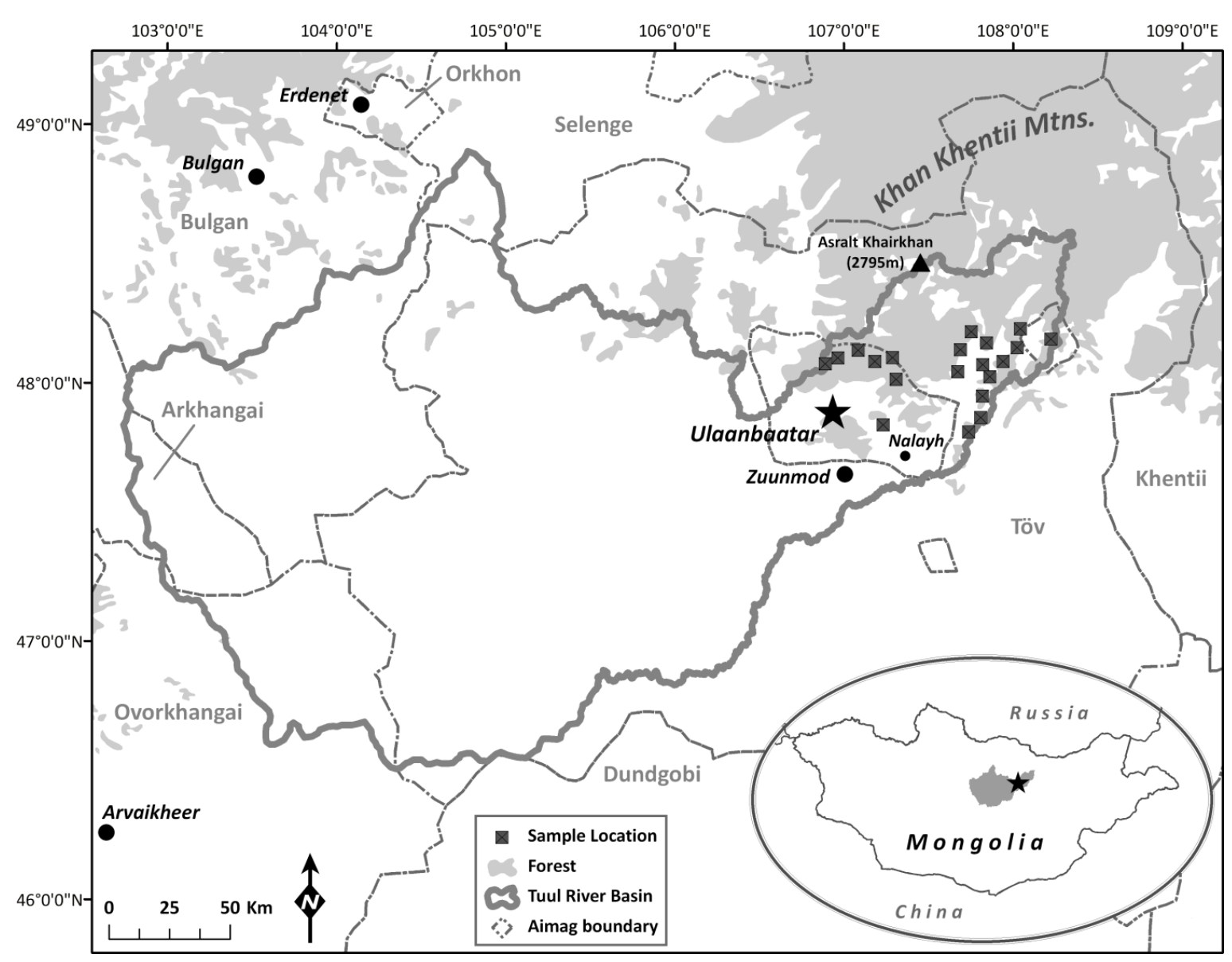

Figure 4 


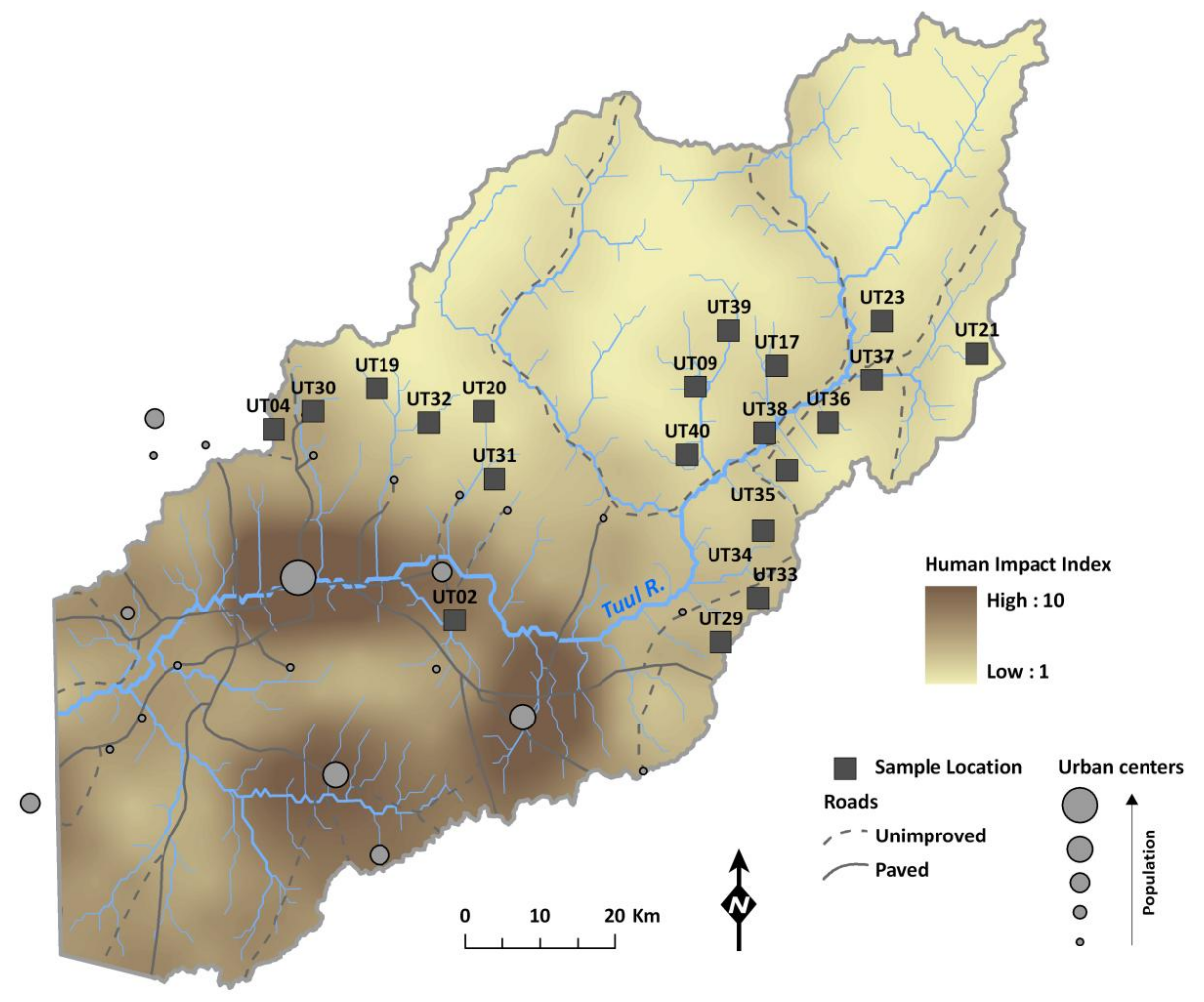

Figure 5

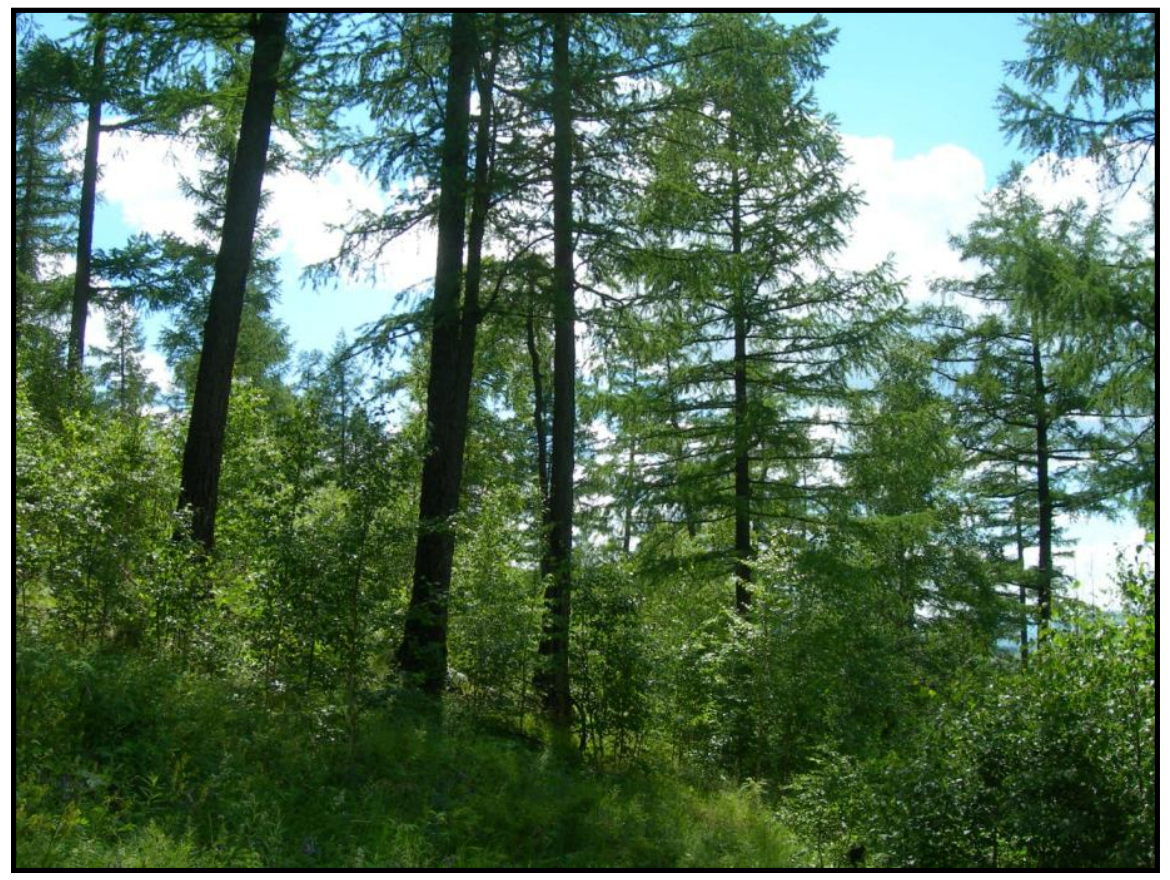

Figure 6 


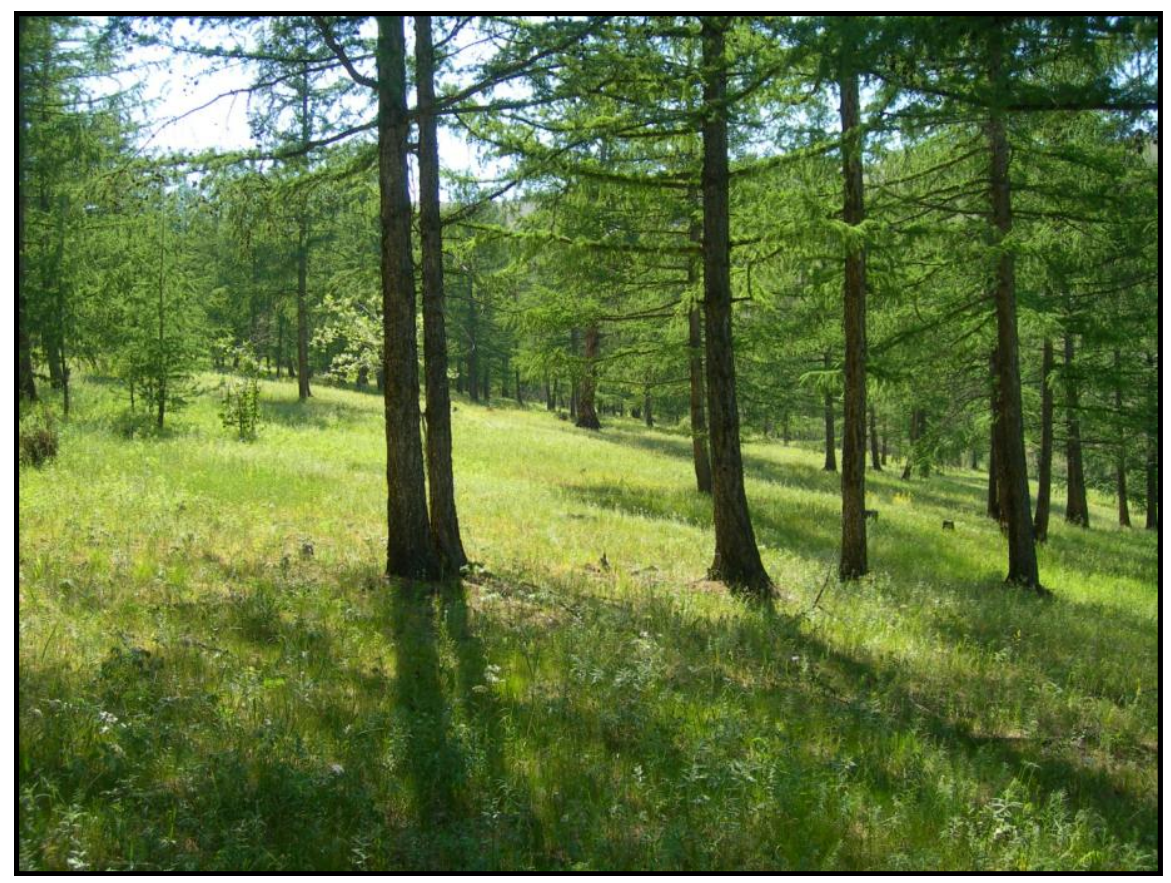

Figure 7

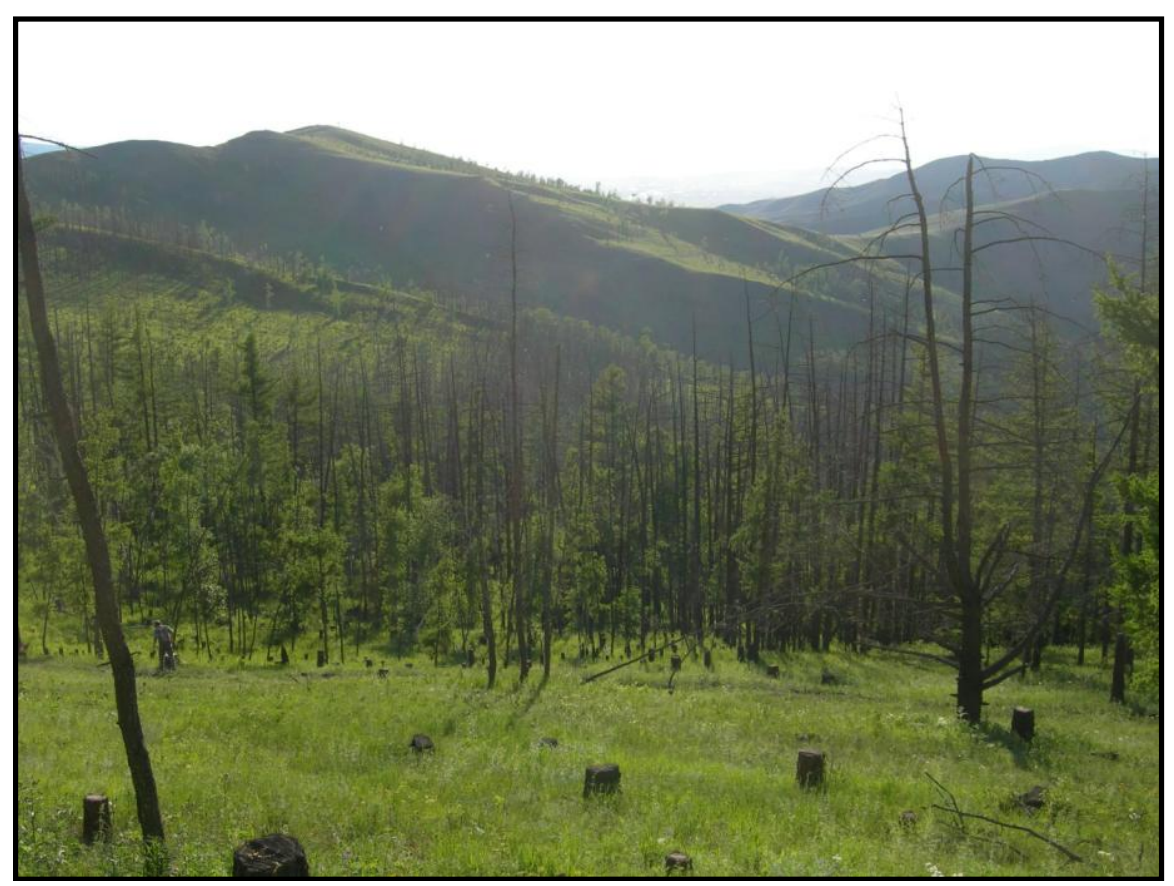

Figure 8 


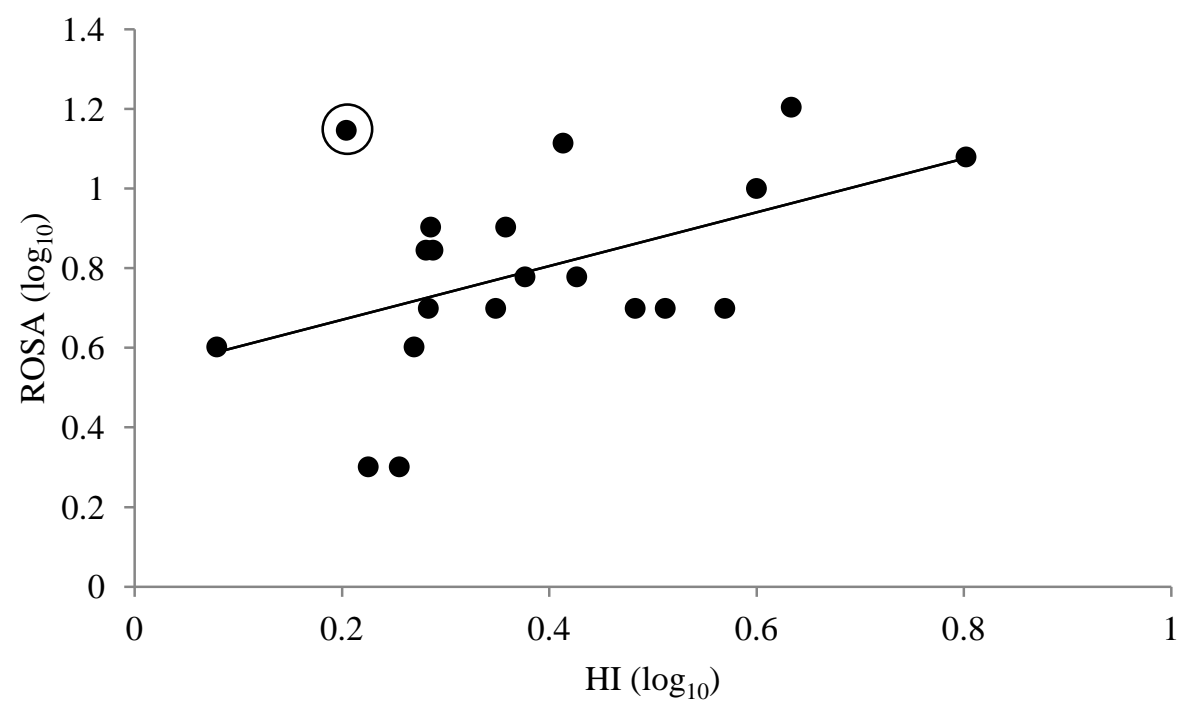

Figure 9 

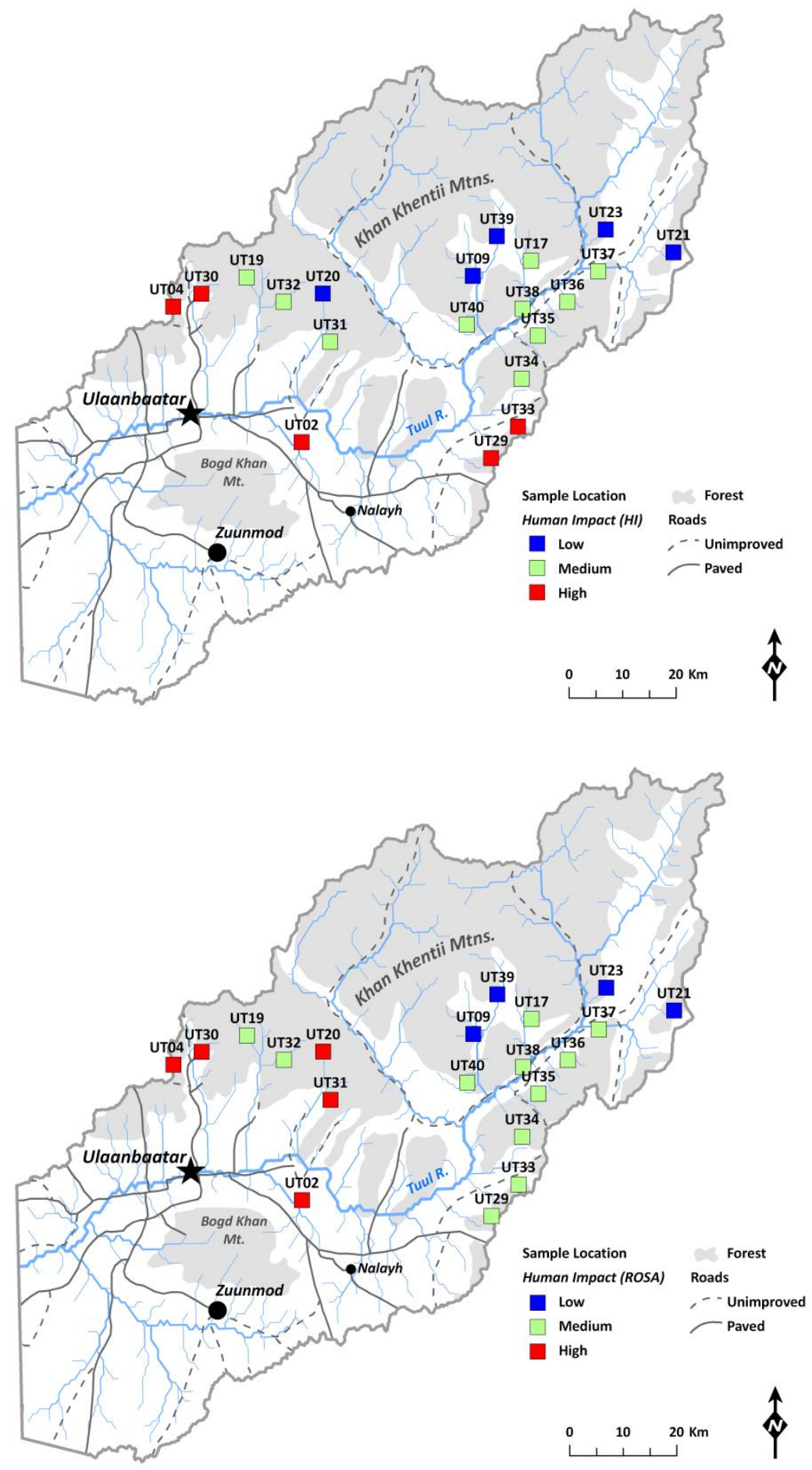

Figure 10 

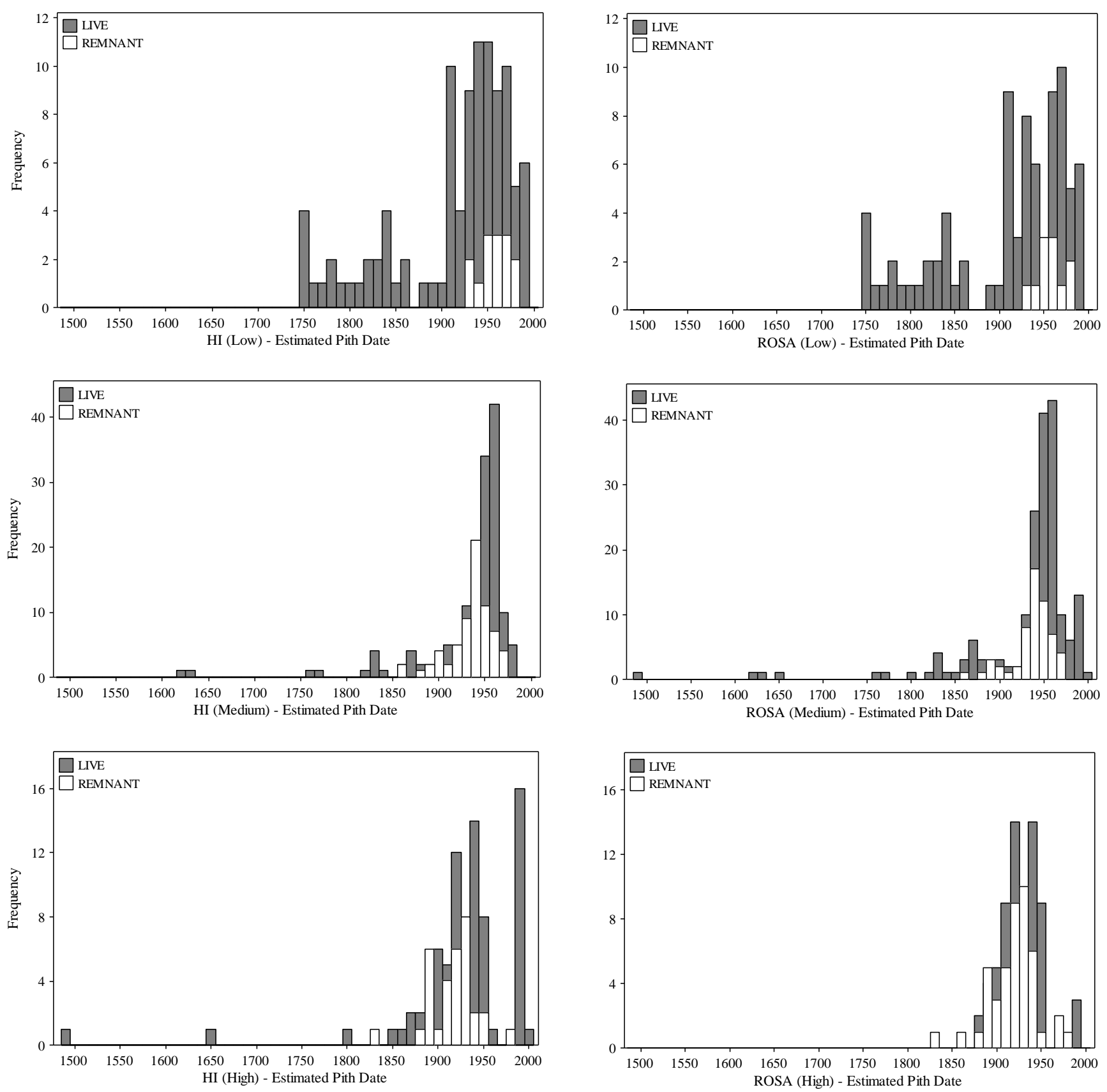

Figure 11 


\section{Appendix}

\section{A1. GIS-based human impact index (HI)}

- $\quad 10 \mathrm{~km}$ buffer of Upper Tuul River watershed (to limit edge effects)

- $5 \mathrm{~km}$ grid overlain the buffer and watershed (533 grid cells)

- Variables ${ }^{1}$ :

1. Distance to nearest urban center

2. Urban center level (based on population/original map symbol)

3. Distance to nearest road

4. Road type (paved/unimproved)

5. Elevation difference between grid cell and nearest urban center

- Value assignment for each grid cell ${ }^{2}$ :

O If distance to nearest urban center $\leq 10 \mathrm{~km}$, then +1

O If urban level $=1$, then +6

○ If urban level $=2$, then +5

If urban level $=3$, then +3.5

○ If urban level $=4$, then +2

$\circ$ If urban level $=5$, then +1

O If distance to nearest road $\leq 5 \mathrm{~km}$, then +1

If road type $=$ paved, then +1

$\circ$ If elevation difference between grid cell and nearest urban center $\leq 100 \mathrm{~m}$, then +1

- Kriging interpolation using 533 grid points

- Result: human impact gradient for the Upper Tuul River watershed with a range 1-10

${ }^{1}$ Variables chosen are based on a combination of field observations in 2009 and previous regional and/or global scale studies (e.g. WCS and CIESIN 2005)

${ }^{2}$ Appropriate thresholds were developed using detailed field notes (2009) and conversations with Mongolian researchers. 


\section{A2. Human impact indices}

\begin{tabular}{lcc|cccc}
\hline & & \multicolumn{5}{|c}{ ROSA Variables* } \\
\hline Site ID & HI & ROSA & Grazing & Logging & Trash & Campfire \\
\hline UT02 & 6.34 & 12 & 4 & 6 & 2 & 0 \\
\hline UT04 & 4.30 & 16 & 4 & 7 & 2 & 3 \\
\hline UT09 & 1.80 & 2 & 1 & 1 & 0 & 0 \\
\hline UT17 & 2.23 & 5 & 2 & 3 & 0 & 0 \\
\hline UT19 & 1.91 & 7 & 2 & 5 & 0 & 0 \\
\hline UT20 & 1.60 & 14 & 6 & 6 & 1 & 1 \\
\hline UT21 & 1.20 & 4 & 2 & 2 & 0 & 0 \\
\hline UT23 & 1.68 & 2 & 1 & 1 & 0 & 0 \\
\hline UT29 & 3.71 & 5 & 3 & 2 & 0 & 0 \\
\hline UT30 & 3.98 & 10 & 3 & 5 & 1 & 1 \\
\hline UT31 & 2.59 & 13 & 5 & 7 & 1 & 0 \\
\hline UT32 & 1.92 & 5 & 2 & 2 & 1 & 0 \\
\hline UT33 & 3.25 & 5 & 3 & 1 & 1 & 0 \\
\hline UT34 & 3.04 & 5 & 3 & 1 & 1 & 0 \\
\hline UT35 & 2.28 & 8 & 4 & 3 & 1 & 0 \\
\hline UT36 & 1.93 & 8 & 6 & 1 & 1 & 0 \\
\hline UT37 & 2.38 & 6 & 3 & 3 & 0 & 0 \\
\hline UT38 & 2.67 & 6 & 4 & 2 & 0 & 0 \\
\hline UT39 & 1.86 & 4 & 2 & 1 & 0 & 1 \\
\hline UT40 & 1.94 & 7 & 3 & 2 & 2 & 0 \\
\hline & & & & & & \\
\hline
\end{tabular}

HI = GIS-based human impact index (range 1-10)

ROSA = Rapid on-site assessment (max score of 33)

\section{* $\underline{\text { ROSA variables }}$}

\section{Presence}

$\mathbf{0}=$ no presence

$\mathbf{1}=$ extremely limited presence/areal extent

$2=$ limited presence/areal extent

$\mathbf{3}=$ presence/areal extent is ubiquitous with the site

Evidence of grazing $(\max 15)$

Dry dung

Wet dung

Hoof prints

Livestock remains

Livestock trails
Evidence of logging $(\max 12) \quad$ Other human disturbance (max 6) Stumps

Slash

Trash

Campfire remains

Machinery tracks

Other altered microtopography 


\title{
Chapter 2: Tree-Ring Based Drought Reconstruction for the Central Khan Khentii Mountains, Mongolia (1675-2000)
}

\author{
Thomas M. Saladyga \\ West Virginia University \\ Department of Geology and Geography \\ P.O. Box 6300 \\ Morgantown, WV 26506-6300 \\ Email: tom.saladyga@gmail.com
}




\begin{abstract}
In mountainous regions where climate change is least understood, long, high-resolution records of climate variability are typically unavailable. Here, we present a tree-ring reconstruction of spring and summer (April-August) Palmer Drought Severity Index (PDSI) for a grid point in the central Khan Khentii Mountains (48.75 N, 108.75 E) near the capital city of Ulaanbaatar. Our nested reconstruction extends from 1675 to 2000 and explains $60 \%$ of the variance in instrumental PDSI (1945-1993). Major drought events occurred from 1722-1726, 1730-1739, 1898-1907, 1928-1932, 1943-1947, and 1978-1983. The most recent drought event from 19962005 is the most severe only when instrumental data (2001-2005) are appended to the end of the reconstruction. The strongest pluvial events were 1933-1942 followed by 1783-1790. We used regime shift detection to indentify major discontinuities in moisture availability throughout the reconstruction. These shifts were more frequent during the $20^{\text {th }}$ century than any other period of the reconstruction, suggesting a growing need for increased adaptability of the livestock industry and natural resource managers. This study also highlights the need for meteorological stations in mountainous regions in order to decrease uncertainties in predicting and understanding localized climate change.
\end{abstract}




\section{Introduction}

Regional drought and local historical circumstances have influenced land use strategies in inner Asia for centuries (Lattimore 1938; Humphrey and Sneath 1999; Fernández-Giménez 2000). This adaptability and risk management in the face of extreme climatic conditions, including drought, is characteristic of pastoralist societies across the vast steppe and forest-steppe ecosystems of the region. However, recent trends of increasing drought frequency and severity have been documented in parts of China (Ma and Fu 2006; Li et al. 2007), Chinese Inner Mongolia (Liang et al. 2007) and Mongolia (Davi et al. 2010). In Mongolia, the $20^{\text {th }}$ century in particular was a period of continuous social and political change including the establishment of the People's Republic of Mongolia in 1924, the intensification of livestock collectives in the 1950s, and the transition from a centrally-planned economy to privatization in the 1990s.

Following privatization, prolonged drought conditions and severe winters from 1999-2002 resulted in the death of approximately 12 million livestock (Batima et al. 2005). More recently, drought in 2009 , followed by harsh winter conditions (referred to as $d z u d$ ) resulted in the loss of more than 7.8 million livestock. Due to these effects on the Mongolian economy and potential risk to limited water resources, it is of great importance to place these recent trends in moisture availability into a historical context.

Since the mid-1990s there has been a concerted effort to describe the historical variability of temperature and hydroclimatic conditions in Mongolia using tree-ring data (Jacoby et al. 1996; D’Arrigo et al. 2000; Pederson et al. 2001; Jacoby et al. 2003; Davi et al. 2006, 2010).

This research has shown warming temperatures for the latter half of the $20^{\text {th }}$ century (e.g. Jacoby et al. 1996), especially in high mountain regions such as the Altai in western Mongolia (Batima et al. 2005). Spatial trends in moisture availability, however, are highly variable. For example, 
there has been a general drying trend in eastern Mongolia since the 1950s, while no significant trend exists in the central and western part of the country (Li et al. 2009). This inherent variability creates issues when attempting to generalize large-scale historic trends in drought occurrence and severity.

It is not only important to consider the severity of individual events, but also the temporal context of change from one event to the next. That is, it might not be the event itself, but the rapid shift from one relatively stable state to another that is more influential on the resilience of ecological and social systems (Holling 1973; Scheffer et al. 2001; Folk et al. 2004; Walker et al. 2004). Such is the case, fluctuations in surface and groundwater resources will have profound effects on the economy and urban population in the Ulaanbaatar metropolitan area (Tsogtbaatar et al. 2009). Furthermore, adaptability of the livestock sector to predicted temperature increases (IPCC 2007) and spatially complex precipitation patterns (Davi et al. 2010) in the mountainous Khan Khentii region will be dependent upon the seamless use of meteorological data and local herder knowledge (Fernández-Giménez 2000; Marin 2010).

Here we use an already established network of tree-ring chronologies $(n=15)$ to develop a local-scale drought reconstruction of mean April-August Palmer Drought Severity Index (PDSI) for the central Khan Khentii Mountains, near the capital city of Ulaanbaatar (Figure 1). Ten of the fifteen chronologies were developed since the publication of the most recent hydroclimatic reconstruction in eastern Mongolia (Pederson et al. 2001). Climate data from the nearby Ulaanbaatar meteorological station indicate a spring-summer (April-August) temperature increase of $2.5^{\circ} \mathrm{C}$ during the last forty years. This increase is likely reflective of actual warming as the urban heat island effect has been shown to be negligible for other cities in Asia (Li et al. 2004). Increasing temperatures and drought occurrence in this region will have profound 
impacts on the health and volume of headwater streams (Gomi et al. 2002) and aquifer levels. These impacts will be particularly noticeable in the Tuul River basin, which is home to more than half of Mongolia's population.

The main objective of this study is to use climate-sensitive tree-ring records to create a local spring-summer PDSI reconstruction that places moisture availability into a regional and historical context. Additionally, we intend to indentify major drought and pluvial events as well as significant shifts in moisture regimes throughout the time series. The results can be used to further understand local variation in drought conditions and to inform sustainable resource management initiatives in this mountainous region.

\section{Study area}

The Khan Khentii Mountains are located in north-central Mongolia at approximately $48^{\circ} 40^{\prime}$ north latitude and $107^{\circ} 45^{\prime}$ east longitude (Figure 1). The region is characterized by an extremely continental climate with average temperatures ranging from $-19.3^{\circ} \mathrm{C}$ in winter $(\mathrm{Dec} / \mathrm{Jan} / \mathrm{Feb})$ to $16.4^{\circ} \mathrm{C}$ in summer (Jun/Jul/Aug) based on data from the nearest meteorological station in Ulaanbaatar (1969-2010). Total annual precipitation is low $(252 \mathrm{~mm})$ and peaks in summer when approximately $72 \%$ of precipitation falls (Davagdorj and Mijidorg 1996).

The mountains are situated at the interface between the western Siberian dark taiga (Picea obovata, Abies sibirica, Pinus sibirica, and Larix sibirica), the eastern Siberian light taiga (Betula platyphylla, Larix sibirica, and Pinus sylvestris) and the Mongolian forest-steppe zone (Ermakov et al. 2002). Elevations range from approximately 950 meters in the northwestern foothills to 2795 meters at Asralt Khairkhan Mountain. This region is particularly species rich, relative to the rest of central Asia, due to the intersection of boreal, temperate and steppe 
vegetation. Three major rivers originate within an area of $785 \mathrm{~km}^{2}$ in the central Khan Khentii Mountains including the Onon, Kherlen, and Tuul. The Onon is the only river that reliably flows into the Pacific Ocean via the Amur River which forms the border between Russia and China. The Kherlen also flows east and ultimately drains into Lake Hulun in Chinese Inner Mongolia where its waters typically evaporate in the arid climate. The Tuul River flows south and then west through Ulaanbaatar and eventually drains into Lake Baikal in Russia via the Orkhon and Selenge Rivers.

\section{Data and methods}

\section{Tree-ring data}

Regional tree-ring chronologies were obtained from the International Tree-Ring Data Bank (ITRDB) maintained by the National Oceanic and Atmospheric Administration's (NOAA) World Data Center for Paleoclimatology (Mongolian American Tree-Ring Project and unpublished data). Sample sites are located east of the Khan Khentii Mountains along the Onon River, in the southern and western foothills, the northern border forests, and on the eastern flank of the Khangai Mountains (Figure 1). Median elevation of sites is $1125 \mathrm{~m}$. Samples were taken from both living and remnant specimens of Siberian pine (Pinus siberica), Scots pine (Pinus sylvestris), and Siberian larch (Larix siberica).

In total, 417 series from fifteen chronologies were used for the drought reconstruction (Table 1). All time-series of ring width were crossdated using standard dendrochronology techniques (e.g. Stokes and Smiley 1968) and checked for quality control using the program COFECHA (Holmes 1983; Grissino-Mayer et al. 1997). Chronologies were developed using the program ARSTAN (Cook 1985) and the statistic of expressed population signal (EPS) was used 
with a threshold of 0.85 to determine reasonable signal strength of the chronologies (e.g. Wigley et al. 1984). The common period of all the chronologies with an acceptable EPS is 1815-1994.

\section{Climate data}

Tree-ring chronologies were compared to Palmer Drought Severity Index (PDSI) data. PDSI is a dryness index based on temperature, precipitation, and soil evaporation (Palmer 1965) and has been utilized for paleoclimate reconstructions in Asia (Liang et al. 2007; Fan et al. 2008; Fang et al. 2010; Davi et al. 2010) and other regions (Stahle et al. 1985; Cook et al. 1999; Pohl et al. 2002; Touchan et al. 2010). The PDSI network used in this study was developed by Dai et al. (2004), which is based on a $2.5^{\circ} \times 2.5^{\circ}$ gridded system that does not account for elevation or topography. Instrumental temperature and precipitation data from regional meteorological stations and soil moisture data from forty-two stations in Mongolia were used to interpolate PDSI for the selected gridpoint. We chose one grid point situated over the central Khan Khentii Mountains (48.75 N, 108.75 E) to reconstruct PDSI. This location was chosen for its proximity to the headwaters of three major rivers and for use in a nearby assessment of climate-wildfire relationships (see Chapter 3).

\section{Calibration and verification}

We used correlation analysis between monthly PDSI data and individual chronologies to indentify April-August as the optimum season for reconstruction. The average April-August PDSI reconstruction was developed using the common period of the fifteen chronologies and instrumental data (1945-1994) at lags $t$ or $t+1$, taking into account the effect of previous year's climate on tree growth. We used a split calibration-verification procedure to test model reliability (Meko and Graybill 1995). We calibrated on 1970-1993 and verified 1945-1969, as 
well as calibrated on 1945-1969 and verified 1970-1993. To assess model strength, we calculated Pearson's correlation coefficient $(r), r$ square $\left(r^{2}\right)$, reduction of error $(R E)$ and coefficient of efficiency (CE). We used a nesting procedure to develop a statistically robust reconstruction as well as extend the length of the reconstruction (Meko 1997; Cook et al. 2002; Davi et al. 2010). This included eight backwards nests that extend the model 140 years prior to the common period (1815-1994) to 1675 and two forward nests that extend the model to the year 2000. Calibration and verification statistics, including variance explained, are summarized in Table 2.

\section{Temporal variation in PDSI}

We quantified the relative severity of multi-year ( $\geq 2$ years) drought and pluvial events using an approach developed by Biondi et al. (2002). This method utilizes three temporal parameters including duration (number of years an event remains above or below the median PDSI value of the entire time series), magnitude (cumulative departure of an event), and intensity (magnitude/duration). An overall score for each event is calculated by summing the individual value rankings for duration, magnitude, and intensity. These scores provide a useful means for ranking the severity of individual drought and pluvial events in the context of historical moisture availability.

We used regime shift detection to identify significant changes in our reconstructed AprilAugust PDSI. Regime shift detection uses a sequential analysis algorithm and a user-determined cut-off length to indentify discontinuities in time series datasets (Rodionov 2004). For our purposes, the regime shift detector (RSD; Microsoft Excel add on) used a sequential t-test to indentify rapid changes in mean PDSI value using cut-off lengths of 5, 10, and 20 years $(\alpha=$ 
0.05). The cut-off length determines the minimum length of regimes, for which the magnitude of the shifts remains intact. Similar methods have been used to identify regimes shifts in a variety of ecological and climate systems (D’Arrigo and Wilson 2006; Litzow 2006; Daskalov et al. 2007; Oguz and Gilbert 2007; Marty 2008).

\section{Results}

\section{PDSI reconstruction}

Fifteen chronologies and 20 of the 30 possible predictors $(t$ and $t+1)$ were significantly correlated $(\alpha=0.05)$ to April-August PDSI during the common period for all chronologies (1815-1994). The reconstruction (Figure 2) accounts for $60 \%$ of the variance in instrumental PDSI for the period 1945-1993 (Table 2). Although the number of chronologies decreases with each backwards nest, the percentage of variance explained remains generally stable as the model is extended back in time (Figure 4). A backwards nest testing the model past the year 1664 failed, though marginally, calibration-verification for the 1970-1993 split period (verification RE $=-0.004$ and verification $\mathrm{CE}=-0.074)$ and was not included.

The model was extended to the year 2000 using two forward nests (Table 2). A subsequent forward nest for 2001 failed calibration-verification tests for the 1970-1993 split period (verification $\mathrm{CE}=-0.179$ ). This failure was due to a substantial underestimation of actual drought conditions by the model. For example, instrumental mean April-August PDSI value for 2001 is -6.03 , while the reconstructed value from tree rings was -2.83 . This underestimation at the end of the reconstruction might be a product of trend fitting distortions within individual chronologies caused by decadal to century-long climate variability (Melvin and Briffa 2008). Trends in mean April-August PDSI are reflected by Kherlen River instrumental streamflow at 
Undurkhaan (Figure 2). Most notable is the extreme drought from 1978-1983 and a shift to prolonged drought conditions in 1996. Reliable streamflow data for the Tuul and Onon Rivers are not available, but it can be inferred that drought conditions in the central Khan Khentii Mountains would have similar effects on these major rivers.

\section{Multi-annual and decadal-scale events}

The top ten drought and pluvial events were indentified based on duration, magnitude, and intensity. The drought event from 1730-1739 was ranked the highest followed by the events of 1722-1726, 1898-1907, 1928-1932, 1943-1947, and 1978-1983 (Table 3). The drought event

from 1996-2000 is ranked tenth, which again could be the result of trend-fitting distortion during standardization of individual time-series. The most recent drought event from 1996-2005 is ranked the highest in all three variables (duration, magnitude, and intensity) when instrumental data (2001-2005) are appended to the end of the reconstruction, although with the loss of variance in the reconstructed record, this needs to be considered with caution. The highest ranked pluvial events occurred during the 1930 s and during the mid to late $18^{\text {th }}$ century (Table 4). Of note is the relatively high intensity pluvial event that occurred from 1993-1995, just prior to a shift to prolonged drought conditions.

\section{Drought and pluvial regimes}

Regime shift detection was used to indentify discontinuities in mean April-August PDSI using three temporal scales (cut-off lengths of 5, 10, and 20 years). Although instrumental data (20012005) show continued drought conditions, these years were excluded from the analysis. Using a five-year cut-off length, we indentified twenty-three regimes ranging from 4 to 69 years (Table 5). Shifts from pluvial (low Drought:Pluvial ratio) or intermediate moisture regimes 
(Drought:Pluvial ratio near 1) to periods of sustained drought $(\geq 5$ years, mean PDSI $\leq-1.5)$ occurred frequently throughout the time series. Years in which this type of shift occurred include 1692, 1723, 1771, 1903, 1928, 1943, 1978, and 1996. Regime shift detection is designed to indentify rapid changes in systems and, therefore, identified only two regime shifts during the $19^{\text {th }}$ century, which is characterized by more gradual changes in April-August PDSI. There were eight and ten regime shifts during the $18^{\text {th }}$ and $20^{\text {th }}$ centuries, respectively.

Decreasing the temporal resolution to a ten-year cut-off length resulted in fourteen regimes ranging from 6 to 117 years (Table 6, Figure 4). Five shifts during the $18^{\text {th }}$ century, none during the $19^{\text {th }}$ century, and eight during the $20^{\text {th }}$ century were identified. A shift into prolonged drought conditions $(\geq 5$ years, mean PDSI $\leq-1.5)$ from a pluvial or intermediate moisture regime occurred in 1731, 1771, 1922, 1942, 1978, and 1996. With a cut-off length of ten years, the shifts to drought conditions at the end of the $17^{\text {th }}$ century (1692) and at the turn of the $20^{\text {th }}$ century (1903) are not identified. Figure 5 shows these regime shifts in relation to multiannual and decadal-scale drought and pluvial events. Regime shifts that occurred in the same year or within one year of the start of a major drought (D) or pluvial (P) event include 1731 (D), 1740 (P), 1771 (D), 1784 (P), 1908 (P), 1933 (P), 1942 (D), 1978 (D), and 1996 (D). Not only do these years mark the beginning of a new PDSI regime, they are also the onset of major drought or pluvial events in terms of duration, magnitude, and intensity.

We also used a twenty-year cut-off length to highlight long-term trends in mean AprilAugust PDSI, which resulted in five regimes ranging from 10 to 192 years (Table 7). The only shift from a pluvial or intermediate moisture regime to prolonged drought conditions ( $\geq 5$ years, mean PDSI $\leq-1.5)$ occurred in 1996. Regimes 2 (1740-1766) and 4 (1959-1995) were dominated by pluvial years, while regimes 1 (1675-1739) and 3 (1767-1958) were generally dry. 
Even with a twenty-year cut-off length, the drought magnitude for the years 1996 to 2000 was great enough to be identified as a unique regime.

\section{Discussion}

We found significant correlations between regional tree growth and average April-August PDSI over the central Khan Khentii Mountains. Variance explained (60\%) during the full common period (1945-1993) was similar to a large-scale drought reconstruction in Mongolia (Davi et al. 2010), but had greater predictive strength than studies in western Mongolia (Davi et al. 2009) and China (Fan et al. 2008; Fang et al. 2010). The latter studies utilized high-elevation trees to reconstruct PDSI for mountainous regions, which typically experience localized precipitation patterns due to complex topography and orographic effects (Batima et al. 2005; Sato et al. 2007). Therefore, an inherent disconnect exists between high elevation tree growth and instrumental data that is typically available only in accessible (i.e. less mountainous) locations. Our model used trees sampled at an elevation of approximately $1125 \mathrm{~m}$ to reconstruct a PDSI gridpoint representing an elevation of $2030 \mathrm{~m}$. The relative robustness of our model might be attributed to high correlations between tree growth and the local instrumental data used by Dai et al. (2004) to interpolate values for the PDSI gridpoint. Consequently, our model is an estimation of interpolated April-August PDSI for the study area. These results must be interpreted with caution as neither tree-ring data or instrumental data were collected at higher elevations in the central Khan Khentii Mountains.

Our average April-August reconstructed PDSI is similar to reconstructed Kherlen River streamflow $(r=0.80)$ and precipitation for eastern Mongolia $(r=0.69)$ during the period 16751995 (Pederson et al. 2001) in that both reconstructions contain severe droughts occurring during 
the 1720s, 1730s, 1920s and 1940s. The six-year drought event from 1978 to 1983 also correlates with both streamflow and precipitation records from eastern Mongolia (Pederson et al. 2001) . The most recent drought (1996-2000) was relatively less severe than previous events. However, when instrumental data (2001-2005) is appended to the reconstruction, the drought at the turn of the $21^{\text {st }}$ century is ranked highest. Periods of drought in the central Khan Khentii Mountains occurred during wet periods in western Mongolia (Davi et al. 2009); most notably during the $1940 \mathrm{~s}$, the late $1990 \mathrm{~s}$, and turn of the $21^{\text {st }}$ century. These regional differences are consistent with the spatial complexities of moisture availability present in Mongolia (Davi et al. 2009, 2010).

\section{Moisture regime shifts}

In the context of our 326-year reconstruction of average April-August PDSI, it is evident that the $20^{\text {th }}$ century was a period in which moisture availability in central Mongolia changed frequently and with great magnitude. If these rapid changes in moisture availability continue, they will have profound impacts on water resource planning, especially as population growth and urbanization in central Mongolia place additional pressure on groundwater sources (Dore and Nagpal 2006).

We have indentified significant changes in average April-August PDSI using regime shift detection methods. A cut-off length of five years was the most sensitive to short-term drought and pluvial events, identifying twenty-three regime shifts. Only two regime shifts were detected during the $19^{\text {th }}$ century due to low variability and gradual change in PDSI values; a trend which is consistent with precipitation and streamflow reconstructions in eastern Mongolia (Pederson et al. 2001). Four of the seven shifts from a pluvial or intermediate moisture regime to a period of 
prolonged drought occurred during the $20^{\text {th }}$ century. These major changes in moisture conditions have the potential to impact water resource use and the livestock industry in Mongolia. Increased frequency of dramatic shifts in moisture availability can make planning for water resource allocation difficult and can potentially cause instability in the livestock sector.

Increasing the temporal scale for regime shift detection to ten years resulted in fourteen

drought and pluvial regimes. Eight of the fourteen regime shifts occurred during the $20^{\text {th }}$ century and four of the six shifts from a pluvial or intermediate moisture regime to a period of prolonged drought occurred during the $20^{\text {th }}$ century. Additionally, five of the nine regime shifts that occurred within one year of the beginning of a major drought or pluvial event happened during the $20^{\text {th }}$ century. Finally, common patterns observed for each cut-off length included drought in the early $18^{\text {th }}$ century, less variable moisture conditions from the late $18^{\text {th }}$ century to the early $20^{\text {th }}$ century, a wetting trend from the mid-20 th century to 1995 , and drought through 2000.

\section{Conclusions}

We have developed a multi-century spring and summer drought reconstruction for the central Khan Khentii Mountains in Mongolia. The robustness of the model was related to strong correlations between tree growth and instrumental data used to develop the PDSI gridded network (Dai et al. 2004). Nevertheless, our model provides the best available estimation of average April-August PDSI for a mountainous region that is lacking meteorological data. Drought events, especially the 1720s, 1730s, 1920s, 1940s and from 1978 to 1983, reflect events previously reported in eastern Mongolia (Pederson et al. 2001). Pluvial conditions from 1933 to 1942 were ranked highest, whereas the drought from 1996 to 2005 was the most severe only when instrumental data is appended to the reconstruction. 
Regime shift detection was useful for identifying rapid changes in moisture availability, which might be more influential on the resilience of ecological and social systems than isolated events. These shifts were more frequent during the $20^{\text {th }}$ century than any other period of the reconstruction, suggesting the growing need for appropriate and flexible climate adaptation measures in the Khan Khentii region. This study also emphasizes the need for meteorological stations in mountainous regions in order to decrease uncertainties in understanding and predicting the inherent complexities of local precipitation patterns.

\section{References}

Batima, P., L. Natsagdorj, P. Gombluudev, and P. Erdenetsetseg. 2005. Observed climate change in Mongolia. Assessments and Adaptations to Climate Change (AIACC) Working Paper No. 12 (www.aiaccproject.org, accessed March 2011).

Biondi, F., T.J. Kozubowski, and A.K. Panorska. 2002. Stochastic modeling of regime shifts. Climate Research. 23: 23-30.

Cook, E. R. 1985. A time series approach to tree-ring standardization. Ph.D. dissertation, 171 pp., University of Arizona, Tuscon.

Cook, E.R., D.M Meko, D. Stahle, and M.K. Cleveland. 1999. Drought reconstructions for the continental United States. Journal of Climate. 12: 1145-1162.

Cook, E.R., R. D’Arrigo, and M. Mann. 2002. A well-verified, multi-proxy reconstruction of the winter North Atlantic Oscillation index since AD 1400. Journal of Climate. 15: 17541764.

Dai, A., E. Trenberth, and T. Qian. 2004. A global dataset of Palmer Drought Severity Index for 1870-2002: Relationship with soil moisture and effects of surface warming. American Meteorological Society. 5: 1117-1130.

D'Arrigo, R. D., G.C. Jacoby, N. Pederson, D. Frank, B. Buckley, B. Nachin, R. Mijiddorj, and C. Dugarjav. 2000. Mongolian tree-rings, temperature sensitivity and reconstructions of Northern Hemisphere temperature. The Holocene. 10: 669-672.

D'Arrigo, R. and R. Wilson. 2006. On the Asian expression of the PDO. International Journal of Climatology. 26: 1607-1617. 
Daskalov, G.M., A.N. Grishin, S. Rodionov, and V. Mihneva. 2007. Trophic cascades triggered by overfishing reveal possible mechanisms of ecosystem regime shifts. Proceedings of the National Academy of the Sciences. 104: 10518-10523.

Davagdorj, D. and R. Mijidorg. 1996. Climate change issues in Mongolia. In: D. Davagdorj and L. Natsagdorj (eds.) Hydrometeorological Issues in Mongolia, Papers in Hydrometeorology, Ulaanbaatar, 230 pp. pp. 79-88.

Davi, N., G. Jacoby, K. Fang, J. Li, R. D’Arrigo, N. Baatarbileg, and D. Robinson. 2010. Reconstructing drought variability for Mongolia based on a large-scale tree ring network: 1520-1993.

Davi, N., G.C. Jacoby, R.D. D’Arrigo, N. Baatarbileg, L. Jinbao, and A.E. Curtis. 2009. A treering-based drought index reconstruction for far-western Mongolia: 1565-2004. International Journal of Climatology. 29: 1508-1514.

Davi, N., G. Jacoby, A.E. Curtis, and N. Baatarbileg. 2006. Extension of drought records for central Asia using tree rings: west-central Mongolia. Journal of Climate. 19: 288-299.

Dore, G. and T. Nagpal. 2006. Urban transition in Mongolia: Pursuing sustainability in a unique environment. Environment: Science and Policy for Sustainable Development. 48: 10-24.

Ermakov, N., M. Cherosov. and P. Gogoleva. 2002. Classification of ultracontinental boreal forests in central Yakutia. Folia Geobotanica. 37: 419-440.

Fan, Z., A. Brauning, and K. Cao. 2008. Tree-ring based drought reconstruction in the central Hengduan region (China) since A.A. 1655. International Journal of Climatology. 28: 18791887.

Fang, K., X. Gou, F. Chen, R. D’Arrigo, and J. Li. 2010. Tree-ring based drought reconstruction for the Guiqing Mountain (China): linkages to the Indian and Pacific Oceans. International Journal of Climatology. 30: 1137-1145.

Fernández-Giménez, M. E. 1999. Sustaining the steppes: a geographical history of pastoral land use in Mongolia. The Geographical Review. 89: 315-342.

Fernández-Giménez, M. E. 2000. The role of Mongolian nomadic pastoralists' ecological knowledge in rangeland management. Ecological Applications. 10: 1318-1326.

Folke, C., S. Carpenter, B. Walker, M. Scheffer, T. Elmquist, L. Gunderson, and C.S. Holling. Regime shifts, resilience, and biodiversity in ecosystem management. Annual Review in Ecology, Evolution, and Systematics. 35: 557-581.

Gomi, T., R.C. Sidle, and J.S. Richardson. 2002. Understanding processes and downstream linkages of headwater systems. BioScience. 52: 905-916. 
Grissino-Mayer, H.D., R.L. Holmes, and H.C. Fritts. 1997. The International Tree-Ring Data Bank Program Library, version 2.1, Users Manual, Tucson, Arizona.

Holling, C.S. 1973. Resilience and stability of ecological systems. Annual Review in Ecology, Evolution, and Systematics. 4: 1-23.

Holmes, R.L. 1983. Computer-assisted quality control in tree-ring dating and measurement. Tree-Ring Bulletin. 43: 69-78.

Humphrey, C. and D. Sneath. 1999. The End of Nomadism? Society, State, and the Environment in Inner Asia. Duke University Press, 355 pp.

IPCC (Intergovernmental Panel on Climate Change). 2007. Climate Change 2007 - The Physical Science Basis. Working Group I Contribution to the Fourth Assessment Report of the IPCC. Cambridge University Press, Cambridge, UK.

Jacoby, G.C., R.D. D'Arrigo, and T. Davaajamts. 1996. Mongolian tree rings and $20^{\text {th }}$ century warming. Science. 273: 771-773.

Jacoby, G.C., N. Pederson, and R. D’Arrigo. 2003. Temperature and precipitation in Mongolia based on dendroclimatic investigations. Chinese Science Bulletin. 48: 1474-1479.

Lattimore, O. 1938. The geographical factor in Mongol history. The Geographical Journal. 91: $1-16$.

Li, J. F. Chen, E.R. Cook, X. Gou, and Y. Zhang. 2007. Drought reconstruction for north central China from tree rings: the value of the Palmer drought severity index. International Journal of Climatology. 27: 903-909.

Li, J., E.R. Cook, R. D’Arrigo, F. Chen, and X. Gou. 2009. Moisture variability across China and Mongolia. Climate Dynamics. 33: 409-445.

Li, Q., H. Zhang, X. Liu, and J. Huang. 2004. Urban heat island effect on annual mean temperature during the last 50 years in China. Theoretical Applications in Climatology. 79: 165-174.

Liang, E., X. Shao, H. Liu, and D. Eckstein. 2007. Tree-ring based PDSI reconstruction since AD 1842 in the Ortindag Sand Land, east Inner Mongolia. Chinese Science Bulletin. 52: 2715-2721.

Litzow, M.A. 2006. Climate regime shifts and community reorganization in the Gulf of Alaska: how do recent shifts compare with 1976/1977? Journal of Marine Science. 63: 1386-1396.

Ma, Z. and C. Fu. 2006. Some evidence of drying trend over northern China from 1951 to 2004. Chinese Science Bulletin. 51: 2913-2925. 
Marin, A. 2010. Riders under storms: Contributions of nomadic herders' observations to analyzing climate change in Mongolia. Global Environmental Change. 20: 162-176.

Marty, C. 2008. Regime shift of snow days in Switzerland. Geophysical Research Letters. 35: L12501.

MATRIP (Mongolian-American Tree-Ring Project). 2006. Overview. Web-based document:http://www.ldgo.columbia.edu/res/fac/trl/research/Mongolia/Moverview.htmlMon golianRiverResources.2008.http://www.mongolianriverresources.mn/index.php?option=com _frontpage\&Itemid=1, accessed March 2011.

Melvin, T.M. and K.R. Briffa. 2008. A "signal free" approach to dendroclimatic standardization. Dendrochronologia. 26: 71-86.

Meko, D.M. 1997. Dendroclimatic reconstruction with time varying predictor subsets of tree indices. Journal of Climate. 10: 687-696.

Meko, D.M. and D.A. Graybill. 1995. Tree-ring reconstruction of Upper Gila River discharge. Water Resources Bulletin. 31: 605-616.

Oguz, T. and D. Gilbert. 2007. Abrupt transitions of the top-down controlled Black Sea pelagic ecosystem during 1960-2000: Evidence for regime-shifts under strong fishery exploitation and nutrient enrichment modulated by climate-induced variations. Deep-Sea Research. 54: 220-242.

Palmer, W.C. 1965. Meteorological drought. Research paper, 45. U.S. Department of Commercial Weather Bureau, Washington, D.C.

Pederson, N., G. Jacoby, R. D’Arrigo, E. Cook, B. Buckley, C. Dugarjav, and R. Mijiddorj. 2001. Hydrometeorological reconstructions for north-eastern Mongolia derived from tree rings: AD 1651-1995. Journal of Climate. 14: 872-881.

Pohl, K.A., Hadley, K.S., and K.B. Arabas. 2002. A 545-year drought reconstruction for central Oregon. Physical Geography. 23: 302-320.

Rodionov, S.N. 2004. A sequential algorithm for testing climate regime shifts. Geophysical Research Letters. 31:4 pp.

Sato, T. and F. Kimura. 2006. Regional climate simulations to diagnose environmental changes in Mongolia. Bulletin of the Terra Environmental Research Center. 7: 59-69.

Scheffer, M., S. Carpenter, J.A. Foley, C. Folke, and B. Walker. 2001. Catastrophic shifts in ecosystems. Nature. 413: 591-596.

Stahle, D.W., M.K. Cleveland, and J.G. Hehr. 1985. A 450-year drought reconstruction for Arkansas, United States. Nature. 316: 530-532. 
Stokes, M. A. and T.L. Smiley. 1968. An introduction to tree-ring dating, 73 pp. University of Chicago Press, Chicago.

Touchan, R., K.J. Anchukaitis, D.M. Meko, M. Sabir, S. Attalah, and A. Aloui. 2010. Spatiotemporal drought variability in northwestern Africa over the last nine centuries. Climate Dynamics. 35:L13705.

Tsogtbaatar, J., L. Janchivdorj, D. Unurjargal, and B. Erdenechimeg. 2009. The groundwater problem in Mongolia. In Proceedings of UNESCO Workshop on International Strategy for Sustainable Groundwater Management: Transboundary Aquifers and Integrated Watershed Management. University of Tsukuba, Tsukuba City, Japan, 6 October, 2009. IHP VII Technical Documents in Hydrology, No. 2, UNESCO Office Beijing, China 2009.

Walker, B., C.S. Holling, S.R. Carpenter, and A. Kinzig. 2004. Resilience, adaptability and transformability in social-ecological systems. Ecology and Society. 9(2): 5.

Wigley, T.M.L., K.R. Briffa, and P.D. Jones. 1984. Average value of correlated time series, with applications in dendroclimatology and hydrometeorology. Journal of Applied Meteorology. 23: 201-234. 


\section{Tables and Figures}

Table 1 Chronologies used and their statistics for the April-August PDSI reconstruction.

\begin{tabular}{|c|c|c|c|c|c|c|c|c|c|c|}
\hline Site & $\begin{array}{l}\text { Lat. } \\
\left({ }^{\circ} \mathrm{N}\right)\end{array}$ & $\begin{array}{l}\text { Long. } \\
\left({ }^{\circ} \mathrm{E}\right)\end{array}$ & Species $^{\mathrm{a}}$ & Full Period & $\begin{array}{l}\text { No. of } \\
\text { Series }\end{array}$ & $\begin{array}{l}\text { Median } \\
\text { Length }\end{array}$ & $\begin{array}{c}\text { EPS } \\
\left(_{\text {(Tree) }}^{\text {b }}\right.\end{array}$ & $\begin{array}{c}\text { EPS } \\
>0.85^{\mathrm{c}}\end{array}$ & $\begin{array}{l}\text { Yr EPS } \\
>0.85^{d}\end{array}$ & $\begin{array}{l}\text { Chron. } \\
\text { Type }^{\mathrm{e}}\end{array}$ \\
\hline Bugant* & 49.41 & 107.57 & PISY & $1730-2008$ & 34 & 210 & 0.970 & 1815 & 1793 & ARS \\
\hline Dadal* & 49.01 & 111.59 & PISY & $1704-2001$ & 22 & 259 & 0.968 & 1735 & 1716 & STD \\
\hline $\begin{array}{l}\text { Dulaan } \\
\text { Khan Nars* }\end{array}$ & 49.94 & 106.20 & PISY & $1653-2008$ & 44 & 281 & 0.981 & 1675 & - & STD \\
\hline $\begin{array}{l}\text { Inferno } \\
\text { Ridge }\end{array}$ & 48.83 & 111.67 & PISI & $1692-1996$ & 35 & 175 & 0.980 & 1750 & - & ARS \\
\hline $\begin{array}{l}\text { Manzshir } \\
\text { Hiid }\end{array}$ & 47.77 & 107.00 & PISI & 1505-1994 & 25 & 183 & 0.985 & - & 1787 & ARS \\
\hline $\begin{array}{l}\text { Narstain } \\
\text { Davaa* }\end{array}$ & 48.37 & 106.18 & PISY & $1740-2008$ & 20 & 181 & 0.972 & - & 1802 & ARS \\
\hline Onon Gol* & 48.83 & 111.69 & LASI & $1576-2001$ & 25 & 201 & 0.952 & 1680 & - & ARS \\
\hline $\begin{array}{l}\text { Orkhon Gol } \\
\text { Hurshee* }\end{array}$ & 46.79 & 101.95 & LASI & $1503-2009$ & 27 & 290 & 0.966 & 1585 & - & STD \\
\hline $\begin{array}{l}\text { Shaamar } \\
\text { Mahan } \\
\text { Nars* }\end{array}$ & 50.25 & 106.18 & PISY & $1770-2008$ & 17 & 208 & 0.965 & - & 1786 & ARS \\
\hline Terelj & 47.96 & 107.46 & LASI & $1590-2002$ & 28 & 288 & 0.980 & - & 1622 & STD \\
\hline Tujin Nars* & 50.15 & 106.37 & PISY & $1731-2008$ & 18 & 169 & 0.897 & 1815 & - & ARS \\
\hline $\begin{array}{l}\text { Uglugchiin } \\
\text { Herem* }\end{array}$ & 48.41 & 110.20 & PISY & $1705-2009$ & 16 & 171 & 0.924 & 1770 & - & ARS \\
\hline Urgun Nars & 48.58 & 110.55 & PISY & 1651-1996 & 33 & 189 & 0.984 & - & 1664 & STD \\
\hline Zurkh Uul* & 48.65 & 106.03 & PISY & 1714-2009 & 22 & 192 & 0.971 & - & 1737 & STD \\
\hline Zuun Mod & 47.78 & 107.50 & LASI & $1582-2001$ & 51 & 332 & 0.993 & - & 1582 & STD \\
\hline
\end{tabular}

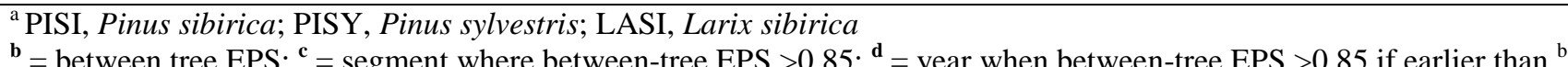

= between tree EPS ${ }^{\mathrm{c}}=$ segment where
${ }^{\mathrm{a}}$ ARS $=$ ARSTAN; STD $=$ Standardized

*Chronologies collected since Pederson et al. 2001 
Table 2 Calibration-verification statistics for the April-August PDSI reconstruction. RE = reduction of error. $\mathrm{CE}=$ coefficient of efficiency.

\begin{tabular}{|c|c|c|c|c|c|c|c|c|c|c|c|c|c|c|}
\hline Nest $^{\mathrm{a}}$ & $\begin{array}{l}\text { No. } \\
\text { Crns }\end{array}$ & $\mathbf{r}^{2}$ & \multicolumn{6}{|c|}{ Pearson $r$} & \multicolumn{4}{|c|}{$\mathbf{R E}$} & \multicolumn{2}{|c|}{$\mathbf{C E}$} \\
\hline & & & \multicolumn{12}{|c|}{ Backwards Nests } \\
\hline & & $\begin{array}{c}1945- \\
1993\end{array}$ & \multicolumn{2}{|c|}{$1945-1969$} & \multicolumn{2}{|c|}{$1970-1993$} & \multicolumn{2}{|c|}{$1945-1969$} & \multicolumn{2}{|c|}{$1970-1993$} & \multicolumn{2}{|c|}{$1945-1969$} & \multicolumn{2}{|c|}{$1970-1993$} \\
\hline & & & Calib. & Veri. & Calib. & Veri. & Calib. & Veri. & Calib. & Veri. & Calib. & Veri. & Calib. & Veri. \\
\hline 1675 & 5 & 57.78 & 0.766 & 0.777 & 0.820 & 0.786 & 0.586 & 0.458 & 0.673 & 0.194 & 0.586 & 0.443 & 0.673 & 0.138 \\
\hline 1680 & 6 & 57.65 & 0.766 & 0.777 & 0.827 & 0.749 & 0.586 & 0.458 & 0.684 & 0.086 & 0.586 & 0.443 & 0.684 & 0.022 \\
\hline 1737 & 8 & 60.56 & 0.766 & 0.777 & 0.841 & 0.758 & 0.586 & 0.458 & 0.707 & 0.318 & 0.586 & 0.443 & 0.707 & 0.270 \\
\hline 1750 & 9 & 60.98 & 0.766 & 0.777 & 0.843 & 0.732 & 0.586 & 0.458 & 0.711 & 0.188 & 0.586 & 0.443 & 0.711 & 0.131 \\
\hline 1770 & 10 & 59.55 & 0.728 & 0.775 & 0.839 & 0.723 & 0.530 & 0.479 & 0.704 & 0.203 & 0.530 & 0.464 & 0.704 & 0.147 \\
\hline 1787 & 12 & 59.81 & 0.757 & 0.766 & 0.850 & 0.763 & 0.573 & 0.481 & 0.722 & 0.339 & 0.573 & 0.466 & 0.722 & 0.293 \\
\hline 1793 & 13 & 61.32 & 0.757 & 0.766 & 0.838 & 0.754 & 0.573 & 0.481 & 0.703 & 0.351 & 0.573 & 0.466 & 0.703 & 0.305 \\
\hline 1802 & 14 & 61.14 & 0.757 & 0.766 & 0.833 & 0.745 & 0.573 & 0.481 & 0.694 & 0.421 & 0.573 & 0.466 & 0.694 & 0.381 \\
\hline $1815^{\mathrm{b}}$ & 15 & 60.13 & 0.757 & 0.766 & 0.839 & 0.715 & 0.573 & 0.481 & 0.703 & 0.300 & 0.573 & 0.466 & 0.703 & 0.250 \\
\hline & & & \multicolumn{12}{|c|}{ Forward Nests } \\
\hline $1995^{\mathrm{c}}$ & 14 & 56.68 & 0.728 & 0.736 & 0.822 & 0.704 & 0.530 & 0.453 & 0.676 & 0.26 & 0.530 & 0.439 & 0.676 & 0.218 \\
\hline $2000^{\mathrm{d}}$ & 12 & 57.79 & 0.761 & 0.652 & 0.813 & 0.677 & 0.579 & 0.328 & 0.661 & 0.425 & 0.579 & 0.216 & 0.661 & 0.177 \\
\hline
\end{tabular}

${ }^{\mathrm{a}}$ Date $=1^{\text {st }} \mathrm{yr}$ of nest $;{ }^{\mathrm{b}}=$ common period of all CRNs $;{ }^{\mathrm{c}}=1945-1995$ full calibration, $1945-1969,1970-1995$ cali-veri; ${ }^{\mathrm{d}}=$ 1945-2000 full calibration, 1945-1972, 1973-2000 cali-veri 
Table 3 Multi-annual to decadal-scale drought events.

\begin{tabular}{cccccc}
\hline Rank & Event & Duration & Magnitude & Intensity & Score \\
\hline 1 & $1730-1739$ & 10 & -28.67 & -2.87 & 102 \\
2 & $1722-1726$ & 5 & -14.34 & -2.87 & 93 \\
3 & $1898-1907$ & 10 & -21.95 & -2.19 & 91 \\
& $1943-1947$ & 5 & -14.22 & -2.84 & 91 \\
& $1978-1983$ & 6 & -15.62 & -2.60 & 91 \\
6 & $1928-1932$ & 5 & -13.94 & -2.79 & 89 \\
7 & $1676-1686$ & 11 & -20.86 & -1.90 & 87 \\
& $1771-1778$ & 8 & -16.65 & -2.08 & 87 \\
9 & $1821-1825$ & 5 & -12.06 & -2.41 & 82 \\
10 & $1996-2000$ & 5 & -12.06 & -2.41 & 80 \\
\hline
\end{tabular}

${ }^{\mathrm{a}}$ Duration is the number of years in the event.

${ }^{b}$ Magnitude is the cumulative departure of the event from a median PDSI value of -0.793 .

${ }^{c}$ Intensity is the average magnitude of the event over event duration.

${ }^{\mathrm{d}}$ Score is the sum of the rankings for absolute duration, absolute magnitude, and absolute intensity. Higher score values indicate stronger drought events.

Table 4 Multi-annual to decadal-scale pluvial events.*

\begin{tabular}{cccccc}
\hline Rank & Event & Duration & Magnitude & Intensity & Score \\
\hline 1 & $1933-1942$ & 10 & 28.10 & 2.81 & 101 \\
2 & $1761-1766$ & 6 & 23.86 & 3.98 & 100 \\
& $1783-1790$ & 8 & 24.13 & 3.02 & 100 \\
4 & $1908-1912$ & 5 & 19.35 & 3.87 & 96 \\
5 & $1826-1833$ & 8 & 19.81 & 2.48 & 92 \\
6 & $1716-1721$ & 6 & 16.63 & 2.77 & 90 \\
7 & $1812-1814$ & 3 & 9.56 & 3.19 & 85 \\
8 & $1749-1757$ & 9 & 16.75 & 1.86 & 84 \\
9 & $1893-1897$ & 5 & 11.46 & 2.29 & 82 \\
& $1962-1968$ & 7 & 13.88 & 1.98 & 82 \\
& $1993-1995$ & 3 & 8.78 & 2.93 & 82 \\
\hline a,b,c,d
\end{tabular}

See table 3 
Table 5 Drought and pluvial regimes as determined by regime shift detection (5-year cut-off length, $\alpha=0.05$ ) including time period, duration (years), mean, minimum, and maximum PDSI value and variance for each regime and drought to pluvial ratio (D : P).

\begin{tabular}{|c|c|c|c|c|c|c|c|}
\hline $\begin{array}{l}\text { April-August } \\
\text { PDSI Regime }\end{array}$ & Period & Years & Mean & Variance & Min & Max & $\mathrm{D}: \mathrm{P}$ \\
\hline 1 & $1675-1686$ & 12 & -2.440 & 2.026 & -4.239 & 0.293 & $11: 1$ \\
\hline 2 & $1687-1691$ & 5 & 0.794 & 0.313 & 0.680 & 1.408 & $0: 5$ \\
\hline 3 & $1692-1702$ & 11 & -1.911 & 1.677 & -3.921 & 0.258 & $10: 1$ \\
\hline 4 & $1703-1722$ & 20 & 0.065 & 4.539 & -4.051 & 4.423 & $10: 10$ \\
\hline 5 & $1723-1739$ & 17 & -3.280 & 2.582 & -5.019 & -0.616 & $17: 0$ \\
\hline 6 & $1740-1761$ & 22 & 0.294 & 2.994 & -3.207 & 4.471 & $10: 12$ \\
\hline 7 & $1762-1765$ & 4 & 4.522 & 0.507 & 3.663 & 5.404 & $0: 4$ \\
\hline 8 & $1766-1770$ & 5 & -0.662 & 0.645 & -1.873 & 0.190 & $4: 1$ \\
\hline 9 & $1771-1783$ & 13 & -2.325 & 3.038 & -5.439 & 0.402 & $12: 1$ \\
\hline 10 & $1784-1790$ & 7 & 2.604 & 2.181 & 0.730 & 4.716 & $0: 7$ \\
\hline 11 & $1791-1828$ & 38 & -1.119 & 4.645 & -5.928 & 3.166 & $29: 9$ \\
\hline 12 & $1829-1833$ & 5 & 2.640 & 6.684 & -0.001 & 5.686 & $1: 4$ \\
\hline 13 & 1834-1902 & 69 & -1.107 & 3.501 & -5.325 & 4.211 & $52: 17$ \\
\hline 14 & 1903-1907 & 5 & -3.856 & 2.545 & -5.058 & -1.675 & $5: 0$ \\
\hline 15 & 1908-1912 & 5 & 3.078 & 0.851 & 1.928 & 4.019 & $0: 5$ \\
\hline 16 & $1913-1927$ & 15 & -0.624 & 2.873 & -3.212 & 1.696 & $9: 6$ \\
\hline 17 & 1928-1932 & 5 & -3.581 & 1.442 & -5.053 & -1.966 & $5: 0$ \\
\hline 18 & 1933-1942 & 10 & 2.018 & 1.400 & -0.160 & 3.206 & $1: 9$ \\
\hline 19 & $1943-1958$ & 16 & -1.862 & 2.743 & -6.066 & -0.110 & $16: 0$ \\
\hline 20 & 1959-1977 & 19 & 0.643 & 2.975 & -3.072 & 2.749 & $6: 13$ \\
\hline 21 & $1978-1983$ & 6 & -3.340 & 1.576 & -4.808 & -1.374 & $6: 0$ \\
\hline 22 & 1984-1995 & 12 & 0.561 & 3.357 & -3.059 & 3.178 & $4: 8$ \\
\hline 23 & $1996-2000$ & 5 & -3.204 & 1.677 & -5.049 & -1.960 & $5: 0$ \\
\hline
\end{tabular}


Table 6 Drought and pluvial regimes as determined by regime shift detection (10-year cut-off length, $\alpha=0.05$ ) including time period, duration (years), mean, minimum, and maximum PDSI value and variance for each regime and drought to pluvial ratio (D : P).

\begin{tabular}{cccccccc}
\hline $\begin{array}{c}\text { April-August } \\
\text { PDSI Regime }\end{array}$ & Period & Years & Mean & Variance & Min & Max & D : P \\
\hline 1 & $1675-1730$ & 56 & -1.164 & 4.373 & -5.019 & 4.423 & $37: 17$ \\
2 & $1731-1739$ & 9 & -3.951 & 0.874 & -4.776 & -2.144 & $9: 0$ \\
3 & $1740-1770$ & 31 & 0.685 & 4.611 & -3.207 & 5.404 & $14: 17$ \\
4 & $1771-1783$ & 13 & -2.325 & 3.038 & -5.439 & 0.402 & $11: 2$ \\
5 & $1784-1790$ & 7 & 2.604 & 2.181 & 0.587 & 4.716 & $0: 7$ \\
6 & $1791-1907$ & 117 & -1.088 & 4.780 & -5.928 & 5.686 & $87: 30$ \\
7 & $1908-1921$ & 14 & 1.281 & 3.191 & -2.052 & 4.019 & $3: 11$ \\
8 & $1922-1932$ & 11 & -2.710 & 2.152 & -5.053 & -0.162 & $11: 0$ \\
9 & $1933-1941$ & 9 & 2.260 & 0.916 & 0.683 & 3.206 & $0: 9$ \\
10 & $1942-1958$ & 17 & -1.761 & 2.741 & -6.066 & -0.110 & $17: 0$ \\
11 & $1959-1977$ & 19 & 0.643 & 2.975 & -3.072 & 2.749 & $6: 13$ \\
12 & $1978-1983$ & 6 & -3.400 & 1.576 & -4.808 & -1.374 & $6: 0$ \\
13 & $1984-1995$ & 12 & 0.561 & 3.357 & -3.059 & 3.178 & $4: 8$ \\
14 & $1996-2000$ & 5 & -3.204 & 1.677 & -5.049 & -1.960 & $5: 0$ \\
\hline
\end{tabular}

Table 7 Drought and pluvial regimes as determined by regime shift detection (20-year cut-off length, $\alpha=0.05$ ) including time period, duration (years), mean, minimum, and maximum PDSI value and variance for each regime and drought to pluvial ratio (D : P).

\begin{tabular}{cccccccc}
\hline $\begin{array}{c}\text { April-August } \\
\text { PDSI Regime }\end{array}$ & Period & Years & Mean & Variance & Min & Max & D : P \\
\hline 1 & $1675-1739$ & 65 & -1.551 & 4.808 & -5.019 & 4.423 & $48: 17$ \\
2 & $1740-1766$ & 27 & 0.903 & 4.850 & -3.207 & 5.404 & $11: 16$ \\
3 & $1767-1958$ & 192 & -0.823 & 5.440 & -6.066 & 5.686 & $133: 59$ \\
4 & $1959-1995$ & 37 & -0.038 & 4.976 & -4.808 & 3.178 & $16: 21$ \\
5 & $1996-2000$ & 5 & -3.204 & 1.677 & -5.049 & -1.960 & $5: 0$ \\
\hline
\end{tabular}




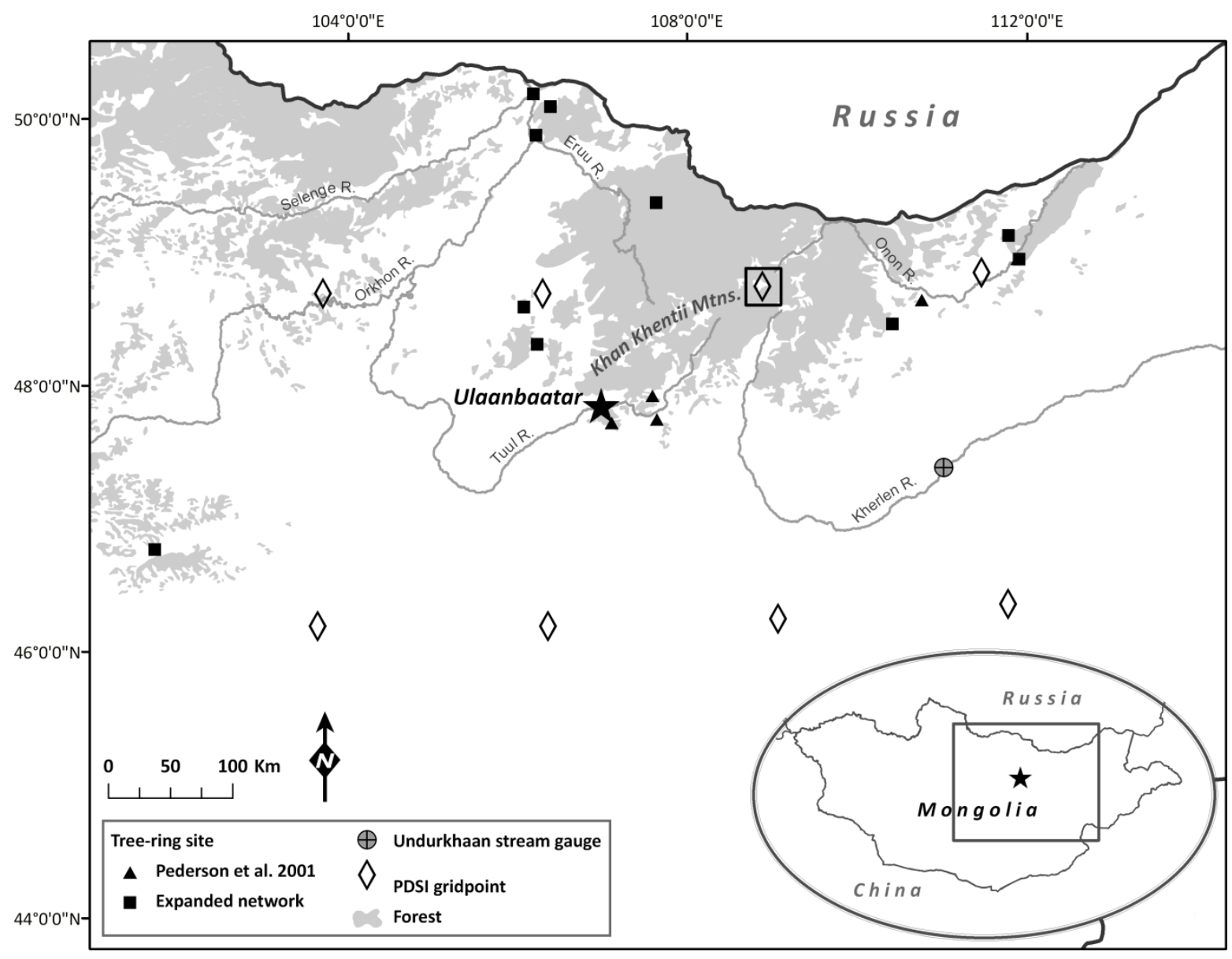

Figure 1 Map of north-central Mongolia showing the location of regional PDSI grid points (diamonds) and the locations of the 15 tree-ring sites (triangles, Pederson et al. 2001; squares, expanded network) used for the reconstruction. The reconstructed PDSI grid point situated over the Khan Khentii Mountains is indicated by the boxed diamond. 


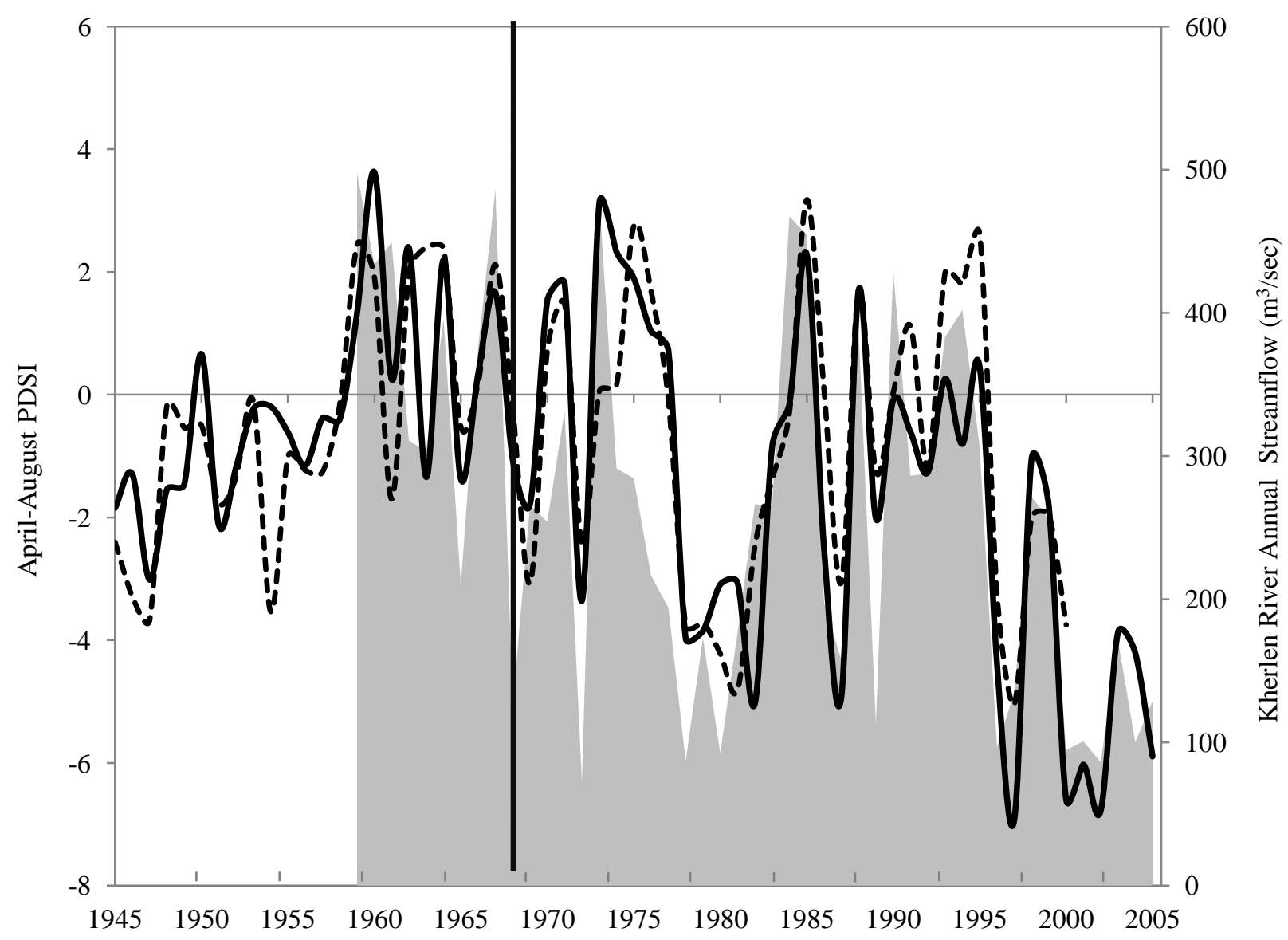

Figure 2 Actual (solid line) and reconstructed (dotted line) mean April-August PDSI. Instrumental data are from Dai et al. 2004 (grid point $48.75 \mathrm{~N}, 108.75 \mathrm{E}$ ). Vertical line indicates where the data are split for calibration and verification. $\mathrm{R}=0.78$ for the entire period (19451993). Instrumental streamflow data for the Kherlen River at Undurkhaan (shaded area) is provided for comparison (1959-2008). Note the extreme drought from 1978-1983 and the abrupt shift to prolonged drought conditions in 1996. 

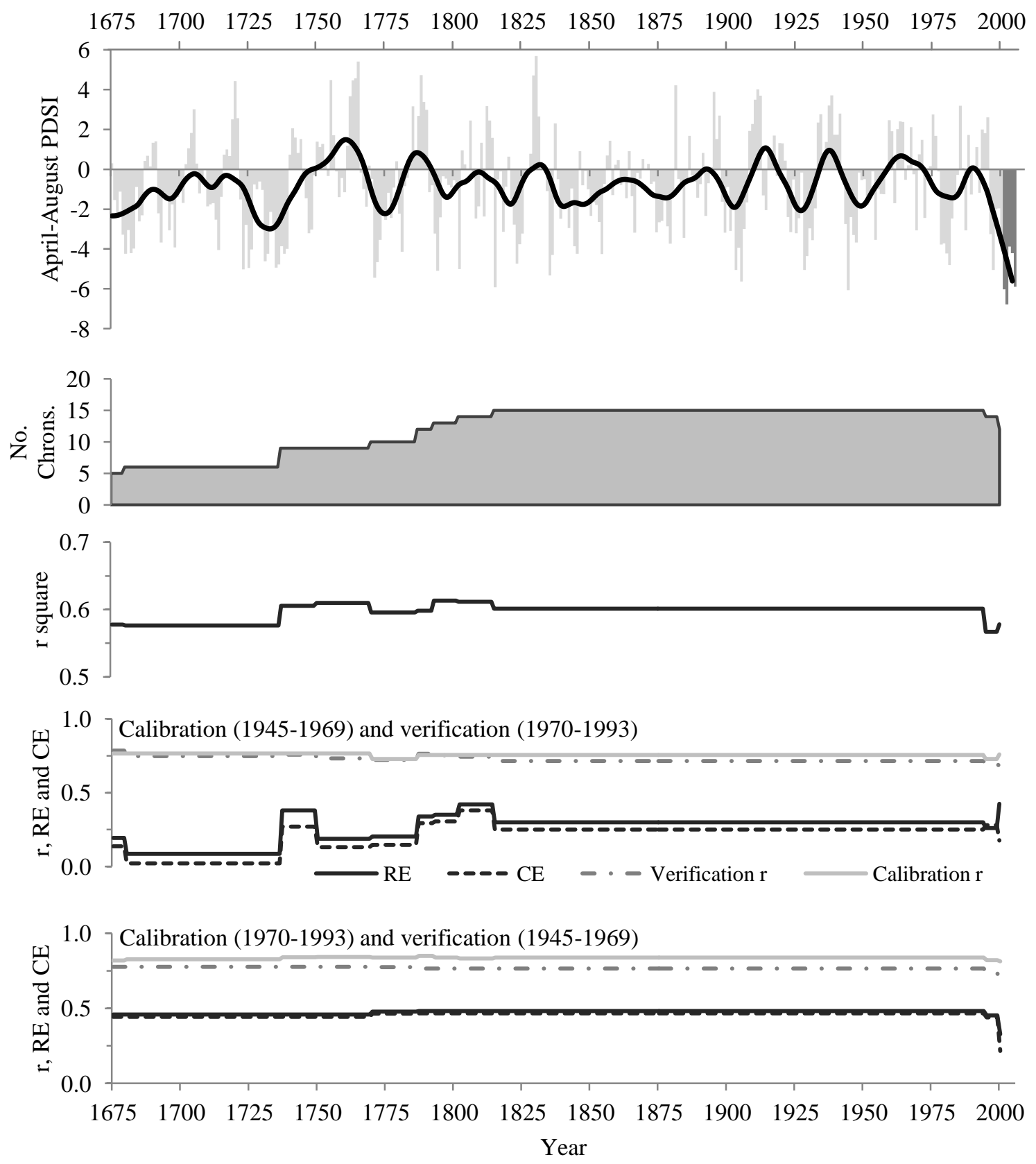

Figure 3 Mean April-August PDSI reconstruction based on tree rings (1675-2000; light gray bars) with instrumental April-August PDSI values from 2001-2005 (Dai et al. 2004; dark gray bars). The black line shows the data smoothed by a 21-year loess curve. Below are the number of chronologies included in the model through time, calibration $r$ square for nested full period reconstruction, and the statistics of correlation (r), reduction of error (RE), and coefficient of efficiency (CE) for calibration and verification of the split periods (1945-1969 and 1970-1993). 


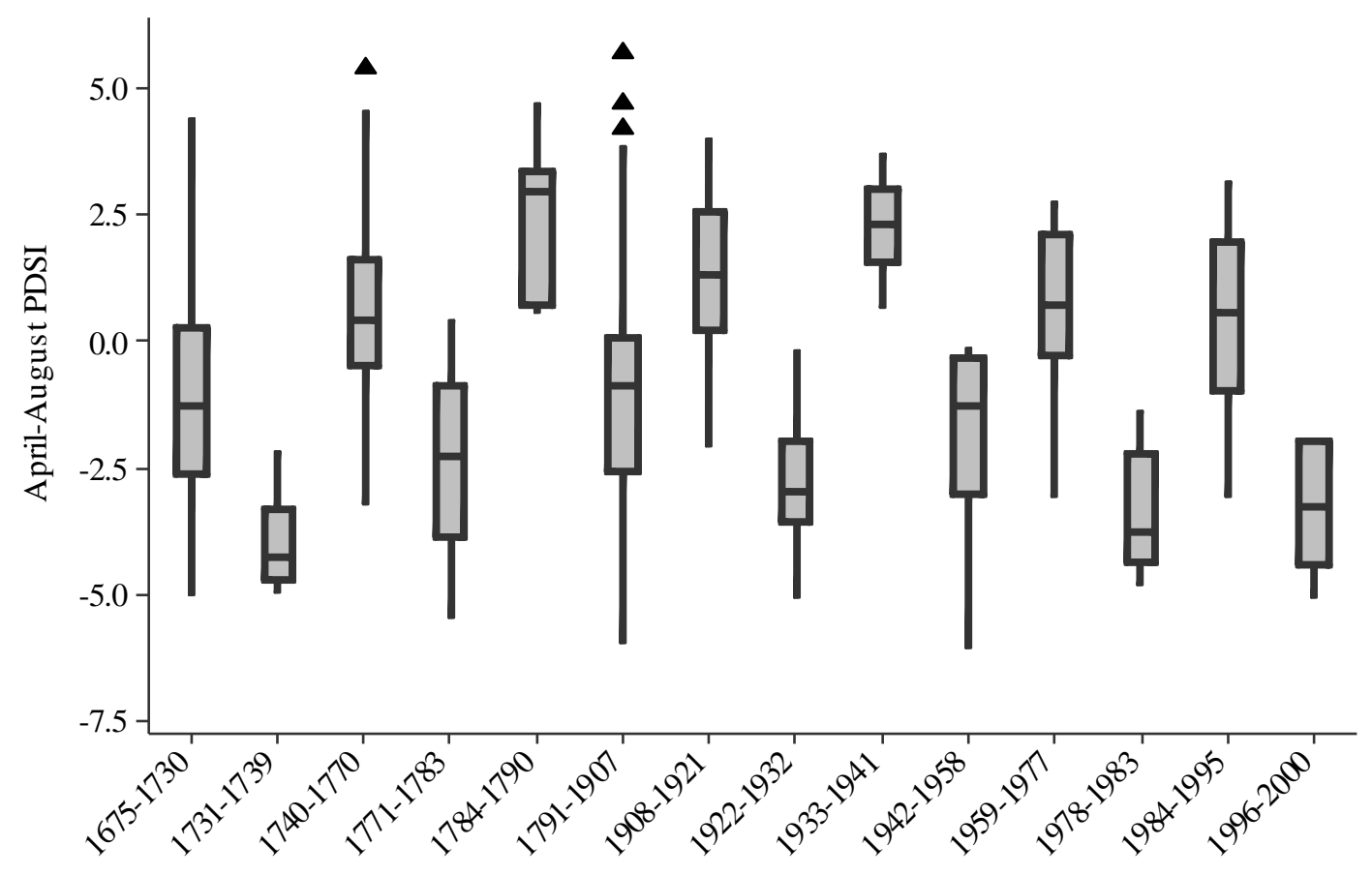

Figure 4 Box plots of April-August reconstructed PDSI regimes (10-year cut-off length, $\alpha=$ 0.05 ). Drought conditions continue into the $21^{\text {st }}$ century based on instrumental data (Dai et al. 2004). 


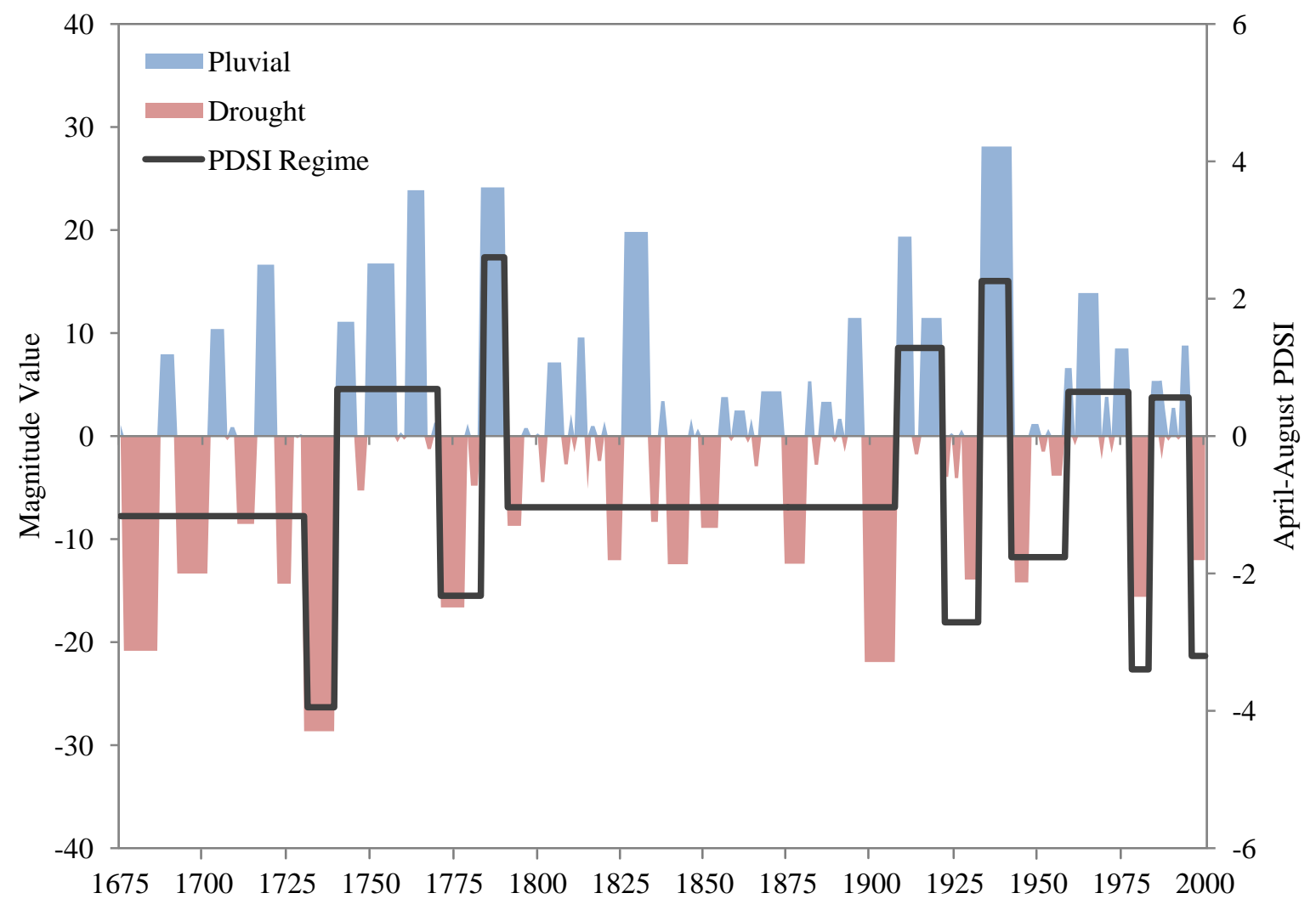

Figure 5 Magnitude values for multi-annual and decadal-scale drought and pluvial events (16752000, reconstructed April-August PDSI). High magnitude and short duration (i.e. long, narrow bars) $=$ greater intensity. Also shown are April-August drought and pluvial regimes (sold line is mean PDSI value during each regime; 10-year cut-off, $\alpha=0.05$ ). 


\title{
Chapter 3: Tree-Ring Reconstruction of Wildfire in the Upper Tuul River Watershed, Mongolia (1875-2009)
}

Thomas M. Saladyga

\author{
West Virginia University \\ Department of Geology and Geography \\ P.O. Box 6300 \\ Morgantown, WV 26506-6300 \\ Email: tom.saladyga@gmail.com
}




\section{Abstract}

Global wildfire frequency and extent are expected to increase under projected climate change scenarios in the $21^{\text {st }}$ century, but little is known about how human activities might affect this trend. In Ulaanbaatar, the capital city of Mongolia, there has been a $2.5^{\circ} \mathrm{C}$ rise in spring and summer temperatures during the last 40 years and a decrease in moisture availability during the latter half of the $20^{\text {th }}$ century. Concurrently, Mongolia has experienced multiple shifts in socioeconomic systems during the $20^{\text {th }}$ century, most notably the establishment of a Sovietbacked communist economy in the 1920 s and a rapid transition to privatization in the 1990s. Our objective was to identify trends in wildfire activity in the context of changing climatic and social conditions since 1875 . We used tree rings to reconstruct wildfire frequency and extent during the period 1875-2009 during which we identified four distinct wildfire regimes using regime shift detection methods. Fifty site-level and seven watershed fire events $(\geq 20 \%$ sites recording) were dated from 1877-2009, with the most extensive fire occurring in 1914. Fire events were infrequent, but extensive during the first regime (1875-1913) and were associated with significant departures in tree-ring reconstructed April-August PDSI (Palmer Drought Severity Index). Fire frequency and extent was greatest during the third regime (1965-1997). The most recent regime (1998-2009) is characterized by the lowest frequency and extent of wildfire, which is contrary to expected trends in wildfire activity. Areas with the greatest presentday human impact have recorded less fire than other areas throughout the entire period of analysis, suggesting fire exclusion via grazing and fuelwood collection. As temperatures rise, similar trends of decreased wildfire frequency and extent might be observed in other arid regions where prolonged drought and human land use inhibit fuel accumulation. 


\section{Introduction}

Sustainable use and management of forest resources will be integral to preventing landscape degradation as rapid changes in climate (e.g. temperature and precipitation) are expected to alter historic fire regimes during the coming century (Overpeck et al. 1990; Dale et al. 2000;

Sivakumar et al. 2005). This is especially critical in regions of the world where lands with low productivity are vulnerable to abrupt changes in climate and land use pressure. The earliest and most extreme increases in temperature are expected to occur at high latitudes, while many arid and semi-arid regions will experience increased drought incidence (IPCC 2007). Changes in hydroclimatic regimes might have profound effects on wildfire occurrence such as increased fire frequency and a longer fire season (Wotton and Flannigan 1993; Stocks et al. 1998; McKenzie et al. 2004; Westerling et al. 2006; Kilpeläinen et al. 2010; Yang et al. 2011). Despite increasing temperatures, however, wildfire occurrence in northern forests might not be as catastrophic as globally predicted (Flannigan et al. 1998) and changes in ignition sources and forest fuels might limit future wildfire occurrence (Hessl 2011). These potential changes in hydroclimatic conditions and wildfire occurrence will have substantial influence on the livelihoods of those dependent upon local environments.

Pastoralist societies in central Asia have a long history of sustainable range and forest management across the expansive steppe and forest-steppe ecosystems of the region. In Mongolia, herders have historically managed livestock in a manner that makes efficient use of spatially and temporally heterogeneous resources (Fernández-Giménez 1999). However, shifts

in social and economic conditions, most notably during the $20^{\text {th }}$ century, have impacted pastoralist mobility, access to resources, and land tenure (Fernández-Giménez 2006; Johnson et al. 2006). Warming temperatures (Jacoby et al. 1996; D'Arrigo et al. 2000, 2001) and an overall 
decrease in moisture availability for the latter half of the $20^{\text {th }}$-century ( $\mathrm{Li}$ et al. 2008) have been documented for the region. Consistent with these findings, Mongolia has experienced a recent increase in frequency and intensity of droughts, with drought from 1999 to 2002 affecting 70\% of the country’s grasslands and killing $~ 12$ million livestock (Batima et al. 2005). More recently, drought in 2009 followed by an extremely harsh winter resulted in the death of more than 7.8 million livestock (FAO United Nations 2011).

As a possible consequence of a $17 \%$ decline in spring precipitation (Batima et al. 2005) and a $2.5^{\circ} \mathrm{C}$ rise in spring and summer (April-August) temperatures during the last 40 years (Ulaanbaatar; Climate Explorer 2011), the observed frequency and aerial extent of forest and grassland fires in Mongolia have markedly increased (Goldammer 2002, Figure 1). At the same time, decreased pastoralist mobility and a general trend of increasing livestock numbers during the $20^{\text {th }}$ century has led to a spatially heterogeneous landscape of fine fuels due to overgrazing in some areas (Sneath 1998). Grazing has strong impacts on forest age structure, fine fuel volume and continuity, and fire regimes in other semi-arid regions (Savage and Swetnam 1990; GrissinoMayer et al. 1995; Swetnam and Betancourt 1998), and it is possible that similar controls on wildfire exist in Mongolia. Where human land use reduces fuel volume, forests might not experience changes in wildfire frequency and extent that are expected under projected climate change in Mongolia.

The history of changes in land-use patterns, land-use regulation, and land tenure in Mongolia during the $20^{\text {th }}$ century can be divided into four eras: Manchu rule and autonomy (pre1911); early communism (1924-1959); collective (1960-1990); and privatization (1992-present) (Fernández-Giménez 1999). With each transition, administrative units decreased in area as each era is characterized by markedly different informal and regulatory institutions and patterns of 
pastoralist movements (Fernández-Giménez 2006). While seasonal rotation of pasture use was maintained, an overall decrease in pastoral mobility during the collective era limited herders' access to the variety of ecological zones and forage resources. The transition from a centrallyplanned economy to a market economy, including the privatization of livestock (early 1990s), marked a further decrease in pastoral mobility, as seen in an increase in the number of inexperienced herders, increased trespassing on leased pastureland, a concentration of livestock near towns and roads, and reduced frequency and distance of moves (Fernández-Giménez 2006). Mongolia's livestock population remained relatively stable during the communist era, but increased sharply (especially goats for Kashmir textiles) after privatization in the 1990s and has experienced multiple crashes during the $21^{\text {st }}$ century (Sankey et al. 2006, Figure 2).

Reduced moisture availability, rising temperatures and intensifying land use pressure can contribute to changes in the frequency and extent of wildfire (Donnegan et al. 2001; GrissinoMayer et al. 2004; Westerling et al. 2006). These interacting drivers of wildfire are often difficult to disentangle, but attempting to understand their individual effects is crucial to developing sustainable fire management plans. Changing social conditions during the 1990s, including high rates of unemployment, forced many people to depend on forest resources (e.g. fuelwood, logging, haymaking, and hunting) for livelihood and/or survival (United Nations Economic and Social Council 2002). Also, the recent influx of inexperienced herders and the collection of non-timber forest products such as deer antlers, pine nuts, berries, herbs, and grasses have increased the potential for anthropogenic fire ignitions. With increasing economic activity and concentrated use of natural resources in central Mongolia, forests are becoming increasingly vulnerable to wildfire. However, this vulnerability and predicted increases in 
wildfire frequency and extent may be buffered by the effects of a drying climate and reduced fuel accumulation.

The purpose of this study was to assess human and climatic influences on fire frequency and extent during the period 1875-2009 in the Upper Tuul River watershed in central Mongolia. Specifically we wanted to address the need to place recent trends in wildfire activity (frequency and extent) in the context of the past 135 years. In doing so, we were interested in addressing the following questions: 1) To what degree does human land use influence fire activity? 2) Is moisture availability related to fire activity? and 3) Has wildfire frequency and extent in the study area increased coincident with rising temperatures?

\section{Methods}

\section{Study area}

The entire Tuul River basin makes up only 3.2\% of the total land area of Mongolia (Figure 3), but contains more than half of the country's population, most of which is in the capital city of Ulaanbaatar (pop. 1,067,472 in 2008). The UTRW includes the upper reaches of the Tuul River and its tributaries, located in central Mongolia spanning approximately $46.5^{\circ}$ to $49^{\circ} \mathrm{N}$ latitude and $103^{\circ}$ to $108^{\circ} \mathrm{E}$ longitude. The UTRW has a drainage area of $8,735 \mathrm{~km}^{2}$ and has a boundary that extends $\sim 180 \mathrm{~km}$ from southwest of Bogd Khan $U u l$ (mountain) to the northeast into the higher elevation Khan Khentii Mountains. Land and resources of the Upper Tuul River watershed currently contribute income and marketed products worth around Tug 28 billion ( 22 million USD) per year in tourism, herding, and forest-based sectors (Emerton et al. 2009). Therefore, in representing the most extreme range of urban to rural development in Mongolia, the UTRW is an ideal case study for exploring human impacts on wildfire in semi-arid Asia. 
Mongolia is characterized by an extremely continental climate. Temperatures in central Mongolia range from approximately $-18^{\circ} \mathrm{C}$ in winter to approximately $16^{\circ} \mathrm{C}$ in summer, though winter temperatures have been rising since the 1940s (Davagdorj and Mijidorg 1996; Jacoby et al. 1996). Total annual precipitation is low (252 $\mathrm{mm})$ and peaks in summer when approximately 72\% of precipitation falls (Davagdorj and Mijidorg 1996). Between 1940 and 2001, spring precipitation declined 17\% (Batima et al. 2005). More recently, between 1979 and 1995, precipitation has decreased 25\% in May and increased 33\% in August, shifting the peak in annual precipitation one month (Jacoby et al. 1996). No single synoptic system strongly influences Mongolian climate except perhaps the winter Siberian High, centered over Mongolia from winter through late spring (Samel et al. 1999; D’Arrigo et al. 2005). The East Asian Monsoon and El Niño-Southern Oscillation have a somewhat stronger influence on Mongolia's climate in the east than the west (Zhang and Lin 1992; Samel et al. 1999).

Forested area in the UTRW totals $3,876 \mathrm{~km}^{2}$ with $55 \%$ dominated by Larix sibirica, $42 \%$ by Pinus spp., and the remaining 3\% by Betula spp., Abies sibirica, and Picea obovata (Ministry of Nature and Environment 2009). Elevation in the UTRW ranges from $1187 \mathrm{~m}$ in the Tuul River valley just southwest of Ulaanbaatar to 2795 m (Asralt Khairkhan $U u l)$ ) in the Khentii Mountains. The mountains are situated at the interface between the western Siberian dark taiga (Picea obovata, Abies sibirica, Pinus sibirica, and Larix sibirica), the eastern Siberian light taiga (Betula platyphylla, Larix sibirica, and Pinus sylvestris) and the Mongolian forest-steppe zone (Ermakov et al. 2002). This region is particularly species rich, relative to the rest of central Asia, due to the intersection of boreal, temperate and steppe vegetation. Three conservation areas exist with the Khentii region including the Strictly Protected Area of Khan Khentii $\left(12.3 \mathrm{~km}^{2}\right)$, the Gorkhi-Terelj National Park $\left(2.9 \mathrm{~km}^{2}\right)$, and the Onon-Balj $\left(4.2 \mathrm{~km}^{2}\right)$. These conservation areas 
have relatively low human use; however, this protection status does not prevent use of resources by local residents.

In Mongolia, the fire season has two peaks with $80 \%$ of fires occurring between March and mid-June, and 5-8\% occurring during a short period in September and October (Valendik et

al. 1998). Fires are rare during the summer months when precipitation is greatest. Annually, 5060 forest fires occur in Mongolia, of which 95\% are human caused (Goldammer et al. 2004).

Unlike other pastoralists, Mongolian herders are not known to deliberately use fire to clear land or encourage grassland productivity (personal communication with forestry officer), suggesting that the majority of these ignitions are unintentional.

\section{Rapid on-site assessment (ROSA)}

A qualitative rapid (15 minutes per site) on-site assessment (ROSA) was used to assess presentday human impacts at each site. We looked for evidence of grazing, logging, trash, and campfire remains and scored each variable ( 0 - 3) based on presence and area (ocular estimations). The index was calculated by summing qualitative assessment scores for each disturbance variable with higher scores indicating more disturbances. Grazing indicators included the presence of dung, hoof prints, livestock remains and trails. Indicators of logging disturbance included the presence of stumps, slash, machinery tracks, and other altered microtopography. These variables were chosen because of their nearly ubiquitous presence on the landscape and their direct or indirect influence on ecosystem processes such as forest regeneration and productivity. Sites with index values less than quantile $1(\mathrm{Q} 1)$ were classified as low impact sites, index values between Q1 and Q3 as medium impact sites, and index values greater than Q3 as high impact sites. This classification method ensured the grouping of sites with typical human impacts 
(Medium) and sites outside the typical range (Low and High). Other methods such as quantiles, natural breaks, or equal intervals were not appropriate due to the non-normal distribution of the index. Each site was located in its own drainage, which decreased spatial autocorrelation in fire chronology development (Figure 4).

\section{Fire history}

All sites fall into the very high, high, or medium classes of natural fire danger established by Arkhipov (2000) and are comprised of pure stands of Larix sibirica or mixed Larix/Pinus stands dominated by Larix sibirica. Our stratified random sampling design targeted an elevation range of 1500-2000 $\mathrm{m}$ and includes an area of $2620 \mathrm{~km}^{2}$ (of a total forested area of $3876 \mathrm{~km}^{2}$ ). Fire histories are based on crossdated fire scars from 19 of the 20 sites. We sampled every firescarred tree in a 4-hectare search area, collecting up to 10 samples per site. We removed partial cross sections from the base of fire-scarred trees with a chainsaw (Arno and Sneck 1977) and recorded their location with a GPS unit. The number of samples at each site varied as a result of individual site histories (see Table 1); with a low number of samples indicating either the absence of fire or the occurrence of a high severity stand replacing fire.

\section{Laboratory}

All fire-scar samples were surfaced with progressively finer grit sandpaper until cells were clearly visible under magnification according to established tree-ring procedures (e.g., Stokes and Smiley 1968). Samples were crossdated using an already established tree-ring chronology (Jacoby, G., D’Arrigo, R.D. B. Buckley and N. Pederson, 2009, International Tree- Ring Data Bank, Manzhir Hiid) to provide absolute dates for all tree rings and fire scar injuries. If possible, 
season of occurrence was assigned to each fire scar based on its position within a ring. It is known that $80 \%$ of all fires occur from March to mid-June; therefore, it can be assumed that any fires with unknown season most likely occurred during this period (Nyamjav et al. 2007). Consequently, fire scars that fell within the dormant season were assigned to the previous year.

\section{Fire chronology}

Analyses were limited to the period 1875-2009 due to a substantial decrease in sample size prior to the late $19^{\text {th }}$ century (see Appendix). Site-level and watershed fire analysis was conducted using FHX2 (Grissino-Mayer 2001) and standard database software. Fire history data were analyzed using a filter of two scars per site (reducing the risk of false positives) to determine fire frequency (i.e. fire events) and fire extent (i.e. \% sites recording fire). Years in which $\geq 20 \%$ sites recorded fire were considered watershed fire events. Fire history data were composited into a time-series of the percentage of sites recording fire during each year (e.g., Brown et al. 2008). An 11-year loess curve was applied to the watershed composite to highlight decadal trends in fire frequency and extent. Similar analyses were conducted with groups of sites classified into the three human impact classes using ROSA.

The definition of a fire regime has varied depending on application and region since the concept first appeared in $19^{\text {th }}$ century France (Krebs et al. 2010). Here, we define fire regimes based on variability and heterogeneity (sensu Lertzman et al. 1998) in fire extent (\% sites recording fire) using regime shift detection. Regime shift detection has been applied to climate data (D'Arrigo and Wilson 2006) and fisheries management (Daskalov et al. 2007) when considering rapid reorganizations of systems from one relatively stable state to another. For this study, we applied the methods developed by Rodionov (2005) to our annual fire event time series 
data. The regime shift detector (RSD; Microsoft Excel add on) used a sequential F-test to indentify rapid changes in the variance of the percentage of sites recording fire. Multiple cut-off lengths were applied $(5,10,15,20,25$, and 50 years $)$ with a significance level of 0.05 to determine the most realistic regime shifts. Shorter cut-off lengths will be more sensitive to interannual variability, whereas longer cut-off lengths might disregard important shorter-term changes in fire activity. The percentage of years with fire, mean fire interval and mean fire extent (\% sites recording fire) were calculated to further characterize each fire regime.

\section{Climate-fire relationships}

A tree-ring reconstruction of April-August PDSI (Palmer Drought Severity Index) was developed near the study area (see Chapter 2) using instrumental data from Dai et al. 2004 (grid point $48.75 \mathrm{~N}, 108.75 \mathrm{E}$ ). PDSI is a moisture index based on temperature, precipitation, and soil evaporation (Palmer 1965). We also used superposed epoch analysis (SEA) to compare average annual April-August PDSI values during years in our site-level and watershed fire chronologies for the six preceding and four years following an event (e.g. Grissino-Mayer and Swetnam 2000; Taylor and Beaty 2005). SEA uses Monte Carlo simulations (1000 runs) to compare average climatic conditions preceding, during, and following event years to conditions present over the entire fire chronology. Significant departures in PDSI were identified as those exceeding the 95\% confidence interval (Grissino-Mayer 2001).

\section{Results}

Past surface fire timing was reconstructed from all fire-scarred trees sampled $(n=140)$. A total of 353 fire scars (52\% dormant season, $18 \%$ early wood, $2 \%$ middle wood and $28 \%$ unknown) 
and 104 cambial injuries were identified and dated for 19 of the 20 sites. The number of firescarred trees sampled at each site ranged from 1 to 13. Sample size reflects the amount of fire evidence at each site, suggesting that sites with only a few samples have experienced standreplacing fires or have not burned often or at a temperature sufficient to create scars during the last approximately 150 years (given typical sample preservation). A total of fifty site-level and seven watershed ( $\geq 20 \%$ sites recording) fire events were recorded from 1877 to 2009 (Table 2, Figure 6). The most extensive event occurred in 1914, when $43 \%$ of sites recorded fire. The most recent major fire events in the study area occurred in 1996 and 1997 when much of Mongolia experienced extensive wildfire (Goldammer 2002). In comparison to the 1914 event, the 1996 and 1997 fire events were recorded at only $29 \%$ and $18 \%$ of the sites, respectively. The low and medium impact classes recorded fire most often and throughout the entire period of analysis, while the high impact class recorded fire only from 1914 to 1980 (Table 2, Figure 7). Using regime shift detection, we identified four distinct fire regimes $(\mathrm{p}<0.05)$ for the study area during the period 1875-2009 (Table 3). These regimes are based on the variance of the percentage of sites recording fire and were determined using a 25 -year cut-off length. The extensive 1914 fire was identified as an anomalous event (i.e. outlier) and, therefore, not included in any fire regime. A 25-year cut-off length was deemed the most appropriate as fire management plans should consider long-term trends in fire activity, but also be flexible to new scientific knowledge and rapidly changing social conditions. Shorter cut-off lengths were too quick to detect very brief periods of fire activity as "regimes" (e.g. 1996-1998) and a 50-year cut-off length washed out important changes in fire activity by detecting only two regimes (1875-1997 and 1998-2009). 
We calculated the number of fire events, the percentage of years with fire, and mean fire interval and extent to further characterize each fire regime (Table 3). The percentage of fire years and fire frequency increase stepwise during the first three regimes, and then markedly decrease during the most recent regime. Variability in the percentage of sites recording fire (i.e. fire extent) is different for each fire regime (Figure 5). Fire frequency and variability in fire extent were greatest during regime 3 (1965-1997), which corresponds to Goldammer's (2002) period of analysis (1963-1997). Although fire frequency was low during regime 1 (1875-1913), seven site-level fires and two watershed fires were recorded. In contrast, fire events during regime 4 (1998-2009) were both infrequent and spatially limited

We observed different patterns of fire frequency and extent between human impact classes over time (Figure 7). Fire regime 1 included events recorded in only the low and medium human impact classes. The absence of fire events in the high impact class may be a result of limited sample size in this class $(<4$ sites). Fire regimes 2 and 3 included events recorded in all three human impact classes, but were more frequent in the low and medium class than events in the high class. Fire frequency and extent during regime 3, the period often referred to when predicting an increase wildfire activity in Mongolia, was limited at sites in the high human impact class. Finally, during regime 4, no fires were recorded in the high impact class and low fire frequency and extent was observed for low and medium impact classes.

Superposed epoch analysis determined no significant departures of average annual AprilAugust PDSI during fire years or any years prior to or following a site-level fire event (Figure 8a). A significant departure was identified six years prior to watershed fire events $(\geq 20 \%$ sites recording fire; $\mathrm{n}=7$ ), but probably has little influence on the timing of wildfire considering the subsequent five years of variability prior to fire events and limited sample size (Figure 8b). 
Average April-August PDSI during watershed fire years was less than any year in the 11-year analysis period, but not significantly so. There was a significant departure in April-August PDSI during fire years as well as six years prior to fire events during fire regime $1(\mathrm{n}=7$; Figure $8 \mathrm{c})$. No significant departures were found for fire regimes 2 and 3 and there were too few events ( 2 with corresponding PDSI data) during fire regime 4 for SEA. Although significant positive departures in April-August PDSI were generally absent, pluvial events (i.e. periods during which PDSI > 0) did precede the 1914, 1966, 1969, and 1996/1997 watershed fire events (Figure 6).

\section{Discussion}

Wildfire potential is expected to increase during the $21^{\text {st }}$ century due to projected increases in temperature and extended fire seasons in many regions including central Asia (e.g. Poñil et al. 1998; Spracklen et al. 2009; Liu et al. 2010). In the forest-steppe ecotone, our results indicate an increase in both wildfire frequency and the percentage of years with fire during the $20^{\text {th }}$ century for each fire regime, but this trend does not continue into the present. Land use intensity has most likely influenced wildfire regimes throughout the $20^{\text {th }}$ century, but its effect might have interacted with the recent severe drought to reduce fuel volume and continuity. Other studies have incorporated the influence of human populations on historic wildfire (e.g. Grissino-Mayer et al. 1995; Guyette et al. 2002; Hessl et al. in review), but none used a sampling scheme that addresses human influence on contemporary fire regimes. The absence of fire management and ongoing land use traditions in Mongolia provided an opportunity to examine wildfire in the context of recent social and environmental conditions.

The frequency and extent of wildfire has varied under different land use pressures in the study area. Human disturbance has been shown to influence fire regimes in many parts of the 
world by altering forest structure and fuel volume (Veblen et al. 1999; Guyette et al. 2002, Hellberg et al. 2003; Keeley et al. 2003). Our results indicate that sites in the low and medium human impact classes continue to experience fire up until the present while the high impact class has recorded none. Excluding the 1914 fire event, the high impact class recorded fire only during the early communism and collective eras (mid- $20^{\text {th }}$ century) when livestock numbers were low. With a rapid increase in herders and livestock numbers in the 1990s, a lack of recent fires in high impact areas can be attributed to fire exclusion via grazing as similar patterns have been observed in Spain (Rozas 2003), the Colorado Front Range (Mast et al. 1998), and southeastern Arizona (Grissino-Mayer et al. 1995). In conjunction with a drying climate and less biomass production in the study area, it is expected that more intense grazing in areas with easier access might reduce fuel volume and wildfire potential.

\section{Fire regimes}

In Mongolia, there has been no departure from a pastoralist-based society for millennia (Fernandez-Gimenez 1999). However, the $20^{\text {th }}$ century in Mongolia was a period of increasing industrialization, urbanization and shifting socioeconomic systems in which we identified four distinct fire regimes independent of any known changes in fire use and management. The first three regimes are marked by an increasing frequency of wildfire, while a shift in the opposite direction occurred in the late 1990s and continues into the $21^{\text {st }}$ century (Figure 6). Although this fourth regime consists of only twelve years, it was identified as a significant departure from the previous fire regime.

Wildfire was infrequent at the end of the $19^{\text {th }}$ century and in the early years of the $20^{\text {th }}$ century as characterized by the first fire regime (1875-1913). During this time, under Manchu 
rule, livestock herds were managed by monasteries, which promoted grazing in a variety of ecological zones, but prohibited use in some areas (Fernandez-Gimenez 1999). Although there were only seven fire events, when fire events occurred, they were associated with statistically significant departures in April-August PDSI (i.e. very dry fire seasons). Human ignition sources were most likely minimal as human population in central Mongolia was low during Manchu rule (Tumurjav 2006), herders were experienced, and a global market for non-timber forest products (e.g. deer antlers) was not yet realized. A lack of ignition sources and periodic wet periods may have allowed forest fuels to accumulate between infrequent, but relatively extensive fire events during dry years.

The major watershed fire in 1914 followed an extended pluvial event and a fire-free period of nine years. This was during a period of social and political upheaval following Mongolia declaring its independence in 1911. In addition to climatic conditions, social and political instability have been linked to widespread forest fires in other regions (e.g. Gellert 1998; Kuhlken 1999) and may have contributed to the extensive fires of 1914 in the study area. The second fire regime begins in 1915, continuing until 1964 and includes Chinese occupation (1919-1921), the establishment of the Soviet-backed People's Republic of Mongolia in 1924 and extended drought events of the 1920s and 1940s. During this regime, wildfire was not associated with significant departures in April-August PDSI and fires occurred under both drought and pluvial conditions. Wildfire frequency increased as the extent of individual fire events decreased. A restructuring of the livestock sector, including further reduced pastoralist mobility, may have led to an increase in human ignition sources.

The third fire regime (1965-1997), which corresponds to Goldammer's (2002) period of analysis, was an era in which human population was increasing, urban population surpassed rural 
population (ca. 1980; United Nations 2011), herding collectives were dismantled (ca. 1990), unemployment rates increased, and there was an influx of inexperienced herders in the newly privatized economy. Like the previous regime, fire events during the third regime were not associated with significant departures in April-August PDSI. The early years of this regime were during the height of the collective era. This may have been a unique period in time that was conducive to increased fire frequency due to specific land use and management strategies. During this era, many herds were transported between grazing grounds via truck (FernándezGiménez 1999), increasing the risk of ignitions from sparking vehicles.

The third fire regime also includes the period of transition to a free market economy during the early to mid-1990s. A combination of increased human ignition risks (i.e. inexperienced herders, unemployment, and poverty [Fernández-Giménez 2006; Johnson et al. 2006]) and the accumulation of forest fuels during a brief pluvial event from 1993-1995 likely caused the widespread wildfires in 1996 and 1997. The shift into the fourth fire regime occurred in 1998 following these major fire years and was also marked by drought conditions that have extended into the $21^{\text {st }}$ century. This particular regime shift is in conflict with projections of increased fire frequency and extent in Mongolia (Goldammer 2004) and globally (e.g. Westerling et al. 2006; Running 2006; Chapin et al. 2008; Fried et al. 2008; Girardin and Mudelsee 2008; Kasischke et al. 2010). Widespread wildfires might occur during the initial years of drought conditions (i.e. 1996/1997). However, sustained drought limits subsequent fuel accumulation and, therefore, wildfire potential in arid systems like the forest-ecotone. 


\section{Conclusions}

Identifying fire regime shifts has proven useful in disentangling the complex interactions between continually evolving social and environmental conditions in the Upper Tuul River watershed and in Mongolia in general. The last fire regime associated with significant departures in PDSI ended in 1913, suggesting that human activity during the majority of the $20^{\text {th }}$ century strongly influenced the frequency and extent of wildfire. We have shown that the frequency and extent of fire events in areas of high human impact have been less compared to other areas, possibly due to continuous pressures from grazing and fuelwood collection. The history of watershed fires throughout the $20^{\text {th }}$ century does not indicate that these fire events are increasing in frequency, but are rather infrequent events occurring throughout the last 135 years. Finally, wildfire frequency and extent may be buffered by the effects of a drying climate and low biomass (fuel) productivity (Hogg and Hurdle 1995) and rapid economic growth and land use intensification in central Mongolia. Similar trends of decreased wildfire frequency and extent might be observed in other arid regions where prolonged drought and intensive human land use inhibit fuel accumulation.

\section{References}

Arkhipov, V., Moukanov, B. M., Khaidarov, K., and Goldammer, J. G. 2000. Overview on Forest Fires in Kazakhstan. International Forest Fire News. 22: 40-48.

Arno, S.F. and K.M. Sneck 1977. A method for determining fire history in coniferous forests of the mountain west. USDA Forest Service GTR. INT-42. Intermountain Forest and Range Experiment Station, Ogden, UT.

Batima, P., L. Natsagdorj, P. Gombluudev, and P. Erdenetsetseg. 2005. Observed climate change in Mongolia. Assessments and Adaptations to Climate Change (AIACC) Working Paper No. 12 (www.aiaccproject.org). 
Brown, P.M., E.K. Heyerdahl, S.T. Kitchen, and M.H. Weber. 2008. Climate effects on historical fires (1630-1900) in Utah. International Journal of Wildland Fire. 17:28-39.

Chapin, F.S., S.F Trainor, O. Huntington, A.L. Lovecraft, E. Zavaleta, D.C. Natcher, A.D. McGuire, J.L. Nelson, L. Ray, M. Calef, N. Fresco, H. Huntington, T.S. Rupp, L. DeWilde, and R.L. Naylor. 2008. Increasing wildfire in Alaska's boreal forest: pathways to potential solutions of a wicked problem. BioScience. 58: 531-540.

Dai, A., E. Trenberth, and T. Qian. 2004. A global dataset of Palmer Drought Severity Index for 1870-2002: Relationship with soil moisture and effects of surface warming. American Meteorological Society. 5: 1117-1130.

Dale, V.H., L.A. Joyce, S. McNulty, and R.P. Neilson. 2000. The interplay between climate change, forests, and disturbances. The Science of the Total Environment. 262: 201-204.

D'Arrigo, R. D., G. Jacoby, R. Wilson and F. Panagiotopoulos. 2005. A reconstructed Siberian High index since A.D. 1599 from Eurasian and North American tree rings. Geophysical Research Letters 32: L05705, doi:10.1029/2004GL022271.

D'Arrigo, R. D., G.C. Jacoby, N. Pederson, D. Frank, B. Buckley, B. Nachin, R. Mijiddorj, and C. Dugarjav. 2000. Mongolian tree-rings, temperature sensitivity and reconstructions of Northern Hemisphere temperature. The Holocene. 10:669-672.

D'Arrigo, R.D., G.C. Jacoby, D. Frank, N. Pederson, E. R. Cook, B. Buckley, B. Nachin, R. Mijiddorj, and C. Dugarjav. 2001. 1738 years of Mongolian temperature variability inferred from a tree-ring width chronology of Siberian pine. Geophysical Research Letters. 28:543546.

D'Arrigo, R. and R. Wilson. 2006. On the Asian expression of the PDO. International Journal of Climatology. 26: 1607-1617.

Daskalov, G.M., A.N. Grishin, S. Rodionov, and V. Mihneva. 2007. Trophic cascades triggered by overfishing reveal possible mechanisms of ecosystem regime shifts. Proceedings of the National Academy of Sciences. 104: 10518-10523.

Davagdorj, D. and R. Mijidorg. 1996. Climate change issues in Mongolia. In: D. Davagdorj and L. Natsagdorj (eds.) Hydrometeorological Issues in Mongolia, Papers in Hydrometeorology, Ulaanbaatar, 230 pp. pp. 79-88.

Donnegan, J.A., T.T. Veblen, and J.S. Sibold. 2001. Climatic and human influences on fire history in Pike National Forest, Central Colorado. Canadian Journal of Forest Research. 31: 1526-1539. 
Emerton, L., N. Erdenesaikhan, B. De Veen, D. Tsogoo, L. Janchivdorj, P. Suvd, B. Enkhtsetseg, G. Gandolgor, Ch.Dorisuren, D. Sainbayar, and A. Enkhbaatar. 2009. The Economic Value of the Upper Tuul Ecosystem. Mongolia Discussion Papers, East Asia and Pacific Sustainable Development Department. Washington, D.C.: World Bank.

Ermakov, N., M. Cherosov. and P. Gogoleva. 2002. Classification of ultracontinental boreal forests in central Yakutia. Folia Geobotanica. 37: 419-440.

Fernández-Giménez, M. E. 1999. Sustaining the steppes: a geographical history of pastoral land use in Mongolia. The Geographical Review. 89: 315-342.

Fernández-Giménez, M. E. 2006. Land use and land tenure in Mongolia: A brief history and current issues. In: Bedunah, Donald J., McArthur, E. Durant, and Fernández-Giménez, Maria. 2006. Rangelands of Central Asia: Proceedings of the Conference on Transformations, Issues, and Future Challenges. 2004 January 27; Salt Lake City, UT. Proceeding RMRS-P-39. Fort Collins, CO: U.S. Department of Agriculture, Forest Service, Rocky Mountain Research Station.

Flannigan, M., Y. Bergeron, O. Engelmark and B. Wotton. 1998. Future wildfire in circumboreal forests in relation to global warming. Journal of Vegetation Science. 9: 469476.

Food and Agriculture Organization (FAO) of the United Nations. 2010. Mongolian dzud appeal 2010. http://www.fao.org/emergencies/tce-appfund/tce-appeals/appeals/emergencydetail0/en/item/42611/icode/?uidf=17866, accessed May 2011.

Fried, J.S., J.K. Gilles, W.J. Riley, T.J. Moody, C.S. de Blas, K. Hayhoe, M. Moritz, S. Stephens, and M. Torn. 2008. Predicting the effect of climate change on wildfire behavior and initial attack success. Climate Change. 87: 251-264.

Gellert, P.K. 1998. A brief history and analysis of Indonesia's forest fire crisis. Indonesia. 65: 63-85.

Girardin, M.P. and M. Mudelsee. 2008. Past and future changes in Canadian boreal wildfire activity. Ecological Applications. 18: 391-406.

Goldammer, J.C. 2002. Fire situation in Mongolia. International Forest Fire News 26:75-83.

Goldammer, J.C., E.P Davidenko, L.G. Kondrashov, and N.I. Ezhov. 2004. Recent trends of forest fires in Central Asia and opportunities for regional cooperation in forest fire management. Regional Forest Congress Forest Policy: Problems and Solutions 25-27 November 2004, Bishkek, Kyrgyzstan. 
Grissino-Mayer, H. D., C. H. Baisan, and T. W. Swetnam. 1995. Fire history in the Pinaleño Mountains of southern Arizona: effects of human-related disturbances. Pages 399-407 in L. F. DeBano, G. J. Gottfried, R. H. Hamre, C. B. Edminster, P. F. Folliott, and A. OrtegaRubio, editors. Biodiversity and management of the Madrean archipelago: the Sky Islands of southwestern United States and northwestern Mexico. USDA Forest Service General Technical Report RM-GTR-264.

Grissino-Mayer, H.D. and T.W. Swetnam. 2000. Century scale climate forcing of fire regimes in the American Southwest. The Holocene. 10: 213-220.

Grissino-Mayer, H.D. 2001. FHX2 - software for analyzing temporal and spatial patterns in fire regimes from tree rings. Tree-Ring Research. 57:115-124.

Grissino-Mayer, H.D., Romme, W.H., Floyd, L., and Hanna, D. 2004. Climate and human influences on fire regimes of the southern San Juan Mountains, Colorado, USA. Ecology. 85: $1708-1724$.

Guyette, R.P., R.M Muzika, and D.C. Dey. 2002. Dynamics of an anthropogenic fire regime. Ecosystems. 5: 472-486.

Hellberg, E., G. Hornberg, and L. Ostlund. 2003. Vegetation dynamics and disturbance history in three deciduous forests in boreal Sweden. Journal of Vegetation Science. 14: 267-276.

Hessl, A.E. 2011. Pathways for climate change effects on fire: Models, data, and uncertainties. Progress in Physical Geography. 35: 393-407.

Hessl, A.E., T. Saladyga, T. Schuler, P. Clark, and J. Wixom. A Fire history from three species on an Appalachian ridge top. In review. Canadian Journal of Forest Research.

Hogg, E.H. and P.A. Hurdle. 1995. The aspen parkland in western Canada: A dry-climate analogue for the future boreal forest? Water, Air, and Soil Pollution. 82: 391-400.

Humphrey, C. and D. Sneath. 1999. The End of Nomadism? Society, State, and the Environment in Inner Asia. Duke University Press, 355 pp.

IPCC (Intergovernmental Panel on Climate Change). 2007. Climate Change 2007 - The Physical Science Basis. Working Group I Contribution to the Fourth Assessment Report of the IPCC. Cambridge University Press, Cambridge, UK.

Jacoby, G.C., R.D. D'Arrigo, and T. Davaajamts. 1996. Mongolian tree rings and $20^{\text {th }}$ century warming. Science. 273: 771-773.

Jacoby, G., R.D. D’Arrigo B. Buckley, and N. Pederson. 2009. Manshiir Hiid, ITRDB MONG002. World Data Center for Paleoclimatology Data. NOAA/NCDC Paleoclimatology Program, Boulder, Colorado, USA. 
Johnson, D.A., D.P. Sheehy, D. Miller and D. Daalkhaijav. 2006. Mongolian rangelands in transition. Sécheresse. 17: 133-41.

Kasischke, E.S., D.L. Verbyla, T.S. Rupp, A.D. McGuire, K.A. Murphy, R. Jandt, J.L. Barnes, E.E. Hoy, P.A. Duffy, M. Calef, and M.R. Turetsky. 2010. Alaska's changing fire regime implications for the vulnerability of its boreal forests. Canadian Journal of Forest Research. 40: 1313-1324.

Keeley, J.E. and D. Lubin. 2003. Fire and grazing impacts on plant diversity and alien plant invasions in the southern Sierra Nevada. Ecological Applications. 13: 1355-1374.

Kilpeläinen, A., S. Kellomäki, H. Strandman, and A. Venäläinen. Climate change impacts on forest fire potential in boreal conditions in Finland. Climate Change. 103: 383-398.

Krebs, P., G.B. Pezzatti, S. Mazzoleni, L.M. Talbot, and M. Conedera. 2010. Fire regime: history and definition of a key concept in disturbance ecology. Theory in Biosciences. 129: 53-69.

Kuhlken, R. 1999. Settin' the woods on fire: rural incendiarism as protest. Geographical Review. 89: 343-363.

Lertzman, K., J. Fall, and B. Dorner. 1998. Three kinds of heterogeneity in fire regimes: at the crossroads of fire history and landscape ecology. Northwest Science. 72: 4-23.

Li, J., E.R. Cook, R. D’Arrigo, F. Chen and X. Gou. 2008. Moisture variability across China and Mongolia: 1951-2005. Climate Dynamics. 1-14.

Liu, Y., J. Stanturf, and S. Goodrick. 2010. Trends in global wildfire potential in a changing climate. Forest Ecology and Management. 259: 685-697.

McKenzie, D., Z. Gedalof, D.L. Peterson and P. Mote. 2004. Climate change, wildfire, and conservation. Conservation Biology. 18: 890-902.

Mast, J.N., T. Veblen, and Y.B. Linhart. Disturbance and climatic influences on a structure of ponderosa pine at the pine/grassland ecotone, Colorado Front Range. Journal of Biogeography. 25: 743-755.

Nyamjav, B., J.G. Goldammer, and H. Uibrig. 2007. The Forest Fire Situation in Mongolia. International Forest Fire News. No. 36: 46-66.

Overpeck, J.T., D. Rind, and R. Goldberg. 1990. Climate induced changes in forest disturbance and vegetation. Nature. 343:51-53.

Palmer, W.C. 1965. Meteorological drought. Research paper, 45. U.S. Department of Commercial Weather Bureau, Washington, D.C. 
Piñol, J., J. Terradas, and F. LLoret. 1998. Climate warming, wildfire hazard, and wildfire occurrence in coastal eastern Spain. Climate Change. 38: 345-357.

Rodionov, S.N. 2005. A brief overview of the regime shift detection methods. In: Large-Scale Disturbances (Regime Shifts) and Recovery in Aquatic Ecosystems: Challenges for Management Toward Sustainability, V. Velikova and N. Chipev (Eds.), UNESCOROSTE/BAS Workshop on Regime Shifts, 14-16 June 2005, Varna, Bulgaria, 17-24.

Rozas, V. 2003. Regeneration patterns, dendroecology, and forest-use history in an old-growth beech-oak lowland forest in Northern Spain. Forest Ecology and Management. 182: 175194.

Running, S.W. 2006. Is global warming causing more, larger wildfires? Science. 13: 927-928.

Samel, A. N., W. C. Wang and X. Z. Liang. 1999. The monsoon rainband over China and relationships with the Eurasian circulation. Journal of Climate. 12: 115-131.

Sankey, T. T., C. Montagne, L. J. Graumlich, R. Lawrence, and J. Nielsen. 2006. Lower forestgrassland ecotones and 20th century livestock herbivory effects in northern Mongolia. Forest Ecology and Management. 233:36-44.

Savage, M. and T.W. Swetnam. 1990. Early $19^{\text {th }}$-century fire decline following sheep pasturing in a Navajo ponderosa pine forest. Ecology. 71: 2374-2378.

Sivakumar, M.V.K., H.P. Das and O. Brunini. 2005. Impacts of present and future climate variability and change on agriculture and forestry in the arid and semi-arid tropics. Climate Change. 70: 31-72.

Sneath, D. 1998. State policy and pasture degradation in inner Asia. Science. 281:1147-1148.

Spracklen, D.V., L.J. Mickley, J.A. Logan, R.C. Hudman, R. Yevich, M.D. Flannnigan, and A.L. Westerling. 2009. Impacts of climate change from 2000 to 2050 on wildfire activity and carbonaceous aerosol concentrations in the western United States. Journal of Geophysical Research. 114: 1-17.

B. J. Stocks, M. A. Fosberg, T. J. Lynham, L. Mearns, B. M. Wotton, Q. Yang, J-Z. Jin, K. Lawrence, G. R. Hartley and J. A. Mason, et al. 1998. Climate change and forest fire potential in Russian and Canadian boreal forests. Climate Change. 38: 1-13.

Stokes, M. A. and T.L. Smiley. 1968. An introduction to tree-ring dating, 73 pp. University of Chicago Press, Chicago.

Taylor, A.H. and R.M. Beaty. 2005. Climatic influences on fire regimes in the northern Sierra Nevada Mountains, Lake Tahoe Basin, Nevada, USA. Journal of Biogeography. 32: 425438. 
Tumurjav, B. 2006. Development of Foreign Relations of Mongolia in the First Half of the $20^{\text {th }}$ Century: Mongolia's Struggle for Independence. Doctoral Disseration. Niigata Unviersity, Niigata, Japan.

United Nations Economic and Social Council. 2002. Poverty statistics in Mongolia. Economic and Social Commission for Asia and the Pacific, Committee on Statistics. Thirteenth session, 27-29 November 2002. Bangkok, Thailand.

United Nations Population Division. 2009. The 2008 Revision Population Database. http://esa.un.org/UNPP/

Valendik, E.N., G.A. Ivanova, Z.O. Chuluunbator and J.G. Goldammer. 1998. Fire in forest ecosystems of Mongolia. International Forest Fire News. 19: 58-63.

Veblen, T., T. Kitzberger, R. Villalba, and J. Donnegan. 1999. Fire history in northern Patagonia: the roles of humans and climatic variation. Ecological Monographs. 69: 47-67.

Westerling, A.L., H.G. Hidalgo, D.R. Cayan and T.W. Swetnam. 2006. Warming and earlier spring increase western U.S. forest wildfire activity. Science. 313: 940-943.

Wotton, B.M. and M.D. Flannigan. 1993. Length of fire season in a changing climate. The Forestry Chronicle. 69: 187-192.

Yatagai, A. and T. Yasunari. 1995. Interannual variations of summer precipitation in the arid/semi-arid regions in China and Mongolia: Their regionality and relation to the Asian Summer Monsoon. Journal of the Meteorological Society of Japan. 73:909-923.

Yang G., X. Di, Q.Guo, Z.Shu, T.Zeng, H.Yu and C.Wang. 2011. The impact of climate change on forest fire danger rating in China's boreal forest. Journal of Forestry Research. 22: 249257.

Zhang, J., and Z. Lin. 1992. Climate of China. Wiley, 376 pp. 


\section{Tables and Figures}

Table 1 Sample locations in the UTRW including latitude, longitude, elevation, number of samples, total number of dated scars and injuries, first and last ring dates, ROSA scores, and ROSA classification bins.

\begin{tabular}{ccccccccccc}
\hline Site ID & Latitude & Longitude & $\begin{array}{c}\text { Elevation } \\
(\mathbf{m})\end{array}$ & $\begin{array}{c}\text { No. } \\
\text { Samples }\end{array}$ & $\begin{array}{c}\text { No. } \\
\text { Scars }\end{array}$ & $\begin{array}{c}\text { No. } \\
\text { Injuries }\end{array}$ & $\begin{array}{c}\text { First } \\
\text { Ring }\end{array}$ & $\begin{array}{c}\text { Last } \\
\text { Ring }\end{array}$ & ROSA & $\begin{array}{c}\text { [ROSA } \\
\text { Bin] }\end{array}$ \\
\hline UT02 & 47.842 & 107.171 & 1734 & 1 & 9 & 0 & 1833 & 2001 & 12 & High \\
UT04 & 48.085 & 106.846 & 1725 & 5 & 9 & 0 & 1857 & 2009 & 16 & High \\
UT09 & 48.123 & 107.629 & 1620 & 9 & 50 & 16 & 1753 & 2009 & 2 & Low \\
UT17 & 48.146 & 107.782 & 1683 & 7 & 26 & 8 & 1626 & 2009 & 5 & Med \\
UT19 & 48.133 & 107.039 & 1707 & 1 & 1 & 0 & 1962 & 2009 & 7 & Med \\
UT20 & 48.101 & 107.236 & 1755 & 8 & 13 & 1 & 1868 & 2009 & 14 & High \\
UT21 & 48.152 & 108.155 & 1793 & 11 & 25 & 0 & 1782 & 2009 & 4 & Low \\
UT23 & 48.196 & 107.981 & 1788 & 10 & 20 & 3 & 1869 & 2009 & 2 & Low \\
UT29 & 47.804 & 107.661 & 1991 & 4 & 16 & 7 & 1488 & 2009 & 5 & Med \\
UT30 & 48.106 & 106.920 & 1712 & 5 & 6 & 0 & 1889 & 2009 & 10 & High \\
UT31 & 48.016 & 107.252 & 1688 & 8 & 9 & 3 & 1864 & 2007 & 13 & High \\
UT32 & 48.088 & 107.134 & 1640 & 6 & 8 & 3 & 1865 & 2009 & 5 & Med \\
UT33 & 47.858 & 107.733 & 1676 & 10 & 16 & 6 & 1945 & 2009 & 5 & Med \\
UT34 & 47.941 & 107.747 & 1834 & 0 & n/a & n/a & n/a & n/a & 5 & Med \\
UT35 & 48.015 & 107.794 & 1699 & 13 & 33 & 19 & 1808 & 2009 & 8 & Med \\
UT36 & 48.072 & 107.874 & 1648 & 10 & 28 & 3 & 1869 & 2009 & 8 & Med \\
UT37 & 48.124 & 107.958 & 1629 & 12 & 22 & 7 & 1942 & 2009 & 6 & Med \\
UT38 & 48.063 & 107.756 & 1571 & 7 & 17 & 15 & 1626 & 2009 & 6 & Med \\
UT39 & 48.191 & 107.695 & 1676 & 8 & 19 & 11 & 1755 & 2009 & 4 & Low \\
UT40 & 48.039 & 107.610 & 1666 & 5 & 26 & 2 & 1625 & 2009 & 7 & Med \\
\hline
\end{tabular}

ROSA = Rapid on-site assessment of human disturbance 
Table 2 Fire events based on a two scar per site filter. Impact class indicates which site(s) recorded fire ( $\mathrm{L}=\mathrm{Low}, \mathrm{M}=$ Medium, $\mathrm{H}=\mathrm{High}$ ). Watershed events with greater than $20 \%$ sites recording fire are highlighted. Mean fire interval $=3.04$ years.

\begin{tabular}{|c|c|c|c|c|c|c|c|c|c|}
\hline Year & $\begin{array}{l}\text { No. Sites } \\
\text { Recording } \\
\text { Fire } \\
\end{array}$ & $\begin{array}{l}\text { No. } \\
\text { Sites }\end{array}$ & $\begin{array}{c}\text { \% Sites } \\
\text { Recording } \\
\text { Fire } \\
\end{array}$ & $\begin{array}{c}\text { Impact } \\
\text { Class }\end{array}$ & Year & $\begin{array}{c}\text { No. Sites } \\
\text { Recording } \\
\text { Fire } \\
\end{array}$ & $\begin{array}{l}\text { No. } \\
\text { Sites }\end{array}$ & $\begin{array}{c}\text { \% Sites } \\
\text { Recording } \\
\text { Fire } \\
\end{array}$ & $\begin{array}{c}\text { Impact } \\
\text { Class }\end{array}$ \\
\hline 2009 & 1 & 16 & 6 & $\mathrm{M}$ & 1950 & 1 & 16 & 6 & $\mathrm{M}$ \\
\hline 2000 & 1 & 17 & 6 & $\mathrm{M}$ & 1949 & 1 & 16 & 6 & $\mathrm{M}$ \\
\hline 1998 & 1 & 17 & 6 & $\mathrm{M}$ & 1948 & 2 & 16 & 13 & $\mathrm{~L} / \mathrm{M}$ \\
\hline 1997 & 3 & 17 & 18 & $\mathrm{M}$ & 1947 & 1 & 16 & 6 & $\mathrm{M}$ \\
\hline 1996 & 5 & 17 & 29 & $\mathrm{~L} / \mathrm{M}$ & 1946 & 2 & 16 & 13 & $\mathrm{M} / \mathrm{H}$ \\
\hline 1990 & 1 & 17 & 6 & $\mathrm{M}$ & 1945 & 2 & 16 & 13 & $\mathrm{~L} / \mathrm{M}$ \\
\hline 1988 & 1 & 17 & 6 & $\mathrm{M}$ & 1942 & 1 & 15 & 7 & $\mathrm{~L}$ \\
\hline 1987 & 1 & 17 & 6 & $\mathrm{M}$ & 1939 & 1 & 14 & 7 & $\mathrm{M}$ \\
\hline 1984 & 1 & 17 & 6 & $\mathrm{~L} / \mathrm{M}$ & 1938 & 1 & 14 & 7 & $\mathrm{H}$ \\
\hline 1983 & 1 & 17 & 6 & $\mathrm{M}$ & 1937 & 1 & 14 & 7 & M \\
\hline 1981 & 1 & 17 & 6 & $\mathrm{M}$ & 1934 & 1 & 14 & 7 & $\mathrm{~L}$ \\
\hline 1980 & 3 & 17 & 18 & $\mathrm{M} / \mathrm{H}$ & 1933 & 3 & 14 & 21 & $\mathrm{~L} / \mathrm{M} / \mathrm{H}$ \\
\hline 1979 & 1 & 17 & 6 & $\mathrm{M}$ & 1925 & 1 & 14 & 7 & $\mathrm{H}$ \\
\hline 1977 & 2 & 17 & 12 & M & 1922 & 1 & 14 & 7 & M \\
\hline 1976 & 1 & 17 & 6 & $\mathrm{M}$ & 1919 & 1 & 14 & 7 & M \\
\hline 1975 & 2 & 17 & 12 & $\mathrm{~L} / \mathrm{M}$ & 1917 & 1 & 14 & 7 & $\mathrm{M}$ \\
\hline 1973 & 1 & 17 & 6 & $\mathrm{M}$ & 1916 & 1 & 14 & 7 & M \\
\hline 1971 & 1 & 17 & 6 & M & 1914 & 6 & 14 & 43 & $\mathrm{~L} / \mathrm{M} / \mathrm{H}$ \\
\hline 1969 & 5 & 17 & 29 & $\mathrm{~L} / \mathrm{M} / \mathrm{H}$ & 1904 & 1 & 13 & 8 & M \\
\hline 1967 & 2 & 17 & 12 & M & 1903 & 2 & 13 & 15 & $\mathrm{~L} / \mathrm{M}$ \\
\hline 1966 & 5 & 17 & 29 & $\mathrm{~L} / \mathrm{M}$ & 1899 & 1 & 13 & 8 & $\mathrm{~L}$ \\
\hline 1965 & 2 & 17 & 12 & $\mathrm{M}$ & 1893 & 1 & 10 & 10 & $\mathrm{~L}$ \\
\hline 1960 & 1 & 17 & 6 & $\mathrm{~L}$ & 1887 & 2 & 9 & 22 & $\mathrm{~L}$ \\
\hline 1957 & 2 & 17 & 12 & $\mathrm{~L} / \mathrm{M}$ & 1880 & 2 & 8 & 25 & $\mathrm{~L} / \mathrm{M}$ \\
\hline 1956 & 1 & 17 & 6 & $\mathrm{~L}$ & 1877 & 1 & 8 & 13 & $\mathrm{~L}$ \\
\hline
\end{tabular}


Table 3 Fire regimes as determined by regime shift detection including time period, number of years, number of fire events, the percentage of years with fire, mean fire interval (MFI), and mean fire extent (MFE; \% sites burned per event).

\begin{tabular}{ccccccc}
\hline Fire Regime & Period & Years & \# Fires & \% Fire Years & MFI & MFE \\
\hline 1 & $1875-1913$ & 39 & 7 & 17.9 & 4.5 & 16 \\
- & 1914 & 1 & 1 & 100.0 & - & - \\
2 & $1915-1964$ & 50 & 20 & 40.0 & 2.3 & 9 \\
3 & $1965-1997$ & 33 & 19 & 57.6 & 1.8 & 12 \\
4 & $1998-2009$ & 12 & 3 & 25.0 & 5.5 & 6 \\
\hline
\end{tabular}

Note: The extent of the 1914 fire event was anomalous and, therefore, considered a unique regime period by regime shift detection.

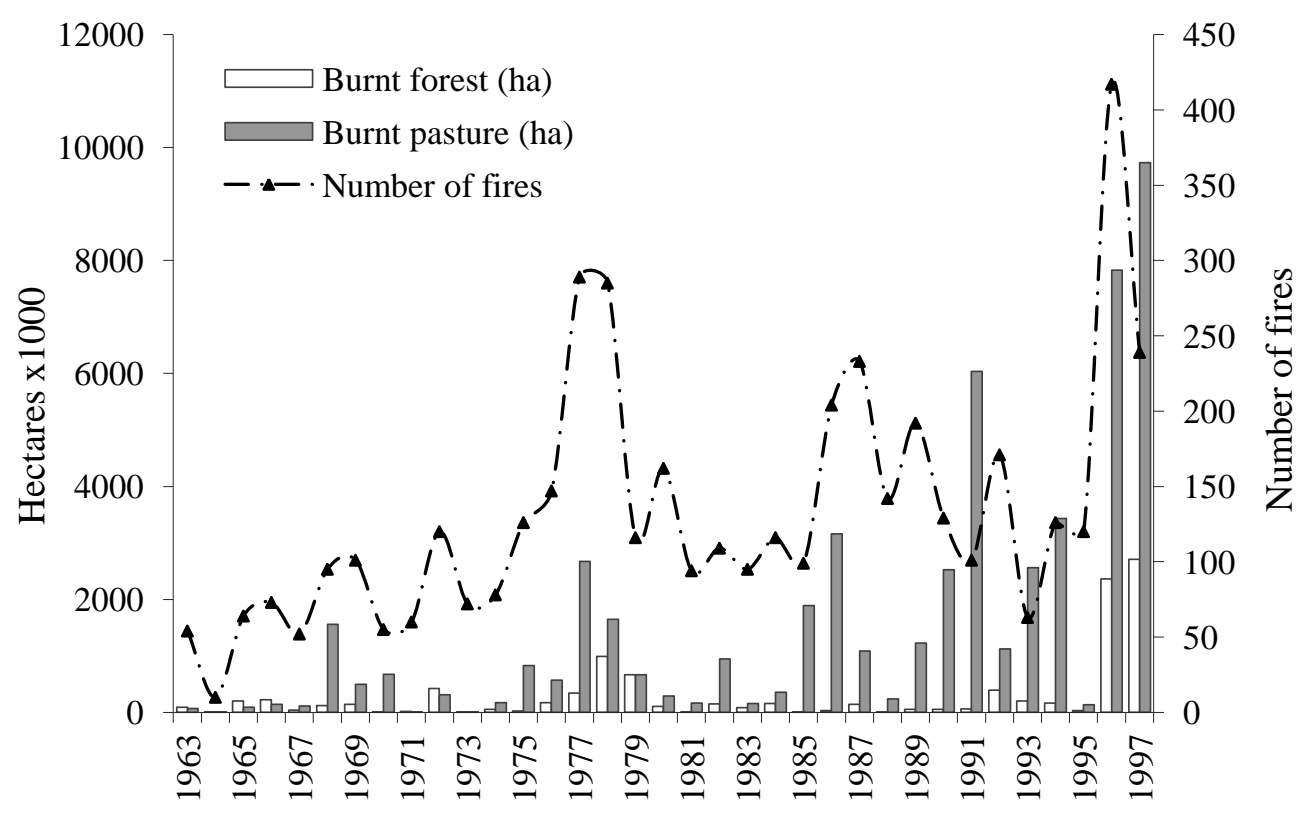

Figure 1 The number of fires and area burned in Mongolia during the period 1963-1997 (redrawn from Goldammer 2002). 


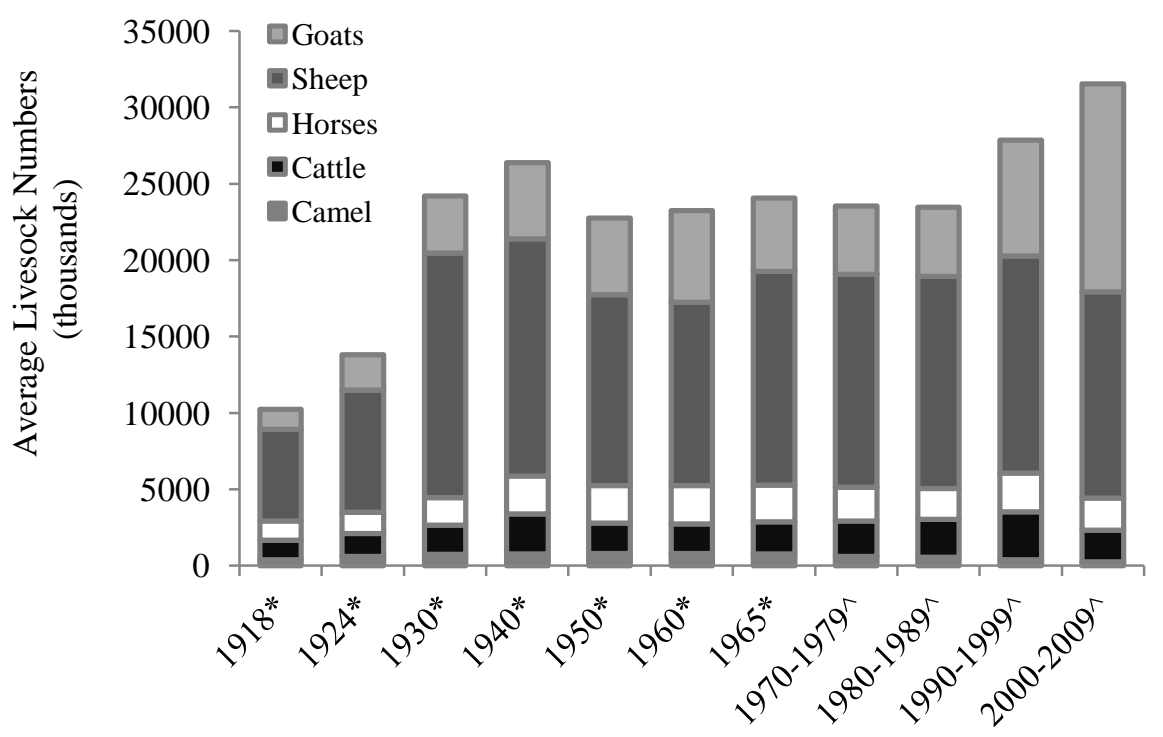

Year(s)

Figure 2 Livestock population of Mongolia 1918-2008 (in thousands).

*Recreated from Humphrey and Sneath 1999. ^Mongolian National Statistics Office 2011 (no data for 1999, 2000, and 2009).

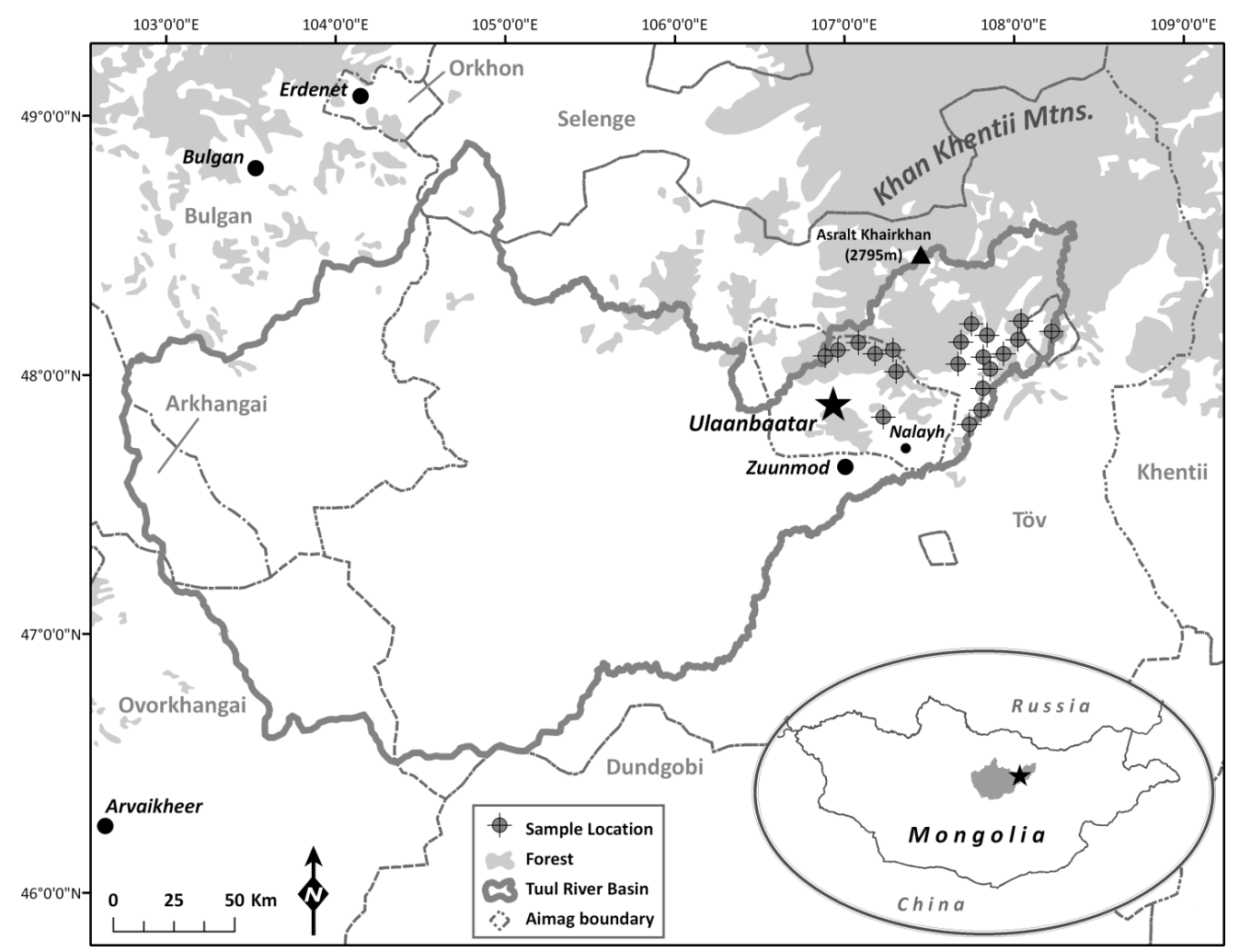

Figure 3 Map of the Tuul River basin in central Mongolia. Sample locations are located in the forest-steppe ecological zone to the north and northeast of the capital city of Ulaanbaatar. 


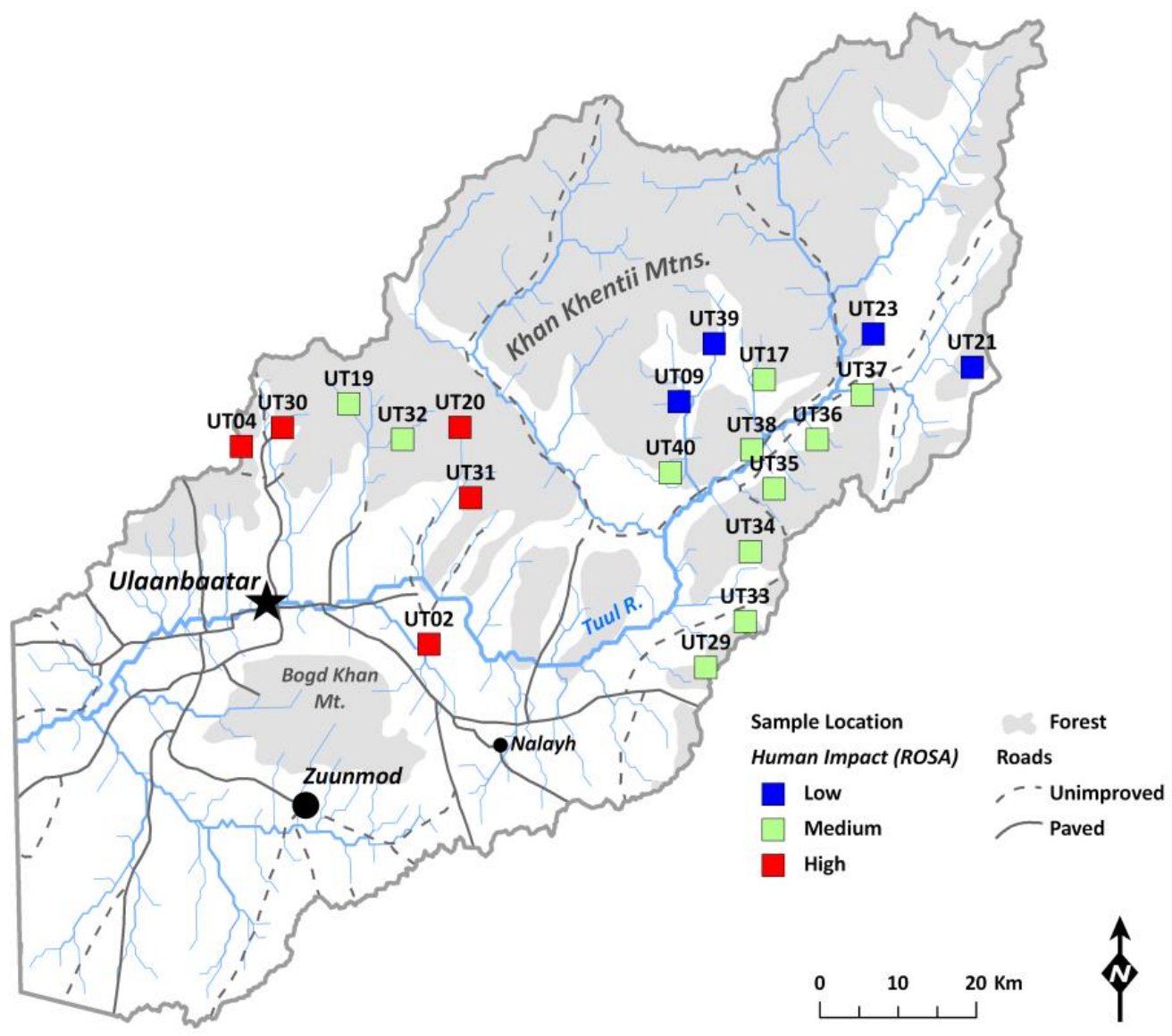

Figure 4 Sample locations in the UTRW classified by human impact (Rapid on-site assessment; ROSA) 


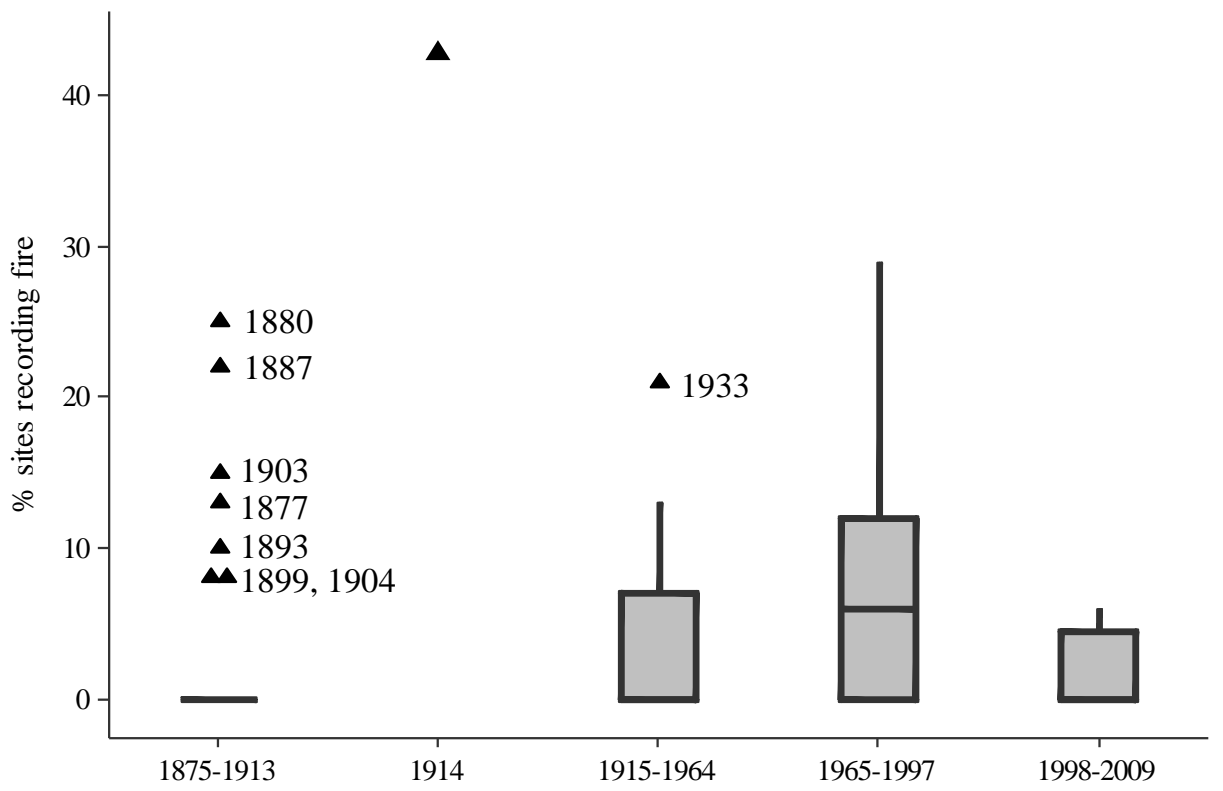

Figure 5 Box plots of four fire regimes as determined by regime shift detection. 1875-1913: low frequency, variable extent. 1915-1964: increased frequency, less variable extent, with one watershed fire. 1965-1997: greatest frequency, highly variable extent. 1998-2009: low frequency and extent, low variability. The 1914 fire event is shown for comparison. 


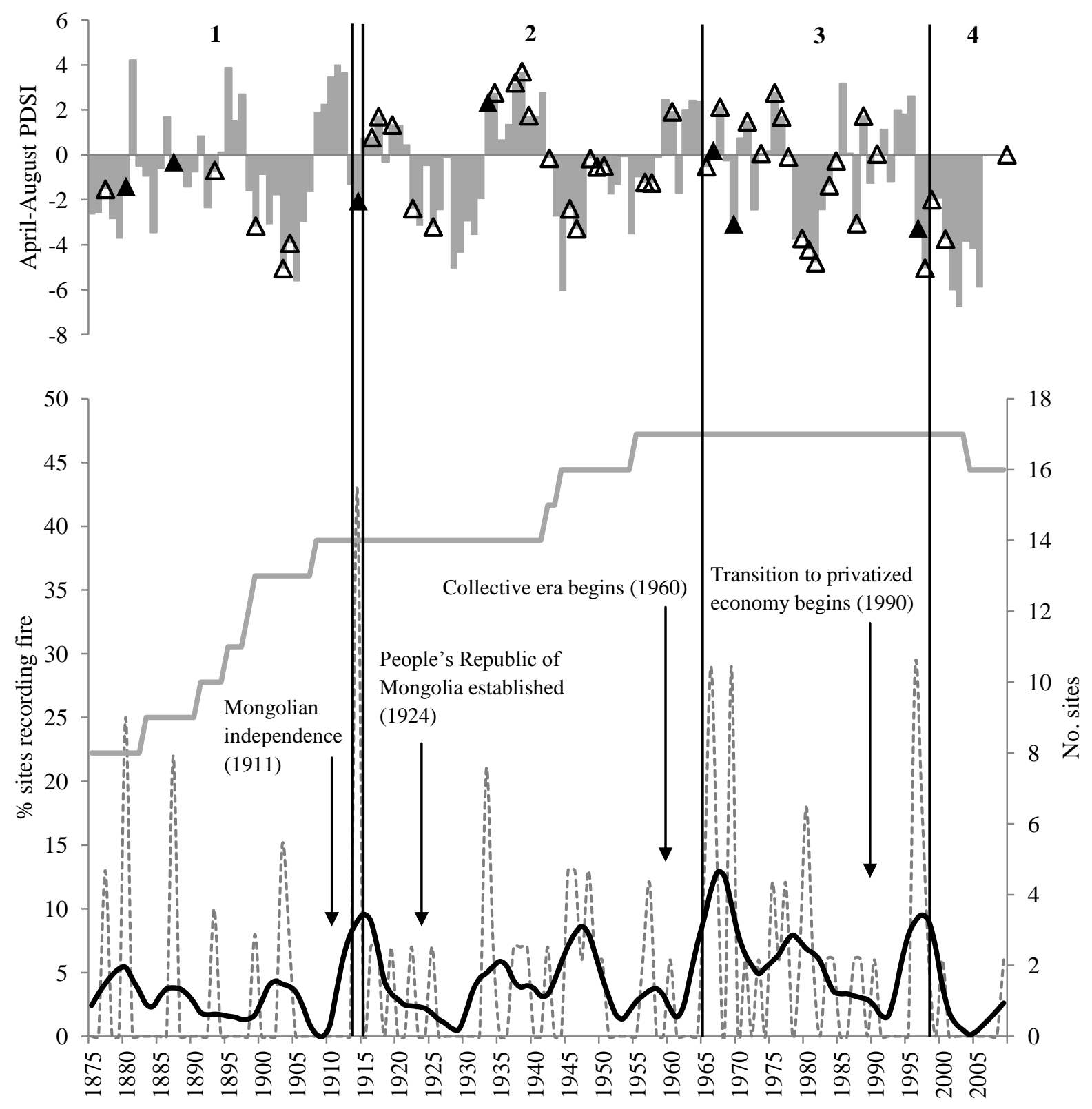

Figure 6 Above: Reconstructed April-August PDSI with fire events using a 2-scar per site filter (closed triangles are $\geq 20 \%$ sites recording; refer to table 2). Below: Percentage of sites recording fire (dotted line) with an 11-year loess curve (solid black line). Number of sites is indicated by the solid gray line. The vertical lines divide the period of analysis into four fire regimes based on regime shift detection. The extent of the 1914 fire event was anomalous and, therefore, considered a unique regime period. There is a documented fire event in 2009 at UT19, but no corresponding PDSI data exists. 


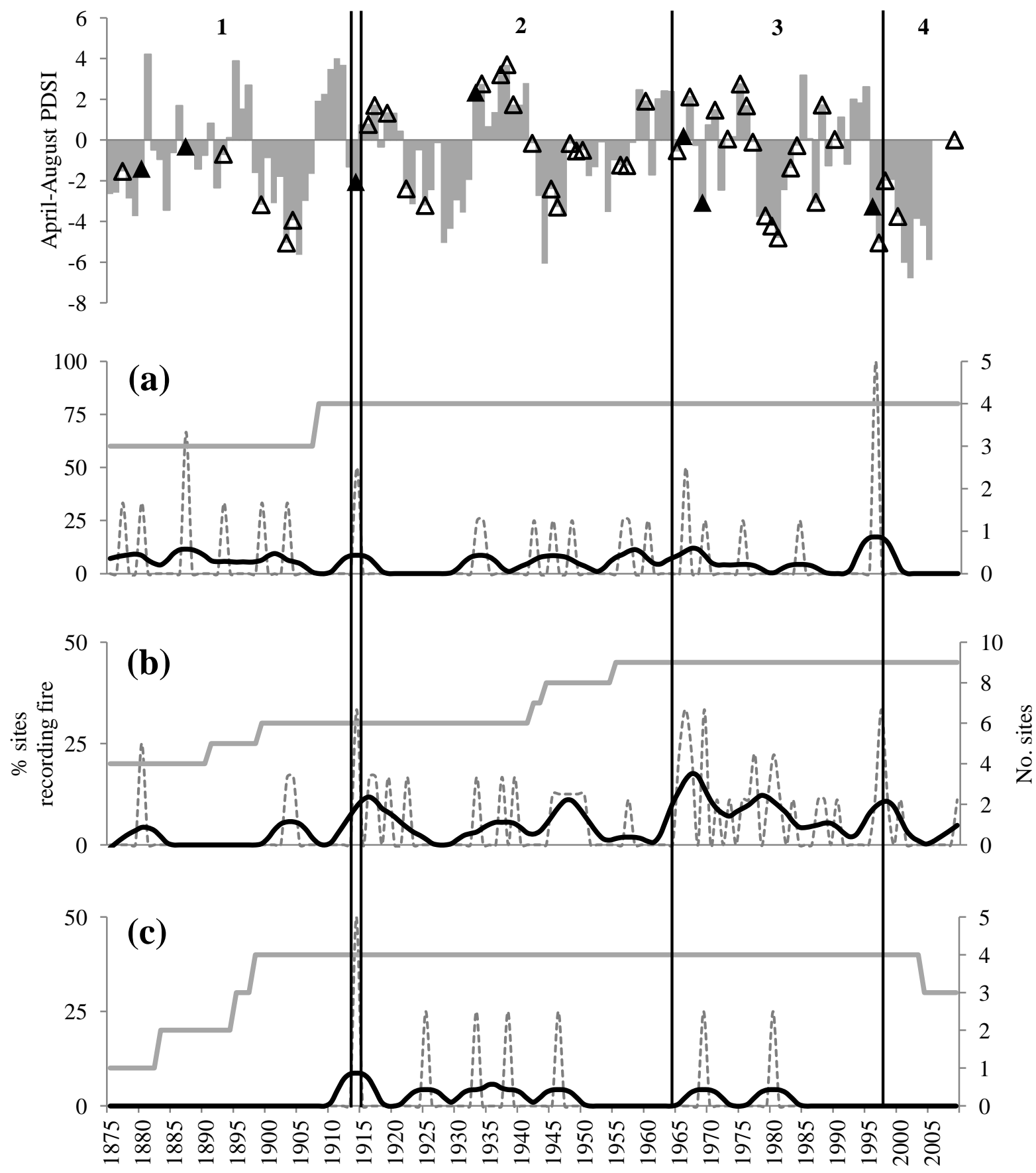

Figure 7 Above: Reconstructed April-August PDSI with fire events using a 2-scar per site filter (closed triangles are $\geq 20 \%$ sites recording; refer to table 2). Below: Percentage of sites recording fire (dotted line) with an 11-year loess curve (solid black line); (a) low (b) medium and (c) high human impact class. Number of sites is indicated by the solid gray line. The vertical lines divide the period of analysis into four fire regimes based on regime shift detection. The extent of the 1914 fire event was anomalous and, therefore, considered a unique regime period. There is a documented fire event in 2009 at UT19, but no corresponding PDSI data exists. 
(a)

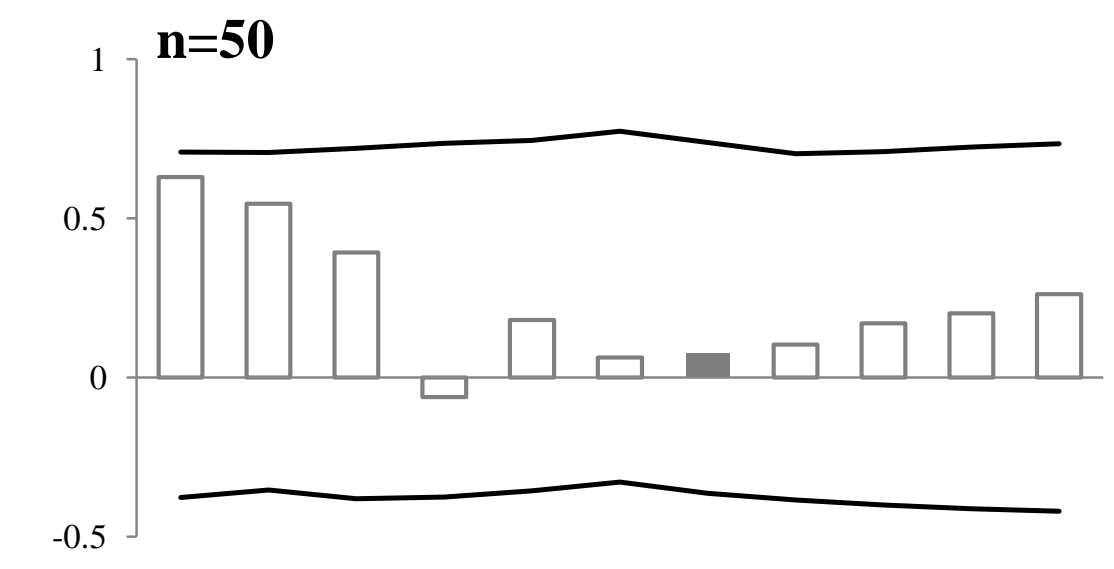

(b)

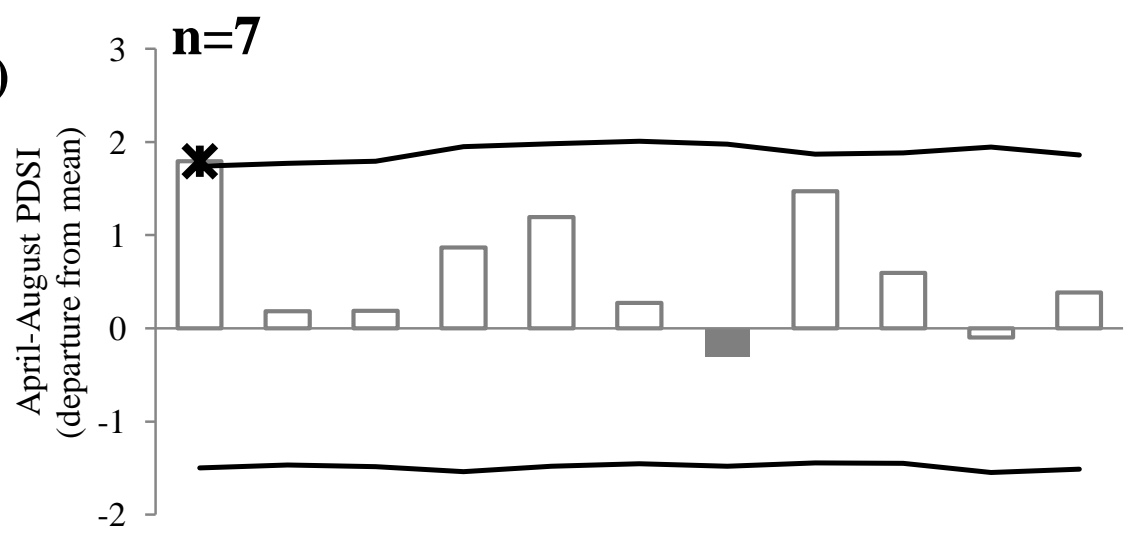

(c)

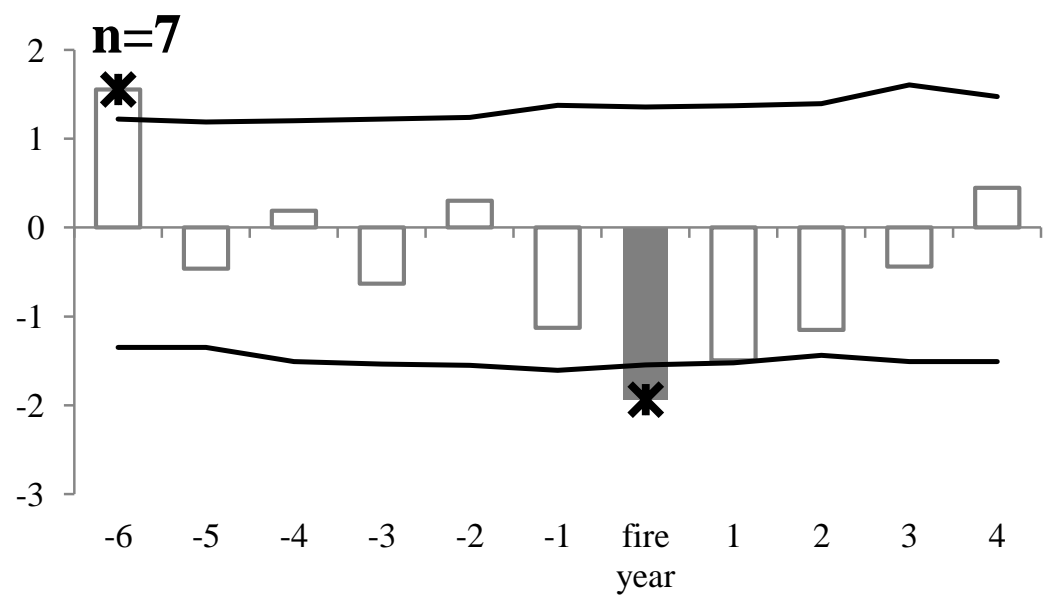

Figure 8 Superposed epoch analysis (SEA) of average April-August PDSI departures for (a) site-level fire events (b) watershed events with $\geq 20 \%$ sites recording fire and (c) events during fire regime 1 (1875-1913). A star indicates a departure exceeding the $95 \%$ confidence interval. Solid lines indicate the $95 \%$ confidence interval. No significant departures were found for fire regimes 2 and 3 and there were too few events during fire regime 4 for SEA. 


\section{Appendix}

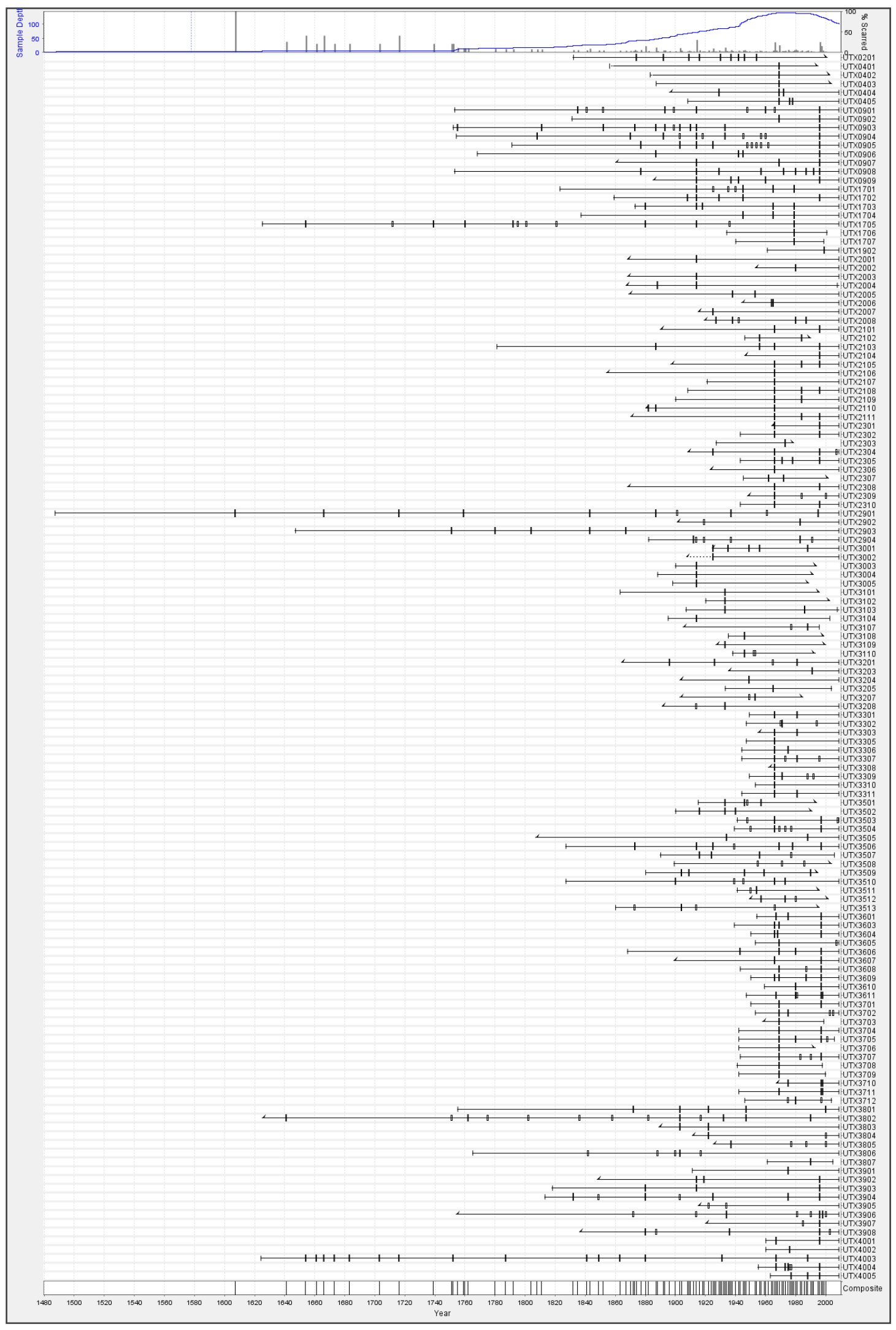




\section{Summary}

I have demonstrated that a basic GIS model can be used to predict on-the-ground human disturbance in the UTRW $\left(\mathrm{r}^{2}=0.37, \mathrm{p}=0.006\right.$, excluding one obvious outlier $)$ and classifying sites into three human impact classes strengthened this prediction (80\% agreement). However, despite its general predictive strength, the GIS model has its limitations, as seen in the over- or underestimation of human disturbance at a few sample locations. For example, human impacts near the Ulaanbaatar metropolitan area were more difficult to predict than in the upper reaches of the Tuul River valley due to unpredicted land use patterns.

The recent (post-1950) decline in forest regeneration and high percentage of remnant samples in the High impact class might be due to the increase in grazing activity near urban areas and roads observed during the latter half of the $20^{\text {th }}$ century, an urbanizing population, and the intensification of economic activity in the Ulaanbaatar metropolitan area. Since all twenty sample locations are situated within the same climatic region, it can be concluded that broadscale variation in moisture availability was not the primary driver of observed regeneration patterns. Instead, the temporal differences in regeneration between human impact classes could only be the result of land use pressure or, alternatively, micro-site variation in soils, solar radiation, or individual site disturbance history (typically associated with land use), which I did not address in this study.

In chapter 2, I found significant correlations between regional tree growth and average April-August PDSI over the central Khan Khentii Mountains. Variance explained (60\%) during the full common period (1945-1993) was similar to a large-scale drought reconstruction in Mongolia (Davi et al. 2010), but much more robust than studies in western Mongolia (Davi et al. 2009) and China (Fan et al. 2008; Fang et al. 2010). Our April-August reconstructed PDSI is 
similar to reconstructed Kherlen River streamflow $(r=0.80)$ and precipitation for eastern Mongolia $(\mathrm{r}=0.69)$ during the period 1675-1995 (Pederson et al. 2001) with severe droughts occurring during the 1720s, 1730s, 1920s and 1940s. In the context of our 331 year record of average April-August PDSI, it is evident that the $20^{\text {th }}$ century was a period in which moisture availability changed frequently and with great magnitude. These rapid changes in moisture availability might have profound impacts on water resource planning, especially as population growth and urbanization in central Mongolia are placing additional pressure on groundwater sources.

Chapters one and two establish that patterns in forest regeneration are associated with human impacts and that the $20^{\text {th }}$ century was a period in which moisture availability changed frequently and with great magnitude, respectively. These results, along with the GIS-based human impact index, allowed me to evaluate fire history in the context of land use intensity and moisture availability. My results in chapter 3 indicate an increase in both wildfire frequency and the percentage of years with fire during the $20^{\text {th }}$ century for each fire regime, but this trend does not continue into the present. Land use intensity has most likely influenced wildfire regimes throughout the $20^{\text {th }}$ century, but its effect has intensified during the recent severe drought. I have shown that the frequency and extent of fire events in areas of high human impact have been less compared to other areas, possibly due to continuous pressures from grazing and fuelwood collection. The history of watershed fires throughout the $20^{\text {th }}$ century does not indicate that watershed fire events are increasing in frequency, but are rather infrequent events occurring throughout the last 135 years. In conjunction with a drying climate and less biomass production in the study area, it is expected that more intense grazing in areas with easier access might reduce fuel volume and wildfire potential. Similar trends of decreased wildfire frequency and extent 
might be observed in other arid regions where prolonged drought and intensive human land use inhibits fuel accumulation.

In conclusion, human use of the landscape was shown to influence both forest regeneration patterns and wildfire activity in the UTRW. With increasing frequency of moisture regime shifts, there will be a growing need for appropriate and flexible climate adaptation measures in the Khan Khentii region. Future work in the UTRW should include 1) research on wildfire ignition sources and patterns 2) expanding the sample area of forest and fire histories to include the higher elevation forests of the Khan Khentii Mountains 3) developing a network of meteorological stations in the headwater region of the Tuul River and 4) further improving communication lines between (foreign) researchers and natural resource managers. 


\section{Thomas M. Saladyga}

Department of Geology and Geography

West Virginia University, P.O. Box 6300, Morgantown, WV 26506

Office/Lab: G-21 Brooks Hall

Phone: 610.413.0715

E-mail: tom.saladyga@gmail.com

\section{Education}

Ph.D. Geography

West Virginia University

2011

M.A. Geography

West Chester University of Pennsylvania

2006

B.S. Geography

The Pennsylvania State University

2002

\section{Employment}

2008-2011

Graduate Research Assistant, Montane Forest Dynamics Lab, Department of Geology \& Geography, West Virginia University, Morgantown, WV

2008

Forestry Technician, Eastern Rivers and Mountains Network, Inventory and Monitoring Program, National Park Service

$2007-2008$

Teaching Assistant/Lab Instructor, Department of Geology \& Geography, West Virginia University, Morgantown, WV

2007

Graduate Research Assistant, Montane Forest Dynamics Lab, Department of Geology \& Geography, West Virginia University, Morgantown, WV

2007

GIS Specialist (contract), Delaware Department of Natural Resources \& Environmental Control, Division of Fish and Wildlife, Dover, DE

2006-2007

Wetland Technician, Delaware Department of Natural Resources \& Environmental Control, Watershed Assessment Section, Dover, DE

2005

GIS Specialist (contract), Delaware Department of Natural Resources \& Environmental Control, Division of Fish and Wildlife, Dover, DE

2004-2005

2004

Environmental Scientist, Environmental Alliance, Inc., Wilmington, DE

Biological Science Technician - Fire-effects Monitor, Ozark National Scenic Riverways, National Park Service, Van Buren, MO

2003-2004

Environmental Scientist, Environmental Alliance, Inc., Wilmington, DE

2001

Research Technician, Vegetation Dynamics Lab, Department of Geography, The Pennsylvania State University, University Park, PA

\section{Teaching}

- Instructor, Environmental Field Geography (Geog 407), Department of Geology \& Geography, West Virginia University, Fall 2010

- Lab Instructor, Physical Geography (Geog 106), Department of Geology and Geography, West Virginia University, 2007 
- Undergraduate mentor, Montane Forest Dynamics Lab, Department of Geology and Geography, West Virginia University, 2007-2011

- Athletic Department Tutor, Physical Geography (Geog 107) and Environmental Geoscience (Geog 110), West Virginia University, 2007-2009

- Guest lectures: "Volcanoes" - Physical Geography, Geography 107, spring 2008

"Species diversity" - Biogeography, Geography 307, spring 2009

"Global forest types" - Global Forest Resources, Forestry 425, spring 2011

\section{Research}

- "Land use and climate impacts on fire regimes and forest regeneration in the upper Tuul River watershed, Mongolia" (Doctoral Dissertation, 2011)

- Fire and forest history at Pike Knob Preserve, W.Va. (2010-2011)

- Nanticoke River Watershed Restoration Plan; GIS analyses (2009)

- North American Dendroecology Fieldweek (2007)

- Bog turtle habitat mapping for Delaware Natural Heritage Program (2007)

- "Native understory and invasive plant response to fire in a mixed-hardwood forest, Chester County, Pennsylvania" (Master's Thesis, 2006)

- Delaware Wildlife Action Plan; habitat mapping (2005)

- Fire ecology of montane chaparral in the Lake Tahoe Basin, Calif. (2001, field assistant)

- Vegetation change at Chiricahua National Monument, Ariz. (2001, field assistant)

\section{Awards/Grants}

- Exploration and Field Research Grant, 2010 (\$3000) Explorer’s Club Washington Group, Inc.

- Vehse Travel Award, 2009 (\$500) Eberly College of Arts and Sciences, West Virginia University

\section{Affiliations and Certifications}

- Association of American Geographers \& Biogeography Specialty Group

- Gamma Theta Upsilon (International Geographical Honor Society)

- Firefighter Type 2 (Courses: I-100, S-130, S-190, and L-180)

\section{Selected Papers and Technical Reports}

Saladyga,T., A. Hessl, and B. Nachin. In Review. Using GIS to map human impacts in the Upper Tuul River watershed, Mongolia. The Geographical Journal.

Hessl, A.E., T. Saladyga, T. Schuler, P. Clark, and J. Wixom. In Review. A century of burning: fire history from three species on a Central Appalachian ridge top. Canadian Journal of Forestry.

Hessl, A.E., P. Brown, U. Ariya, O. Byambasuren, T. Green, G. Jacoby, E. Kennedy-Sutherland, B. Nachin, R. Maxwell, N. Pederson, L. De Grandpré, T. Saladyga, and J. C. Tardif. 
Accepted. Report on Fire History in Central Mongolia. International Journal of Wildland Fire.

Nanticoke Restoration Work Group (T. Saladyga - GIS support). 2009. Nanticoke River Watershed Restoration Plan. Delaware Department of Natural Resources and Environmental Control and US Environmental Protection Agency Wetland Program.

Allen, O., B. Barkus, and K. Bennett (T. Saladyga - GIS support). 2006. Delaware Wildlife Action Plan: 2007-2017. Delaware Natural Heritage and Endangered Species Program, Delaware Division of Fish and Wildlife, Department of Natural Resources and Environmental Control.

Saladyga, T. 2006. Native understory and invasive plant response to fire in a mixed-hardwood forest, Chester County, Pennsylvania. Master's thesis, West Chester University, West Chester, Pennsylvania. Dr. Joan M. Welch, advisor.

\section{Conference Presentations}

Saladyga, T. and A. Hessl. 2011. Fire history at Pike Knob, West Virginia (and other unique locales). Annual Meeting, Central Appalachians Fire Learning Network, 28-30 June 2011, The Mountain Institute at Spruce Knob, West Virginia.

Saladyga, T. and A. Hessl. 2011. Fire history along a human impact gradient in the Upper Tuul River Watershed, Mongolia (poster). Annual meeting, American Association for the Advancement of Science, 17-21 February 2011, Washington, D.C.

Saladyga, T., Hessl, A., P. Brown, N. Pederson, B. Nachin, and B. Suran. 2010. Climate, fire, and land use interactions in the Upper Tuul River watershed, Mongolia (poster). Annual Meeting, Association of American Geographers, 14-18 April 2010, Washington, D.C.

Saladyga, T., P. Clark, A. Hessl, and J. Wixom. 2010. Anthropogenic fire and regeneration of an isolated red pine (Pinus resinosa) stand, Pike Knob, West Virginia (poster). Annual Meeting, Association of American Geographers, 14-18 April 2010, Washington, D.C.

Hessl, A., P. Brown, N. Pederson, B. Nachin, T. Saladyga*, and B. Suran. 2010. Fire history in Mongolia: placing current change in the context of the last 400+ years. Annual Meeting, Association of American Geographers, 14-18 April 2010, Washington, D.C. *Presenter

Leland, C., N. Pederson, A. Hessl, P. Brown, B. Nachin, T. Saladyga, and B. Suran. 2010. Fire and climate interactions in northeastern Mongolia. Annual Meeting, Association of Southeastern Biologists, 7-10 April 2010, Asheville, North Carolina.

Hessl, A., P. Brown, S. Maxwell, B. Nachin, N. Pederson, and T. Saladyga. 2009. Fire, Climate, and Land Use in Mongolia: 400+ Years of Change. Annual Meeting, Association of American Geographers, 22-27 March 2009, Las Vegas, Nevada.

Welch, J. and T. Saladyga. 2008. Fire in the woods: native and invasive plant response. 2008. Annual Meeting, Association of American Geographers, 15-19 April 2008, Boston, Massachusetts.

LaForest, L., P. Brown, N. Benzing, R. DeSantis, G. Dillon, W. Flatley, H.D. Grissino-Mayer, C. Lafon, T. Saladyga, J. Slayton, L. Svenson, K. Tackett, and N. Toth. 2008. Fire history in old-growth pine-oak forest stands along Gold Mine Trail in the Great Smoky Mountains National Park, Tennessee. Annual Meeting, Association of American Geographers, 15-19 April 2008, Boston, Massachusetts. 
Jacobs, A., E. Rehm, and D. Fillis (T. Saladyga - GIS support). 2007. Delaware's wetland monitoring program: using science to inform protection and restoration efforts. Delaware Estuary Science Conference, 22-24 January 2007, Cape May, New Jersey.

Saladyga, T. 2006. Native and invasive plant response to fire: hardwood forest of Chester County, Pennsylvania. Annual Meeting, Middle States Division of the Association of American Geographers, 13-14 October 2006, Rutgers University, New Brunswick, New Jersey.

Saladyga, T. 2006. Invasive plant dynamics as related to forest structure and composition at Hibernia County Park, Chester County, PA. Annual Meeting, Association of American Geographers, 7-11 March 2006, Chicago, Illinois.

Saladyga, T. 2005. Forests lost: invasive vegetation and implications for native habitat restoration through oak regeneration. Annual Meeting, Middle States Division of the Association of American Geographers, 14-15 October 2005, Chautauqua, New York. 